UNIVERSIDADE DE SÃO PAULO

FACULDADE DE ZOOTECNIA E ENGENHARIA DE ALIMENTOS

CARLA ALVES MONACO LOURENÇO

Veiculação de compostos bioativos extraídos do resíduo industrial de camu-camu em filmes de desintegração oral 


\title{
Veiculação de compostos bioativos extraídos do resíduo industrial de camu-camu em filmes de desintegração oral
}

\author{
VERSÃO CORRIGIDA
}

Tese apresentada à Faculdade de Zootecnia e Engenharia de Alimentos da Universidade de São Paulo como parte dos requisitos para a obtenção do título de Doutor em Ciências do Programa de Pós-graduação em Engenharia de Alimentos Área de concentração: Ciências da Engenharia de Alimentos

Orientadora: Profa. Dra. Rosemary Aparecida de Carvalho 
Ficha catalográfica elaborada pelo

Serviço de Biblioteca e Informaçăo, FZEA/USP, com os dados fornecidos pelo(a) autor(a)

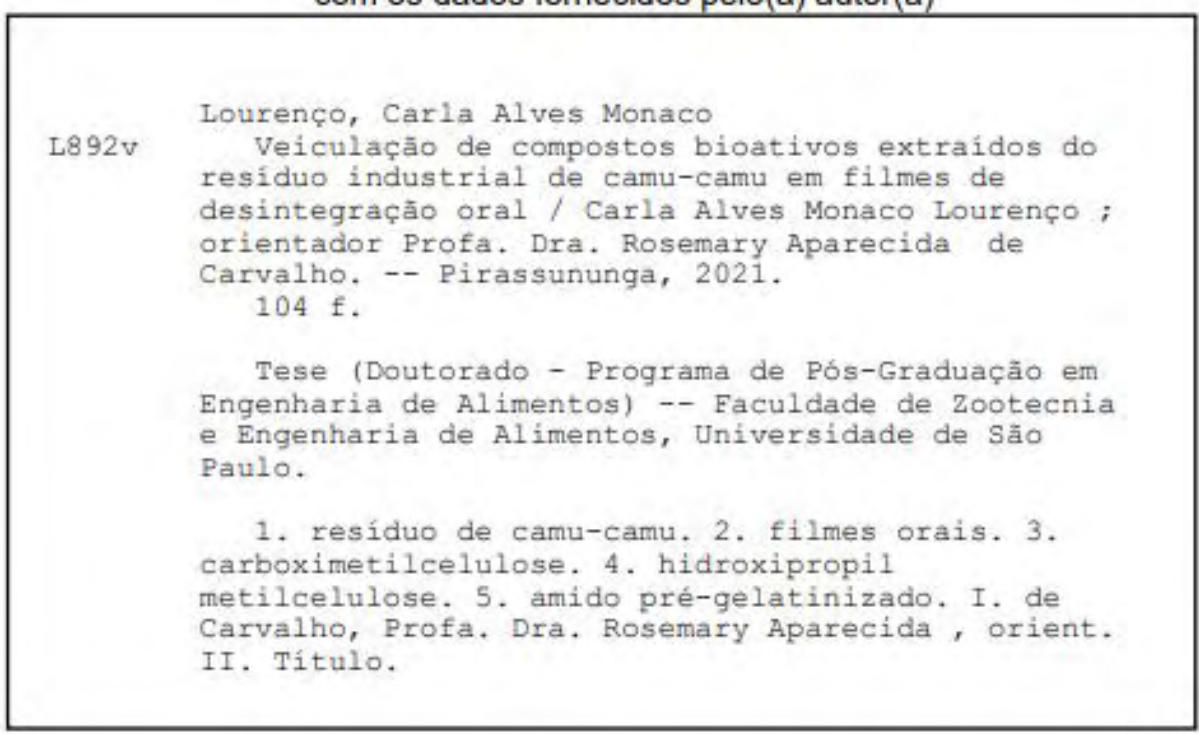

Permitida a copia total ou parcial deste documento, desde que citada a fonte - o autor 


\section{AGRADECIMENTOS}

Primeiramente, obrigada à Deus por mais uma conquista!

Aos meus pais e meu irmão, que desde 2006 quando sai de casa para estudar sabiam que eu não voltaria e sempre me apoiaram e me incentivaram mesmo que de longe.

Ao meu marido, Rodrigo, por todo amor, companheirismo, paciência e apoio ao longo desse trabalho.

Aos meus filhos amados, Enzo e Cauê, que nasceram durante o doutorado, e me fazem ser uma pessoa melhor a cada dia.

À minha orientadora e chefe, Professora Dra. Rosemary Aparecida de Carvalho, por todo o ensinamento, incentivo, compreensão e dedicação.

À Faculdade de Zootecnia e Engenharia de Alimentos pela oportunidade de realização do curso de doutorado.

Aos meus colegas de trabalho, aos professores e funcionários do Departamento de Engenharia de Alimentos pela colaboração.

À empresa Doce Fruta pela doação do resíduo de camu-camu, essencial para o desenvolvimento desse trabalho.

Ao apoio da Coordenação de Aperfeiçoamento de Pessoal de Nível Superior Brasil (CAPES) - Código de Financiamento 001.

Enfim, a todos àqueles que colaboraram com esse trabalho. 


\section{RESUMO}

Camu-camu, fruto nativo da Amazônia, embora rico nutricionalmente, apresenta $\mathrm{pH}$ baixo resultando em baixo consumo in natura do fruto, com isso 0 processamento em forma de sucos, polpas e extratos é muito empregado, o que gera resíduos e constituem um sério problema de descarte uma vez que são propensos à decomposição microbiana. Por outro lado, os resíduos provenientes do processamento do camu-camu são fonte potencial de compostos ativos como fenólicos e podem apresentar capacidade antioxidante, o aproveitamento desses resíduos podem ser utilizados para funcionalizar alimentos e substituir aditivos sintéticos por ingredientes de origem natural. Visando a utilização desses compostos, esse trabalho teve como objetivo a extração dos compostos bioativos a partir do resíduo industrial de camu-camu para incorporação em matrizes poliméricas para veiculação dos compostos antioxidantes através de filmes de desintegração oral (FDOs). O resíduo de camu-camu foi seco a $50{ }^{\circ} \mathrm{C}$ por $9 \mathrm{~h}$, submetido à moagem e padronização de granulometria (mesh 16). A extração do resíduo de camu-camu foi testada com quatro solventes: álcool 70\%, $80 \%, 100 \%$ e água, sendo selecionado o álcool $70 \%$ como melhor solvente para extração, uma vez que este extrato alcoólico apresentou maior teor de compostos fenólicos e maior capacidade antioxidante. O extrato etanólico do resíduo de camu-camu (EERCC) foi caracterizado em relação a: cor, $\mathrm{pH}$, vitamina C (1621 $\pm 172 \mathrm{mg} \mathrm{AA}$ Total/100g resíduo seco), compostos fenólicos totais (39 + $1 \mathrm{mg}$ EAG / $\mathrm{g}$ resíduo seco), flavonoides totais ( $217 \pm 8 \mathrm{mg}$ quercetina / $100 \mathrm{~g}$ resíduo seco), capacidade antioxidante pelo sequestro do radical DPPH (262 $\pm 20 \mu \mathrm{mol}$ Trolox eq./g resíduo seco) e ORAC (232 $\pm 17 \mu \mathrm{mol}$ Trolox eq./g resíduo seco). Os filmes de desintegração oral foram produzidos utilizando as macromoléculas: amido pré-gelatinizado, carboximetilcelulose (CMC) e hidroxipropil metilcelulose (HPMC) caracterizados de acordo com as análises de: espessura, propriedades mecânicas, parâmetros de cor e opacidade, $\mathrm{pH}$ de superfície, ângulo de contato, espectroscopia de infravermelho com transformada de Fourier, microscopia de força atômica, tempo de desintegração, perfil de liberação in vitro, e estabilidade. $O$ filme de amido apresentou baixa tensão na ruptura indicando propriedades mecânicas inferiores aos demais polímeros. Todos os filmes apresentaram $\mathrm{pH}$ de superfície próximo ao pH neutro, 
indicando não causar irritações na mucosa bucal. Quanto a hidrofilicidade, os filmes incorporados com EERCC não apresentaram diferença significativa entre si. Os filmes de CMC incorporados com EERCC além de apresentarem menor tempo de desintegração ( $50 \pm 5 \mathrm{~s}$ ), apresentaram o menor tempo para liberação máxima dos compostos fenólicos (30 minutos), apresentaram maior teor de compostos fenólicos e maior capacidade antioxidante, e ainda exibiram estabilidade da matriz polimérica durante 20 semanas de armazenamento em condição normal $\left(25^{\circ} \mathrm{C}\right.$, UR $\left.60 \%\right)$ e acelerada $\left(40^{\circ} \mathrm{C}, 75 \%\right)$. Desta forma, os filmes de desintegração oral à base de CMC possibilitam a incorporação de extratos naturais, como o extrato do resíduo de camu-camu e a produção e comercialização de FDOs têm potencial para entrega de compostos ativos naturais.

Palavras-chave: Myrciaria dúbia, compostos fenólicos, capacidade antioxidante, amido, carboximetilcelulose, hidroxipropil metilcelulose 


\section{ABSTRACT}

Camu-camu, a native fruit from Amazon, although nutritionally rich, has low $\mathrm{pH}$ resulting in low consumption of the fresh fruit, thus processing it in the form of juices, pulps and extracts is widely used, which generates waste and this constitutes a serious problem since they are prone to microbial decomposition. On the other hand, residues from the processing of camu-camu are source of active compounds such as phenolics and they can present antioxidant capacity, the recovery of these residues can be used to functionalize foods and replace synthetic additives with ingredients of natural origin. Aiming at using of these compounds, this work aimed to extract the bioactive compounds from the industrial residue of camu-camu for incorporation in polymeric matrices to convey the antioxidant compounds through oral disintegrating films (ODFs). The camucamu residue was dried at $50{ }^{\circ} \mathrm{C}$ for $9 \mathrm{~h}$, ground and the granulometry was standardized (16 mesh). The extraction of the camu-camu residue was tested with four solvents: $70 \%, 80 \%, 100 \%$ alcohol and water, $70 \%$ alcohol being selected as the best solvent for extraction since this alcoholic extract had a greater content of phenolic compounds and higher antioxidant capacity. The ethanolic extract of the camu-camu residue (EECCR) was characterized in relation to: color, $\mathrm{pH}$, vitamin $\mathrm{C}(1621+172 \mathrm{mg} \mathrm{AA}$ Total / $100 \mathrm{~g}$ dry residue $)$, total phenolic compounds $(39+1 \mathrm{mg}$ EAG / g dry residue), total flavonoids $(217+8$ mg quercetin / $100 \mathrm{~g}$ dry residue), antioxidant capacity by the sequestration of the DPPH radical $(262+20 \mu \mathrm{mol}$ Trolox eq./g dry residue) and ORAC $(232+17 \mu \mathrm{mol}$ Trolox eq./g dry residue). Oral disintegrating films were produced using the macromolecules: pregelatinized starch, carboxymethylcellulose (CMC) and hydroxypropylmethylcellulose (HPMC) and they were characterized according to the analysis of: thickness, mechanical properties, color and opacity parameters, surface $\mathrm{pH}$, contact angle, Fourier transform infrared spectroscopy, atomic force microscopy, disintegration time, in vitro release profile, and stability. The starch film showed low tensile strength, indicating lower mechanical properties than other polymers. All films had a surface $\mathrm{pH}$ close to neutral $\mathrm{pH}$, indicating that they do not irritate the oral mucosa. The films incorporated with EECCR showed no significant difference in terms of hydrophilicity. The CMC films incorporated with EECCR, besides having the shortest disintegration time (50 $\pm 5 \mathrm{~s})$, had the 
shortest time for maximum release of the phenolic compounds (10 minutes), had the highest content of phenolic compounds and the highest antioxidant capacity, and also exhibited stability of the polymeric matrix during 20 weeks of storage under normal ( $25^{\circ} \mathrm{C}, \mathrm{RH} 60 \%$ ) and accelerated conditions $\left(40^{\circ} \mathrm{C}, \mathrm{RH} 75 \%\right)$. Therefore, CMC-oral disintegrating films allow the incorporation of natural extracts, such as the extract of camu-camu residue and the production and commercialization of ODFs present potential for the delivery of natural active compounds.

Keywords: Myrciaria dúbia, phenolic compounds, antioxidant capacity, starch, carboxymethylcellulose, hydroxypropylmethylcellulose 


\section{Sumário}

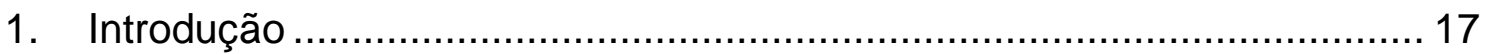

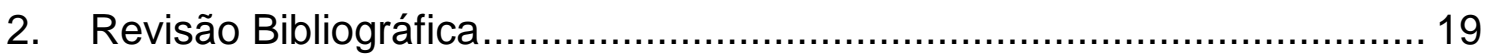

2.1 Resíduos da indústria de alimentos.................................................... 19

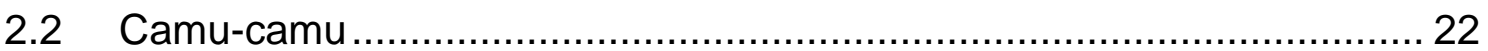

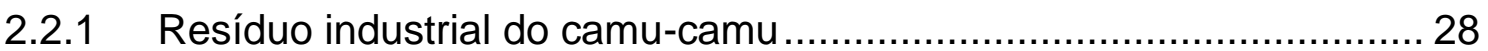

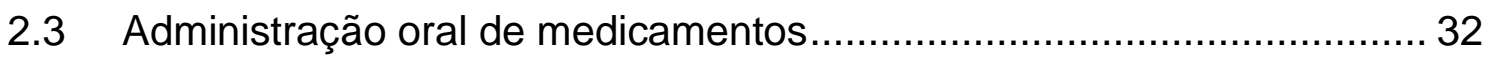

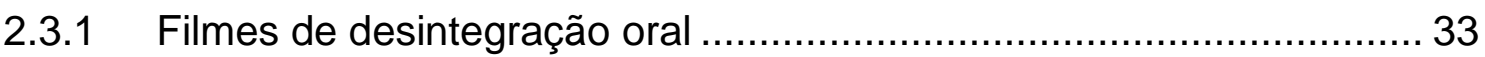

2.3.1.1 Filmes de desintegração oral com compostos naturais .................. 37

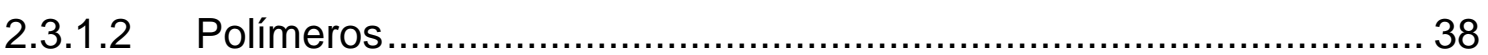

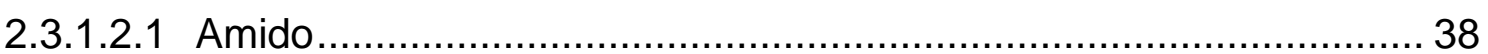

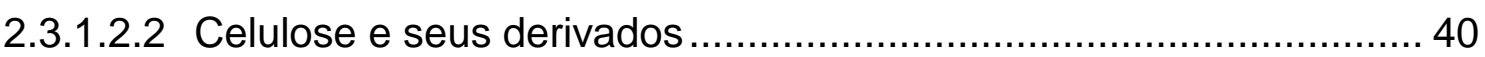

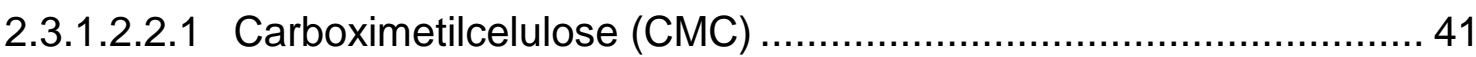

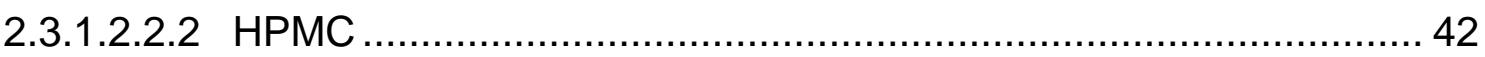

2.3.1.3 Produção dos filmes de desintegração oral .................................... 43

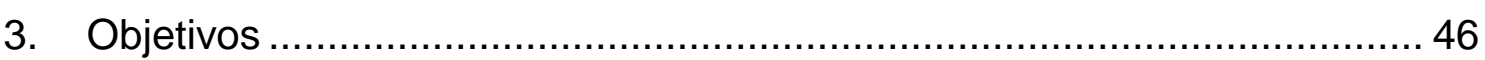

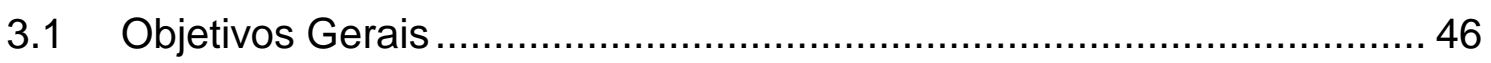

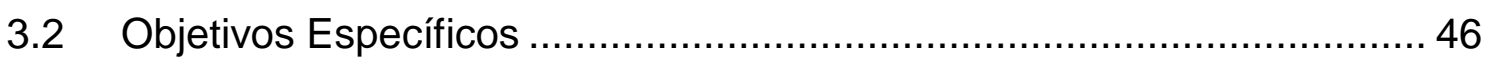

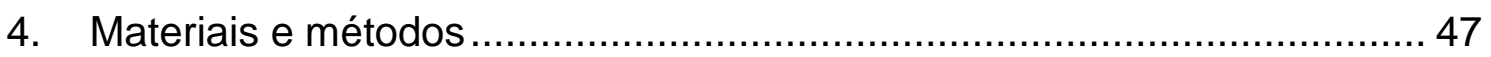

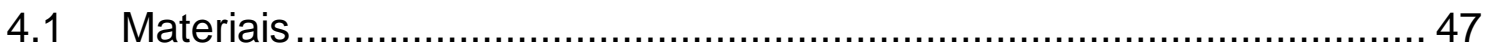

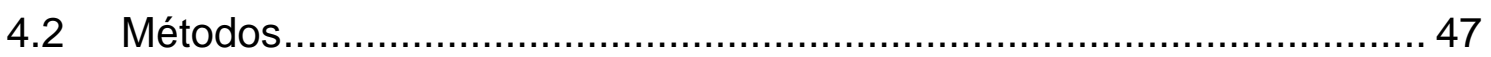

4.2.1 Obtenção do resíduo de camu-camu em pó (RCCP) .......................... 49

4.2.2 Produção e caracterização do extrato do resíduo de camu-camu (ERCC) 50

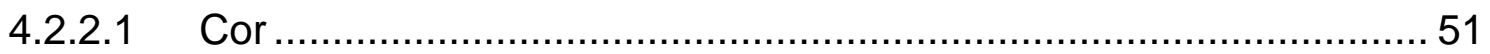

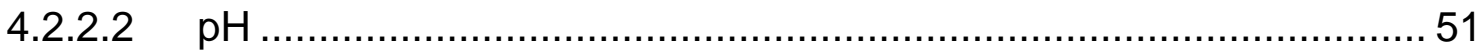

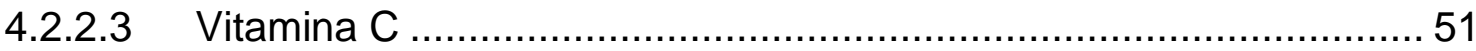

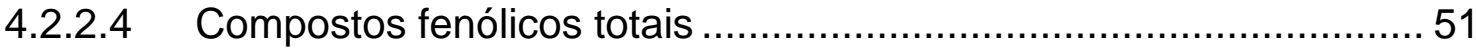

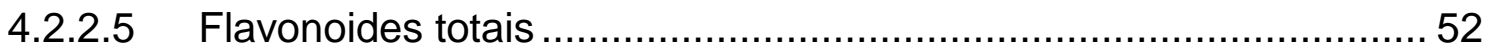

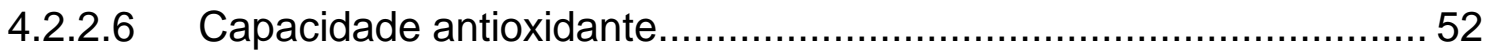

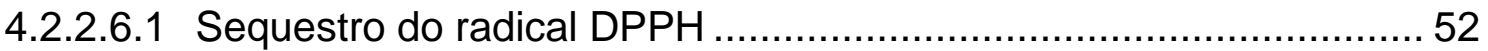

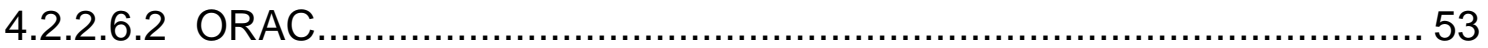

4.2.3 Produção dos filmes de desintegração oral ..................................... 53

4.2.4 Caracterização dos filmes de desintegração oral............................... 56 


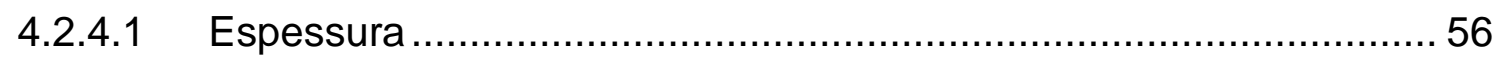

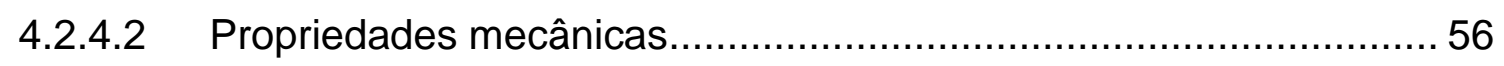

4.2.4.3 Parâmetros de cor e opacidade .................................................... 56

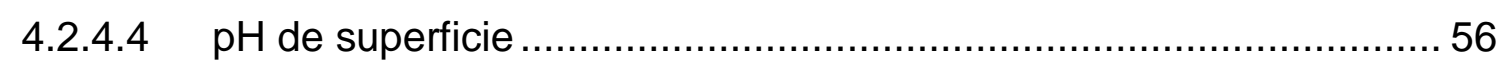

4.2.4.5 Ângulo de contato ...................................................................... 57

4.2.4.6 Espectroscopia de Infravermelho com Transformada de Fourier .... 57

4.2.4.7 Microscopia de força atômica ......................................................... 57

4.2.4.8 Tempo de desintegração ......................................................... 57

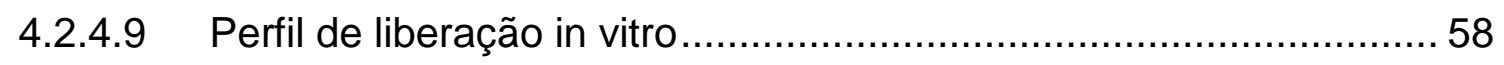

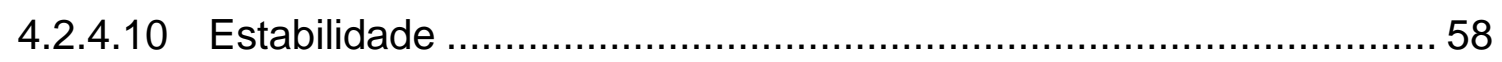

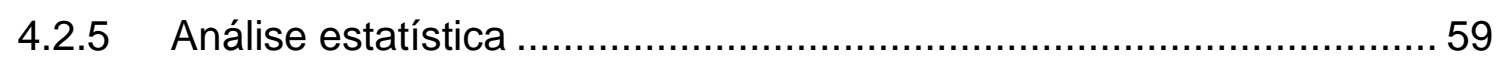

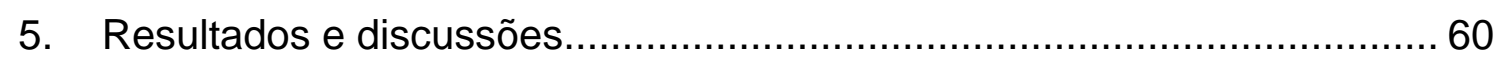

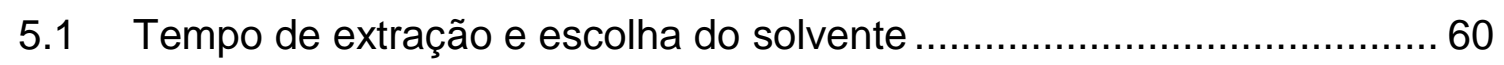

5.2 Caracterização do extrato etanólico de camu-camu................................ 61

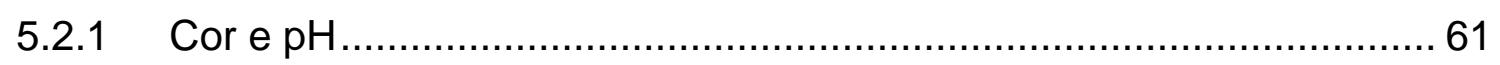

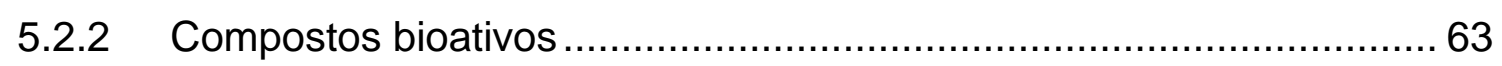

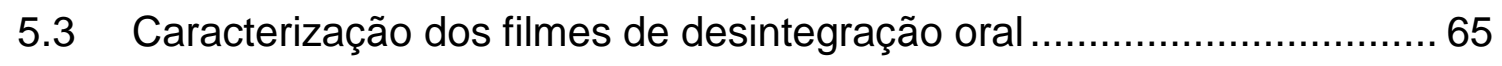

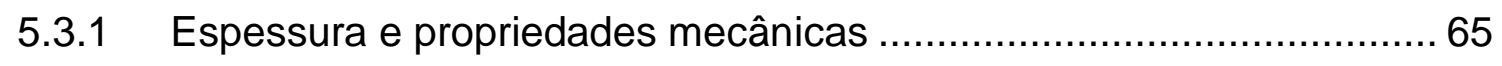

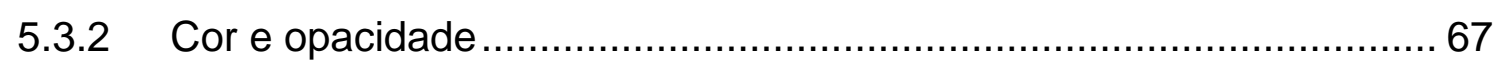

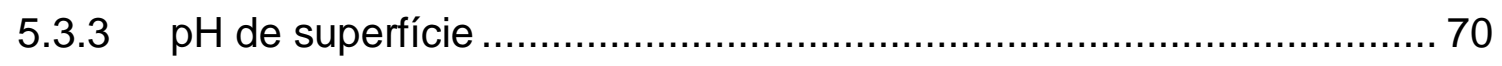

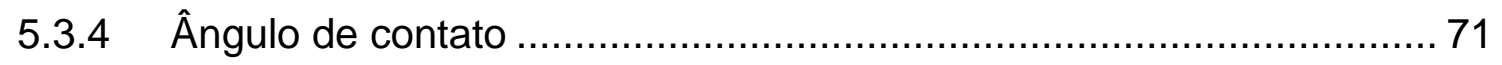

5.3.5 Espectroscopia de Infravermelho com Transformada de Fourier ........ 73

5.3.6 Microscopia de força atômica......................................................... 76

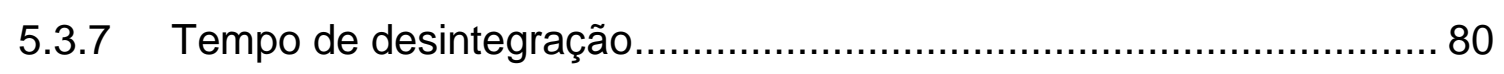

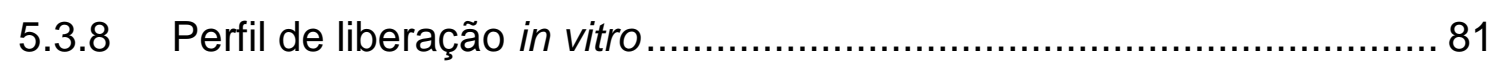

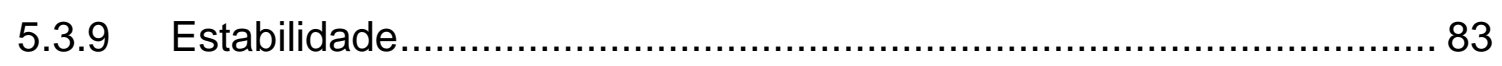

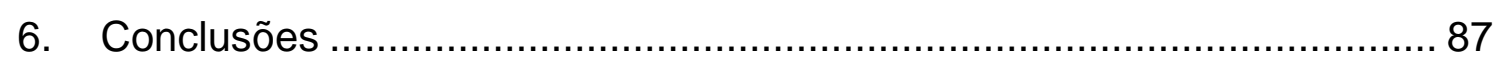

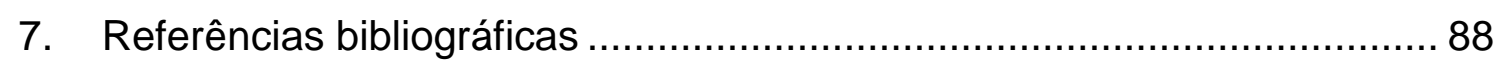




\section{Índice de ilustrações}

Figura 1. Camu-camu: (a) frutos e (b) camu-camuzeiro................................ 23

Figura 2. Estrutura amilose e amilopectina. .............................................. 40

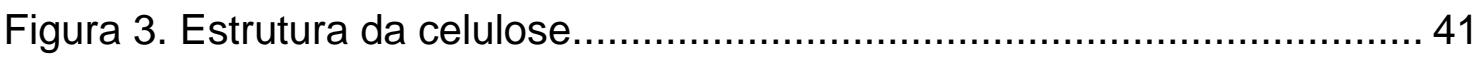

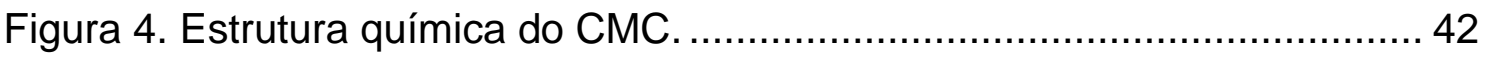

Figura 5. Estrutura química do HPMC........................................................... 43

Figura 6 - Fluxograma de produção e execução do projeto de filmes de desintegração oral a partir do resíduo industrial de camu-camu (RCC)........... 48 Figura 7. Resíduo de camu-camu in natura doado pela empresa Doce Fruta em

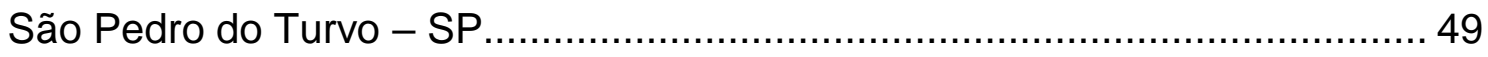

Figura 8. Pó do resíduo industrial de camu-camu após secagem e padronização

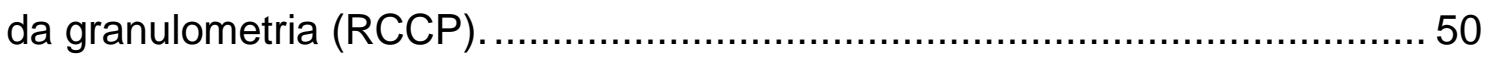

Figura 9. Espalhador automático de filme Zehntner ZAA2300 ........................ 55

Figura 10. Slide frame com filme oral utilizado para a realização do tempo de

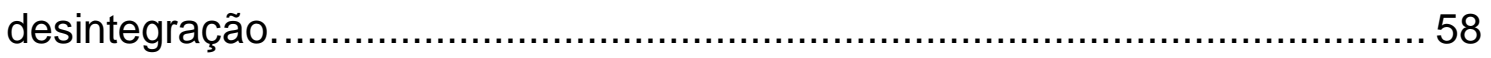

Figura 11. Sólido de cor do sistema CIELab. ................................................ 63

Figura 12. Exemplos de filmes de desintegração oral à base de diferentes macromoléculas sem e com incorporação extrato etanólico obtido do resíduo industrial de camu-camu (EERCC): (a) amido, (a') amido + EERCC; (b) carboximetilcelulose (CMC), (b') CMC + EERCC; (c) hidroxipropil metilcelulose (HPMC), (c') HPMC + EERCC. 69

Figura 13. Espectros de absorção de infravermelho de filmes de desintegração oral à base de: (a) amido pré-gelatinizado (Amido), (b) carboximetilcelulose (CMC) e (c) hidroxipropil metilcelulose (HPMC), sem e com incorporação de extrato etanólico obtido do resíduo industrial de camu-camu (EERCC). 74 
Figura 14. Microscopia de força atômica 2D da superfície dos filmes de desintegração oral à base de diferentes macromoléculas sem e com incorporação de extrato etanólico obtido do resíduo industrial de camu-camu (EERCC): (a) amido, (a') amido + EERCC; (b) carboximetilcelulose (CMC), (b') CMC + EERCC; (c) hidroxipropil metilcelulose (HPMC), (c') HPMC + EERCC.

Figura 15. Microscopia de força atômica 3D da superfície de filmes de desintegração oral à base de diferentes macromoléculas sem e com incorporação de extrato etanólico obtido do resíduo industrial de camu-camu (EERCC): (a) amido, (a') amido + EERCC; (b) carboximetilcelulose (CMC), (b') CMC + EERCC; (c) hidroxipropil metilcelulose (HPMC), (c') HPMC + EERCC.

Figura 16. Perfil de liberação in vitro de compostos fenólicos de filme de desintegração oral (FDO) à base de (a) Amido pré gelatinizado, (b) Carboximetilcelulose (CMC) e (c) Hidroxipropil metilcelulose (HPMC); todos com extrato etanólico obtido do resíduo industrial de camu-camu em concentração de $30 \mathrm{~g} / 100 \mathrm{~g}$ de solução filmogênica. 82

Figura 17. (a) Variação da concentração de compostos fenólicos totais (C Fenólicos $_{\text {aco }}$ totais) e (b) Variação da atividade antioxidante pelo método de ORAC ( $\mu$ mol Trolox Equivalente / grama de filme seco) em função do tempo de armazenamento a 25ํㅡ e $60 \%$ UR nos filmes de desintegração a base de amido, CMC e HPMC com incorporação de extrato etanólico obtido do resíduo industrial de camucamu. 85

Figura 18. (a) Variação da concentração de compostos fenólicos totais ( $\mathrm{C}_{\text {Fenólicos }}$ totais) e (b) Variação da atividade antioxidante pelo método de ORAC ( $\mu$ mol Trolox 
Equivalente / grama de filme seco) em função do tempo de armazenamento a $40^{\circ} \mathrm{C}$ e $75 \%$ UR nos filmes de desintegração a base de amido, CMC e HPMC com incorporação de extrato etanólico obtido do resíduo industrial de camucamu. 


\section{Índice de tabelas}

Tabela 1 - Compostos funcionais encontrados em resíduos de frutas............. 20

Tabela 2 - Exemplos de aplicações de resíduos de frutas............................... 21

Tabela 3 - Composição centesimal da polpa de camu-camu determinada por diversos autores

Tabela 4 - Composição de aminoácidos da polpa de camu-camu................... 24

Tabela 5 - Composição de lipídeos da polpa de camu-camu........................... 24

Tabela 6 - Composição química (vitaminas) da polpa de camu-camu............. 24

Tabela 7 - Composição de minerais da polpa de camu-camu........................... 25

Tabela 8 - Concentração de vitamina C (CVitamina c, mg de ácido ascórbico/100 g) em diferentes partes dos frutos de camu-camu. .......................................... 26

Tabela 9 - Composição centesimal do resíduo industrial de camu-camu

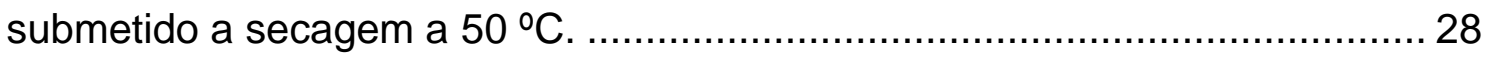

Tabela 10 - Teores de compostos ativos: ácido ascórbico e ácido dehidroascórbico, antocianinas, fenólicos, flavonoides e proantocianidinas em

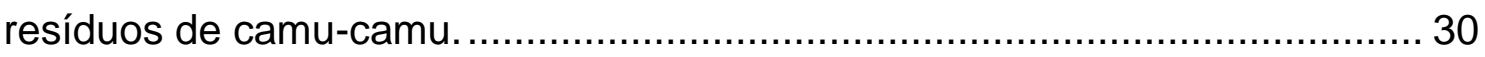

Tabela 11 - Filmes de desintegração oral disponíveis comercialmente. ........... 34 Tabela 12 - Polímeros e princípios ativos utilizados em filmes de desintegração.

Tabela 13 - Estudos de FDO incorporados com extratos de princípios ativos naturais. 38

Tabela 14 - Estudos de filmes desenvolvidos pela técnica de espalhamento. . 45 Tabela 15 - Condições de armazenamento dos FDOs para ensaios de caracterização. 55 


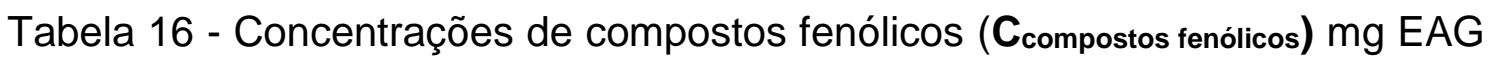
Ig resíduo seco) dos extratos obtidos com diferentes solventes (água, etanol $70 \%$ e etanol 80\%) e diferentes tempos de extração (textração)................................. 60

Tabela 17 - Atividade antioxidante determinada pelos métodos DPPH• e ORAC, dos extratos do resíduo de camu-camu obtidos utilizando-se diferentes solventes (tempo de extração $=5 \mathrm{~min}$ ). 61

Tabela 18 - Caracterização do extrato etanólico de camu-camu (EERCC) em relação ao $\mathrm{pH}$, luminosidade $\left(\mathrm{L}^{*}\right)$, croma $\mathrm{a}^{*}\left(\mathrm{a}^{*}\right)$ e croma $\mathrm{b}^{*}\left(\mathrm{~b}^{*}\right)$. 62 Tabela 19 - Concentração de compostos fenólicos totais, concentração de flavonoides, vitamina $\mathrm{C}$ e atividade antioxidante (DPPH• e ORAC) do extrato etanólico obtido do resíduo industrial de camu-camu (EERCC) 63 Tabela 20 - Conteúdo de água (CA), espessura, tensão de ruptura (TR) e elongação (E) dos filmes de desintegração oral à base de amido pré-gelatinizado (Amido), carboximetilcelulose (CMC) e hidroxipropil metilcelulose (HPMC), sem e com incorporação extrato etanólico obtido do resíduo industrial de camu-camu (EERCC). 65

Tabela 21 - Luminosidade $\left({ }^{*} L\right)$, croma $a^{*}\left(a^{*}\right)$, croma $b^{*}\left(b^{*}\right)$ dos filmes de desintegração oral à base de amido pré-gelatinizado (Amido), carboximetilcelulose (CMC) e hidroxipropil metilcelulose (HPMC), sem e com extrato etanólico obtido do resíduo industrial de camu-camu (EERCC). 70

Tabela 22 - pH de superfície dos filmes de desintegração oral à base de amido pré-gelatinizado (Amido), carboximetilcelulose (CMC) e hidroxipropil metilcelulose (HPMC), sem e com incorporação de extrato etanólico obtido do resíduo industrial de camu-camu (EERCC) 
Tabela 23 - Ângulo de contato dos filmes de desintegração oral de amido prégelatinizado (Amido), carboximetilcelulose $(\mathrm{CMC})$ e hidroxipropil metilcelulose (HPMC), sem e com incorporação de extrato etanólico obtido do resíduo industrial de camu-camu (EERCC).

Tabela 24 - Rugosidade média (Ra) dos filmes de desintegração oral à base de amido pré-gelatinizado (Amido), carboximetilcelulose (CMC) e hidroxipropilmetilcelulose (HPMC) sem com e incorporação de extrato etanólico obtido do resíduo industrial de camu-camu (EERCC).................................... 77 Tabela 25 - Tempo de desintegração dos filmes de desintegração oral incorporados com extrato etanólico obtido do resíduo industrial de camu-camu (EERCC). 80 


\section{Introdução}

O Brasil ocupa a terceira posição na produção mundial de frutas, com aproximadamente 45 milhões de toneladas por ano, ficando atrás apenas da China e da Índia (EMBRAPA, 2019). Desse total, aproximadamente 55\% destina-se ao processamento agroindustrial na forma de sucos, polpas e outras formulações (SEBRAE, 2015).

Estima-se que o processamento de frutas e vegetais gere em torno 10-35\% de resíduo agroindustrial (MAJERSKA; MICHALSKA; FIGIEL, 2019). Dependendo do tipo da fruta processada, os principais resíduos gerados no processamento de polpas de frutas são: casca, bagaço, caroço e/ou sementes (SOUSA et al., 2011). Esses resíduos, provenientes das indústrias de sucos e polpas tem atraído atenção, uma vez que são fontes potenciais de compostos bioativos, possuem em sua composição minerais, vitaminas, fibras e compostos antioxidantes (HERNÁNDEZ-CARRANZA et al., 2016). Compostos antioxidantes, especialmente fenólicos, podem ajudar a proteger os sistemas celulares de danos oxidativos e reduzir o risco de doenças crônicas (LIU, 2003).

Os resíduos agroindústrias muitas vezes são considerados como custo operacional para as empresas e o destino desses resíduos limitado à produção de rações animais e adubo, e a maior parte ainda descartada sem tratamento, sendo fonte de contaminação ambiental (MELO et al., 2011).

Camu-camu, em função do seu alto teor de compostos bioativos, como compostos fenólicos (flavonóides e elagitaninos), ácido ascórbico e $\beta$-caroteno (AKTER et al., 2011; INOUE et al., 2008) tem despertado interesse das indústrias alimentícias e farmacêuticas. Entretanto, o sabor amargo, elevada acidez e a sazonalidade do fruto restringe $\mathrm{o}$ seu consumo in natura, justificando 0 processamento em forma de polpa congelada, extrato seco, suco e sorvete (RODRIGUES et al., 2001; ALVES et al., 2002).

No processamento do camu-camu, o resíduo industrial gerado constitui de pele e sementes, que correspondem a aproximadamente $40 \%$ do peso total do fruto (RODRIGUES et al., 2001). Esses resíduos podem apresentar concentrações elevadas de compostos bioativos como, fenólicos e vitaminas (ARAÚJO et al., 2018; CHAGAS, 2019; DO CARMO et al., 2020; MYODA et al., 2010), além de fibras, com resultados similares ou até superiores aos 
observados para as polpas (MIRABELLA; CASTELLANI; SALA, 2014). Dessa forma, o aproveitamento desses resíduos além de minimizar os impactos ambientais decorrentes do descarte, pode agregar valor a novos produtos nas indústrias farmacêuticas e alimentícias (SILVA; JORGE, 2014).

Embora exista vários estudos sobre extratos e quantificação dos compostos presentes no resíduo de camu-camu (CARMO et al., 2019; DE AZEVÊDO et al., 2014a; FIDELIS et al., 2020; NEVES et al., 2015; YAPU et al., 2008), a aplicação para desenvolvimento de novos produtos ainda é incipiente. Uma alternativa viável e promissora para o aproveitamento das substâncias presentes no resíduo do camu-camu é a extração dos compostos bioativos para incorporação em matrizes poliméricas para produção de filmes de desintegração oral com capacidade antioxidante.

As vantagens dos FDOs incluem rápida absorção, não ingestão de água, mascaramento de sabor e precisão da dose (BALA et al., 2013). Quando colocados na língua, os FDOs se hidratam imediatamente por imersão de saliva seguida da desintegração e/ou dissolução, liberando o agente farmacêutico ativo (IRFAN et al., 2015). A injestão do FDO favorece a biodisponibilidade, pois a absorção pela mucosa oral evita a passagem pelo trato gastrointestinal, diminuindo a degradação do composto ativo devido à ação de enzimas digestivas e metabolismo de primeira passagem hepática (TEUBL et al., 2013). O desenvolvimento bem-sucedido de um FDO é função da seleção e concentração de polímeros, visto que a resistência mecânica e hidrofilicidade dos filmes está fortemente associada a esses fatores; frente à isso, diferentes polímeros são empregados para modular diversas propriedades de filmes (IRFAN et al., 2015). Amido, carboximetilcelulose e hidroxipropil metilcelulose são polímeros muito utilizados na produção de FDOs, apresentam elevada disponibilidade comercial, baixo custo, baixa toxicidade, boa capacidade formadora de filme, entre outras características.

Diante desse contexto, essa tese teve como objetivo extrair e incorporar o extrato obtido do resíduo industrial de camu-camu em filmes de desintegração oral a base de amido pré gelatinizado, carboximetilcelulose e hidroxipropil metilcelulose para veiculação de compostos bioativos com propriedades antioxidante. 


\section{Revisão Bibliográfica}

\subsection{Resíduos da indústria de alimentos}

A indústria de processamento de alimentos, incluindo processamento de frutas e vegetais, é o segundo maior gerador de resíduos, depois do esgoto doméstico (GOWE, 2015). O processamento de frutas e vegetais resulta em grande quantidade de resíduos como cascas, sementes, caroços e polpa não aproveitada, gerados nas diferentes etapas das cadeias de processamento (GOWE, 2015).

O gerenciamento de resíduos oriundos do processamento de frutas e vegetais é um dos grandes problemas das agroindústrias (FIERASCU et al., 2020). Para muitas indústrias processadoras de alimentos, é mais viável e econômico descartar os resíduos do que implementar processos para sua utilização (SCHIEBER, 2019). Estes resíduos são comumente utilizados como: fertilizantes (ESPARZA et al., 2020; MAJERSKA; MICHALSKA; FIGIEL, 2019; SCHIEBER, 2019) ou implementadas em formulações para ração animal (FERREIRA et al., 2021; GODOY et al., 2018; MATRA; TOTAKUL; WANAPAT, 2021). No entanto, o impacto ambiental, pressão regulatória e o aumento da conscientização do consumidor quanto a sustentabilidade vem exigindo estratégias alternativas, que devem preferencialmente levar à valorização desses resíduos, do que à sua disposição (SCHIEBER, 2017).

Os resíduos produzidos na agroindústria constituem uma perda de biomassa e nutrientes valiosos, uma vez que esses resíduos têm o potencial de se tornar produtos úteis ou até matérias-primas para outras indústrias (ESPARZA et al., 2020). Considerando ainda que esses resíduos representam importante fonte de açúcares, fibra dietética, ácidos orgânicos, minerais e compostos bioativos, como compostos fenólicos, carotenoides e vitaminas, o uso desses resíduos como subprodutos para produção de aditivos ou suplementos alimentares com alto valor nutricional vem ganhando interesse crescente (DJILAS; CANADANOVIC-BRUNET; CETKOVIC, 2009).

$\mathrm{Na}$ Tabela 1 é possível verificar alguns exemplos de estudos relacionados com compostos bioativos em resíduos de frutas. 
Tabela 1 - Compostos funcionais encontrados em resíduos de frutas.

\begin{tabular}{|c|c|c|}
\hline Resíduo & Composto funcional & Referência \\
\hline $\begin{array}{l}\text { Casca, semente e polpa } \\
\text { residual de abacaxi e } \\
\text { goiaba }\end{array}$ & Compostos fenólicos & Sousa \& Correia (2012) \\
\hline Casca de manga & $\begin{array}{l}\text { Carotenoides } \\
\text { Fenólicos totais } \\
\text { Flavonoides }\end{array}$ & $\begin{array}{l}\text { Garcia-Mendoza et al. } \\
\text { (2015) }\end{array}$ \\
\hline Bagaço de uva & $\begin{array}{l}\text { Antocianinas } \\
\text { Compostos fenólicos }\end{array}$ & $\begin{array}{l}\text { Stafussa et al. (2016) } \\
\text { Meini et al. (2019) }\end{array}$ \\
\hline $\begin{array}{l}\text { Casca e polpa residual } \\
\text { de açaí }\end{array}$ & $\begin{array}{l}\text { Antocianinas } \\
\text { Compostos fenólicos }\end{array}$ & $\begin{array}{l}\text { Garcia-Mendoza et al. } \\
\text { (2017) }\end{array}$ \\
\hline Bagaço da maçã & Compostos fenólicos & Ferrentino et al. (2018) \\
\hline $\begin{array}{l}\text { Casca e semente de } \\
\text { abacate }\end{array}$ & Compostos fenólicos & Tremocoldi et al. (2018) \\
\hline $\begin{array}{l}\text { Casca, semente e polpa } \\
\text { residual de acerola }\end{array}$ & $\begin{array}{l}\text { Flavonoides } \\
\text { Proantocianidinas } \\
\text { Vitamina C } \\
\text { Compostos fenólicos }\end{array}$ & Tedesco (2018) \\
\hline Semente de mamão & Compostos fenólicos & $\begin{array}{l}\text { Gonçalves Rodrigues et } \\
\text { al. (2019) }\end{array}$ \\
\hline $\begin{array}{l}\text { Casca e semente de } \\
\text { maracujá, laranja e } \\
\text { acerola } \\
\text { Casca e polpa residual } \\
\text { de manga }\end{array}$ & $\begin{array}{l}\text { Fibra dietética } \\
\text { Compostos fenólicos }\end{array}$ & $\begin{array}{l}\text { Albuquerque et al. } \\
\text { (2019) }\end{array}$ \\
\hline Bagaço de jabuticaba & $\begin{array}{l}\text { Antocianinas } \\
\text { Pectina }\end{array}$ & Benvenutti et al. (2020) \\
\hline Casca de melão & $\begin{array}{l}\text { Compostos fenólicos } \\
\text { Carotenoides }\end{array}$ & $\begin{array}{l}\text { Gómez-García et al. } \\
\text { (2021) }\end{array}$ \\
\hline $\begin{array}{l}\text { Casca, semente e polpa } \\
\text { residual de camu-camu }\end{array}$ & Compostos fenólicos & $\begin{array}{l}\text { Das Chagas et al. } \\
(2021)\end{array}$ \\
\hline
\end{tabular}


Por outro lado, os resíduos provenientes da indústria de alimentos apresentam alta carga orgânica, alto teor de umidade, potencial para rápida autooxidação e alta atividade enzimática, o que resulta em deterioração microbiana (MATEOS-APARICIO; MATIAS, 2019; SCHIEBER, 2019). O seu aproveitamento requer processamento imediato ou secagem para estabilização (SCHIEBER, 2019).

$\mathrm{Na}$ literatura inúmeros estudos são reportados para viabilizar o aproveitamento de resíduos provenientes do processamento de frutas para indústrias farmacêuticas, nutracêuticas e alimentícias, seja na forma de matériaprima, aditivo ou extratos. Exemplos de aplicações dos resíduos provenientes do processamento de frutas podem ser observados na Tabela 2.

Tabela 2 - Exemplos de aplicações de resíduos de frutas.

\begin{tabular}{|c|c|c|}
\hline Resíduo & Aplicação & Referência \\
\hline $\begin{array}{l}\text { Bagaço de maçã e } \\
\text { bagaço de tomate }\end{array}$ & Linguiça de frango & Yadav et al. (2016) \\
\hline Casca de abacaxi & logurte com prebiótico & Sah et al. (2016) \\
\hline $\begin{array}{l}\text { Semente e casca de } \\
\text { seriguela }\end{array}$ & $\begin{array}{l}\text { Substituição parcial da farinha de } \\
\text { trigo em cookies }\end{array}$ & $\begin{array}{l}\text { Albuquerque et al. } \\
\text { (2016) }\end{array}$ \\
\hline Casca de manga & Pão Árabe & Mahmoud et al. (2017) \\
\hline Casca de banana & Barra de cereal & $\begin{array}{l}\text { Carvalho \& Conti-Silva } \\
\text { (2018) }\end{array}$ \\
\hline $\begin{array}{l}\text { Resíduo de goiaba, } \\
\text { laranja e maracujá }\end{array}$ & $\begin{array}{l}\text { Adição em produtos fermentados } \\
\text { probióticos }\end{array}$ & Casarotti et al. (2018) \\
\hline $\begin{array}{l}\text { Bagaço de laranja, } \\
\text { maracujá e melancia }\end{array}$ & $\begin{array}{l}\text { Filmes biodegradáveis } \\
\text { enriquecido com pectina para } \\
\text { embalagem }\end{array}$ & Brito et al. (2019) \\
\hline Casca de manga & $\begin{array}{l}\text { Filme comestível e recobrimento } \\
\text { em maçã }\end{array}$ & $\begin{array}{l}\text { Rojas-Bravo et al. } \\
(2019)\end{array}$ \\
\hline Semente de maçã & $\begin{array}{l}\text { Substituição parcial da farinha de } \\
\text { trigo em pão pela torta de óleo de } \\
\text { semente de maçã moída }\end{array}$ & Purić et al. (2020) \\
\hline $\begin{array}{l}\text { Resíduo de acerola e } \\
\text { jabuticaba }\end{array}$ & Recobrimento em mamão & Gomes et al. (2020) \\
\hline $\begin{array}{l}\text { Casca, semente e polpa } \\
\text { residual de camu-camu }\end{array}$ & $\begin{array}{l}\text { Substituição parcial da farinha de } \\
\text { trigo em cookies }\end{array}$ & $\begin{array}{l}\text { Das Chagas et al. } \\
(2021)\end{array}$ \\
\hline
\end{tabular}


Além da incorporação em diversos tipos de alimentos, principalmente na forma desidratada, como indicado na Tabela 2, vários estudos reportam a extração de compostos ativos de interesse, tais como: compostos fenólicos extraídos da semente e casca da uva vermelha com atividade antibacteriana (GALALI; AZIZ; ALI, 2017); compostos fenólicos extraídos de casca de maracujá apresentando atividade antioxidante e antibacteriana em produtos cárneos (RAMLI et al., 2020); flavonoides extraídos da casca de ponkan com atividade antioxidante e potencial para eliminar os radicais livres e controlar a obesidade (HUANG et al., 2020).

Para a recuperação dos compostos bioativos nos resíduos, diferentes métodos convencionais de extração têm sido utilizados, como extração à base de solvente (GALALI; OMAR; SAJADI, 2020). Os compostos fenólicos são facilmente extraídos por solventes polares, portanto, as misturas de etanol e água são boas escolhas, além de econômicas, são amplamente utilizadas e permitidas na indústria de alimentos (GALANAKIS, 2012). Também novas técnicas têm sido estudadas, que incluem tecnologias baseadas em membrana, incluindo microfiltração, ultrafiltração e nanofiltração, extração assistida por ultrassom, extração assistida por microondas, eletrotecnologias, ultrassom, alta pressão hidrostática, nanotecnologia e fluido pressurizado (GALALI; OMAR; SAJADI, 2020).

\subsection{Camu-camu}

O camu-camu (Myrciaria dúbia) é uma espécie frutífera nativa das várzeas e margens dos rios e lagos da Amazônia peruana e brasileira, sendo esta espécie tolerante às inundações, pode permanecer submersa por até cinco meses no ano (MAUÉS; COUTURIER, 2002). Os frutos são redondos (Figura 1a), contém de 3 a 4 sementes cada, a polpa é levemente amarelada, mas a casca apresenta coloração intensa que varia de vermelho escuro a roxo-preto (DA SILVA; ARÉVALO PINEDO; KIECKBUSCH, 2005). O camu-camuzeiro (Figura $1 \mathrm{~b}$ ) é um arbusto lenhoso com altura variando de 1,5 a $4 \mathrm{~m}$, apresenta um conjunto de caules quase do mesmo calibre emergindo do chão (YUYAMA, 2009). 
Figura 1. Camu-camu: (a) frutos e (b) camu-camuzeiro

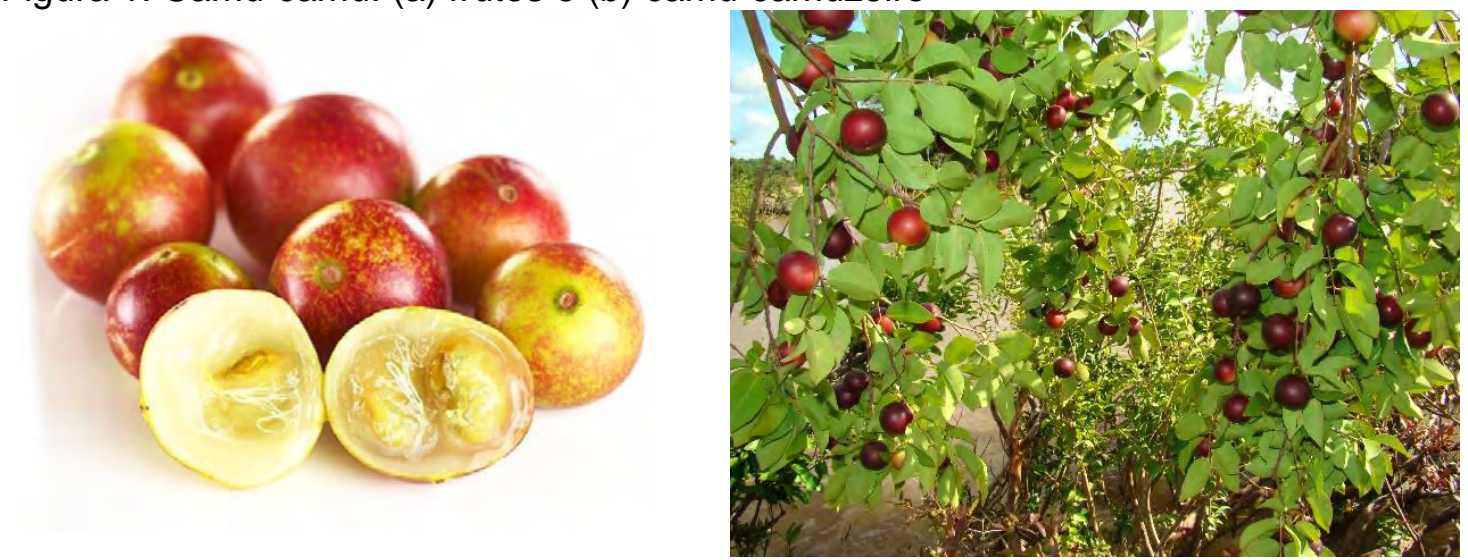

Nota: (a) - Disponível em: https://www.ruralbr.com.br/super-alimentos/frutas/camu-camu/, acesso em: 17 de setembro de 2020 e (b) Foto Arquivo Embrapa Roraima. Disponível em: https://www.embrapa.br/busca-de-noticias/-/noticia/23829362/dia-de-campo-na-tv---cultivo-eaproveitamento-do-camu-camu, acesso em: 17 de setembro de 2020.

Como visto em Castro et al. (2018), o camu-camu possui em sua composição carboidratos, proteínas, lipídios, cinzas, outros constituintes químicos, além de aminoácidos essenciais e ácidos graxos, bem como vitamina C, vitaminas do complexo B e vitamina $A$. Em função de diversos fatores a composição centesimal e composição química (aminoácidos, vitaminas e minerais) da polpa pode variar. Exemplos de alguns resultados relacionados a composição da polpa de camu-camu, podem ser observados nas Tabela 3 à 7 .

Tabela 3 - Composição centesimal da polpa de camu-camu determinada por diversos autores.

\begin{tabular}{lllll}
\hline $\begin{array}{l}\text { Componentes } \mathbf{~ ( g / 1 0 0 g ~ d e ~} \\
\text { polpa de camu-camu) }\end{array}$ & \multicolumn{4}{c}{ Conteúdo } \\
\cline { 2 - 5 } & $\begin{array}{l}\text { Castro et al. } \\
(2018)\end{array}$ & $\begin{array}{l}\text { Maeda et al. } \\
(2006)\end{array}$ & $\begin{array}{l}\text { Justi et al. } \\
(2000)\end{array}$ & $\begin{array}{l}\text { Aguiar } \\
(1996)\end{array}$ \\
\hline Umidade & $94,1-94,4$ & $92,65 \pm 0,03$ & $94,1 \pm 0,1$ & 92,16 \\
Carboidrato & $3,5-4,7$ & $\mathrm{NI}$ & 3,5 & 6,88 \\
Proteínas & $0,4-0,5$ & $0,29 \pm 0,00$ & $0,4 \pm 0,0$ & 0,45 \\
Lipídios & $0,2-0,3$ & $0,05 \pm 0,01$ & $0,2 \pm 0,0$ & 0,23 \\
Cinzas & $0,2-0,3$ & $\mathrm{NI}$ & $0,3 \pm 0,0$ & 0,28 \\
Fibras & $0,1-0,6$ & $\mathrm{NI}$ & $0,1 \pm 0,0$ & $\mathrm{NI}$ \\
\hline
\end{tabular}

Nota: NI- Valor não informado 
Tabela 4 - Composição de aminoácidos da polpa de camu-camu.

\section{Referências}

Aminoácidos essenciais

Castro et al. (2018) Justi et al. (2000)

Fenilalanina (mg/100g de polpa) 22-43 N

Treonina $(\mathrm{mg} / 100 \mathrm{~g}$ de polpa) $\quad 28-36 \quad \mathrm{NI}$

Valina $(\mathrm{mg} / 100 \mathrm{~g}$ de polpa) $\quad 16,8-31,6 \quad \mathrm{NI}$

Leucina $(\mathrm{mg} / 100 \mathrm{~g}$ de polpa) 13,2-28,9 NI

Notas: ${ }^{*}=$ Porcentagem em lipídios totais, $\mathrm{NI}$ - Valor não informado

Tabela 5 - Composição de lipídeos da polpa de camu-camu.

\section{Referências}

Lipídeos Castro et al. (2018) Justi et al. (2000)

\begin{tabular}{|c|c|c|}
\hline C18:3w6 (ácido a-linolênico)* & 16 & $9,3 \pm 0,2$ \\
\hline C18:2w6 (ácido linoleico)* & 9,7 & $9,7 \pm 0,4$ \\
\hline C13:0 (Tridecanóico)* & $\mathrm{NI}$ & $7,2 \pm 1,2$ \\
\hline C16:0 (Palmítico)* & $\mathrm{NI}$ & $6,6 \pm 0,6$ \\
\hline C18:0 (Esteárico)* & $\mathrm{NI}$ & $10,0 \pm 0,7$ \\
\hline C18:1 w9 (Oleico)* & $\mathrm{NI}$ & $11,8 \pm 0,5$ \\
\hline C18:3w3* & $\mathrm{NI}$ & $16,0 \pm 0,7$ \\
\hline$C 20: 2 \omega 6^{*}$ & $\mathrm{NI}$ & $10,5 \pm 0,5$ \\
\hline $\mathrm{C} 20: 5 \omega 3(\mathrm{EPA})^{*}$ & $\mathrm{NI}$ & $7,0 \pm 0,1$ \\
\hline C23:0 (Tricosanóico) ${ }^{*}$ & $\mathrm{NI}$ & $11,9 \pm 0,7$ \\
\hline
\end{tabular}

Notas: NI - Não Informado

Tabela 6 - Composição química (vitaminas) da polpa de camu-camu.

\section{Referências}

Vitaminas Castro et al. (2018) Justi et al. (2000)

\begin{tabular}{lll}
\hline Vitamina C (g/100g de polpa) & $0,96-2,99$ & $1,41 \pm 0,02$ \\
Niacina $(\mu \mathrm{g} / 100 \mathrm{~g}$ de polpa) & 62 & $\mathrm{NI}$ \\
Riboflavina $(\mu \mathrm{g} / 100 \mathrm{~g}$ de polpa) & 40 & $\mathrm{NI}$ \\
Tiamina $(\mu \mathrm{g} / 100 \mathrm{~g}$ de polpa) & 10 & $\mathrm{NI}$ \\
Vitamina A ( $\mu \mathrm{g} / 100 \mathrm{~g}$ de polpa) & $14,2-24,5$ & $\mathrm{NI}$ \\
\hline
\end{tabular}

Notas: NI - Não Informado 
Tabela 7 - Composição de minerais da polpa de camu-camu.

\section{Referências}

\begin{tabular}{|c|c|c|}
\hline Minerais & Castro et al. (2018) & Justi et al. (2000) \\
\hline $\mathrm{K}$ (mg/100 g de polpa) & $60-144,1$ & $83,8 \pm 3,62$ \\
\hline $\mathrm{PO}_{4}(\mathrm{mg} / 100 \mathrm{~g}$ de polpa) & $25,6-29,5$ & $\mathrm{NI}$ \\
\hline $\mathrm{SO}_{4}(\mathrm{mg} / 100 \mathrm{~g}$ de polpa) & $13,2-16,3$ & $\mathrm{NI}$ \\
\hline $\mathrm{Ca}(\mathrm{mg} / 100 \mathrm{~g}$ de polpa) & $6,2-15,7$ & $15,73 \pm 0,44$ \\
\hline Mg (mg/100 g de polpa) & $4,7-12,4$ & $12,38 \pm 0,87$ \\
\hline $\mathrm{Cl}$ (mg/100 g de polpa) & $6,6-11,6$ & $\mathrm{NI}$ \\
\hline $\mathrm{Na}$ (mg/100 g de polpa) & $2,7-11,1$ & $11,13 \pm 0,43$ \\
\hline Co (mg/100 g de polpa) & $0,6-2,4$ & $1 \pm 0$ \\
\hline $\mathrm{Cu}(\mu \mathrm{g} / 100 \mathrm{~g}$ de polpa) & $200-800$ & $200 \pm 20$ \\
\hline $\mathrm{Fe}(\mu \mathrm{g} / 100 \mathrm{~g}$ de polpa) & $180-665$ & $530 \pm 40$ \\
\hline $\mathrm{Zn}(\mu \mathrm{g} / 100 \mathrm{~g}$ de polpa) & $120-472$ & $360 \pm 10$ \\
\hline Al ( $\mu \mathrm{g} / 100 \mathrm{~g}$ de polpa) & $210-300$ & $\mathrm{NI}$ \\
\hline Mn ( $\mu \mathrm{g} / 100 \mathrm{~g}$ de polpa) & $140-211$ & $211 \pm 11$ \\
\hline B ( $\mu \mathrm{g} / 100 \mathrm{~g}$ de polpa) & 50 & $\mathrm{NI}$ \\
\hline $\mathrm{Br}(\mu \mathrm{g} / 100 \mathrm{~g}$ de polpa) & $17-26,8$ & $\mathrm{NI}$ \\
\hline $\mathrm{Cr}(\mu \mathrm{g} / 100 \mathrm{~g}$ de polpa) & $8,8-19,9$ & ND \\
\hline Mo ( $\mu \mathrm{g} / 100 \mathrm{~g}$ de polpa) & $2,3-6,2$ & $\mathrm{NI}$ \\
\hline $\mathrm{Se}(\mu \mathrm{g} / 100 \mathrm{~g}$ de polpa) & $0,33-0,52$ & $\mathrm{NI}$ \\
\hline
\end{tabular}

NI - Não Informado e ND - Não detectado

Uma das principais características do camu-camu é o elevado teor de ácido ascórbico, que varia entre 800 a $6.100 \mathrm{mg} / 100 \mathrm{~g}$ de polpa (Yuyama, 2011), sendo superior ao da acerola (ALVES et al., 2002) e até 50 a 60 vezes superior ao de outras frutas cítricas, como limão e a laranja (VILLANUEVA-TIBURCIO; CONDEZO-HOYOS; ASQUIERI, 2010). O teor de vitamina C no camu-camu pode variar em relação ao grau de maturação na colheita e heterogeneidade do material analisado (VILLANUEVA-TIBURCIO; CONDEZO-HOYOS; ASQUIERI, 2010). Na Tabela 8 pode-se observar a concentração de vitamina $C$ no camucamu encontrada por diversos autores. 
Tabela 8 - Concentração de vitamina C ( $\mathrm{C}_{\text {Vitamina }}$, $\mathrm{mg}$ de ácido ascórbico/100 g) em diferentes partes dos frutos de camu-camu.

\begin{tabular}{lll}
\hline Parte do fruto & CVitamina c & Referências \\
\hline Polpa & $2585,40 \pm 8,41$ & Maeda et al. (2006) \\
Polpa & $1882 \pm 43.2$ & Rufino et al. (2010) \\
Casca e polpa frutos verdes & $2280 \pm 34$ & Chirinos et al. (2010) \\
Casca e polpa frutos maduros & $2010 \pm 65$ & \\
Polpa & 2260,57 & Freitas et al. (2016)
\end{tabular}

Entretanto, o sabor ácido da polpa, o amargor da casca e baixo conteúdo de açúcares totais contribuem para o reduzido consumo in natura, levando à necessidade de explorar outras formas de consumo (CHAGAS et al., 2015). O camu-camu é consumido normalmente na forma de suco, polpa e extrato (AZEVEDO et al., 2014). O alto teor de vitamina $\mathrm{C}$ e seus compostos bioativos tem despertado interesse no fruto de camu-camu e seus processados, entre os principais mercados exportadores estão Japão e União Europeia (AKTER et al., 2011; CHIRINOS et al., 2010). O interesse crescente no fruto pode ser observado pelo aumento de sua produção, em 2006 o IBGE (2021a) registrou 13 toneladas de camu-camu produzidos, enquanto que em 2017 a produção dobrou (26 toneladas) (IBGE, 2021b).

A vitamina $C$ corresponde a todos os compostos que apresentem atividade biológica equivalente ao ácido L-ascórbico (L-AA), incluindo as suas formas oxidadas (ácido dehidroascórbico, DHAA), isômeros (ácido isoascórbico), ésteres (palmitato de ascorbilo) e formas sintéticas (6-desoxi-L-ascorbato, 2fosfato-L-ascorbato) (SPINOLA; LLORENT-MARTÍNEZ; CASTILHO, 2014). O ácido ascórbico tem função complexa no metabolismo e sua ação na proteção contra o efeito oxidante de radicais livres é de importância crucial (NOVÁKOVÁ; SOLICH; SOLICHOVÁ, 2008). Além de ser um antioxidante hidrossolúvel, este é necessário para diversas funções biológicas como: síntese de colágeno; formação do composto de vitamina-carnitina; síntese de neurotransmissores como norepinefrina e epinefrina; transporte adequado de ferro não heme; 
redução de intermediários de ácido fólico e para o metabolismo adequado do cortisol (KEITH, 2006).

Os seres humanos são incapazes de sintetizar ácido L-ascórbico devido à sua deficiência de oxidase de L-gulono-gama-lactona, a enzima que catalisa o passo terminal na biossíntese de ácido L-ascórbico (NISHIKIMI et al., 1994). Dessa forma, a ingestão se torna vital, sendo a ingestão diária recomendada (RDA) de vitamina $\mathrm{C}$ correspondente a $90 \mathrm{mg} /$ dia para homens e $75 \mathrm{mg} /$ dia para mulheres (NAS, 2000). Para os fumantes a dose é de $35 \mathrm{mg} / \mathrm{dia}$ maior do que para os não fumantes devido ao stress oxidativo superior e outras diferenças metabólicas (HIGDON; FREI, 2003).

Além da vitamina $\mathrm{C}$, o camu-camu apresenta outros compostos ativos, como compostos fenólicos, incluindo flavonoides, antocianinas e proantocianidinas (AZEVEDO et al., 2014; DA SILVA et al., 2014; NEVES et al., 2015). Dietas ricas em fitoquímicos têm sido associadas à redução de riscos de doenças associadas com o stress oxidativo como doenças cardiovasculares e câncer, devido suas propriedades antioxidantes (BUENO et al., 2012).

Inoue et al. (2008) avaliaram propriedades antioxidante e anti-inflamatória do suco de camu-camu em 20 fumantes do sexo masculino, e concluíram que o suco de camu-camu, em comparação a comprimidos de vitamina $C$, contendo teor de vitamina $\mathrm{C}$ equivalente, pode ter propriedades antioxidantes e antiinflamatórias superiores, e relacionaram os resultados observados além da presença de vitamina $\mathrm{C}$, a prenseça de carotenóides e antocianinas, além ainda, de outras substâncias não totalmentete conhecidas que modulam a cinética de absorção da vitamina $\mathrm{C}$ do camu-camu in vivo, como o potássio presente no fruto.

Da Silva et al. (2012) avaliaram o potencial antioxidante, genotóxico e antigenotóxico do suco de camu-camu em células sanguíneas de camundongos após tratamentos agudos, subagudos e crônicos e concluíram que o suco tem atividades antigenotóxicas e antioxidantes, embora sem genotoxicidade para as células sanguíneas.

Nascimento et al. (2013) estudaram a ação antiobesidade da ingestão da polpa de camu-camu e verificaram que a administração da polpa do camu-camu provocaram a redução da gordura em tecidos adiposos brancos, glicose, colesterol total, triglicerídeos, LDL-c e níveis de insulina no sangue. 
Fujita et al. (2015) identificaram perfis fenólicos bioativos ligados a antioxidantes na polpa de camu-camu seca por spray-dried e liofilização e avaliaram a funcionalidade potencial associada às propriedades antihiperglicemia e anti-hipertensão in vitro.

\subsubsection{Resíduo industrial do camu-camu}

$\mathrm{Na}$ etapa de despolpamento do camu-camu gera-se o resíduo constituído de casca e sementes, sendo o volume de resíduos em torno de $40 \%$ da massa total da fruta (MAEDA; ANDRADE, 2003). De acordo com (DE AZEVÊDO et al., 2014b) no resíduo de camu-camu, $65,6 \%$ corresponde às sementes e $34,4 \%$ a pele e casca residual.

Alguns autores reportaram a composição do resíduo de camu-camu (ANSELMO, 2008; AZEVÊDO, 2015; CHAGAS, 2019). Chagas (2019) reportou

a composição centesimal do resíduo industrial de camu-camu submetido a secagem na temperatura de $50 \stackrel{\circ}{ } \mathrm{C}$ (Tabela 9 ), e observaram valores superiores de proteína, gordura e fibras em relação a semente e casca de seriguela, e casca de jabuticaba; teor de carboidratos superiores ao determinados para bagaço e casca de kiwi, e resíduo de acerola, enquanto cinzas observaram valores inferiores quando comparados a esses resíduos de seriguela, jabuticaba, kiwi e acerola.

Tabela 9 - Composição centesimal do resíduo industrial de camu-camu submetido a secagem a $50^{\circ} \mathrm{C}$.

\begin{tabular}{ll}
\hline Composição centesimal & $\begin{array}{l}\mathbf{g} / \mathbf{1 0 0 g} \text { de matéria seca de farinha do } \\
\text { resíduo do camu-camu }\end{array}$ \\
\hline Proteínas & $6,95 \pm 0,25$ \\
Lipídios & $3,80 \pm 0,23$ \\
Fibra bruta & $13,56 \pm 0,41$ \\
Carboidratos & $74,75 \pm 0,49$ \\
Cinzas & $0,95 \pm 0,06$ \\
\hline
\end{tabular}

Fonte: CHAGAS (2019).

Por outro lado, muitos autores relatam que a concentração de compostos ativos no resíduo de camu-camu é superior à polpa dos frutos (CORREA et al., 
2011; MAEDA et al., 2006; NEVES et al., 2015). Correa et al. (2011) ao estudarem frutos maduros de camu-camu, observaram valor de vitamina $\mathrm{C}$ superior na casca (2496 mg/100g) em relação a polpa (1451 mg/100g). Neves et al. (2015) ao estudarem casca e polpa de camu-camu em diferentes estágios de maturação observaram valores superiores na casca para compostos fenólicos, flavonoides e também ácido ascórbico.

Diversos trabalhos na literatura, relatam que os resíduos provenientes do despolpamento de camu-camu apresentam concentrações relevantes de vitamina $\mathrm{C}$, compostos fenólicos, proantocianidinas, antocianinas e flavonóides (Tabela 10). 
Tabela 10 - Teores de compostos ativos: ácido ascórbico e ácido dehidroascórbico, antocianinas, fenólicos, flavonoides e proantocianidinas em resíduos de camu-camu.

\begin{tabular}{|c|c|c|}
\hline Parte do fruto & Teores de compostos ativos & Referências \\
\hline Casca in natura* & $\begin{array}{l}\text { Ácido ascórbico: } 3092,62 \pm 35,11 \\
\text { Antocianinas: } 181,38 \pm 10,78 \\
\text { Fenólicos: } 1344,72 \pm 118,76 \\
\text { Flavonoides: } 143,27 \pm 8,08\end{array}$ & Maeda et al. (2006) \\
\hline $\begin{array}{l}\text { Casca seca em estágio de } \\
\text { maturação maduro - Secagem a } \\
\text { vácuo a } 48^{\circ} \mathrm{C} \pm 2 ; 72 \text { horas }\end{array}$ & $\begin{array}{l}\text { Ácido ascórbico } 1641 \pm 364 \\
\text { Antocianinas: ND } \\
\text { Fenólicos: } 602 \pm 48\end{array}$ & $\begin{array}{l}\text { Villanueva-Tiburcio } \\
\text { et al. (2010) }\end{array}$ \\
\hline $\begin{array}{l}\text { Casca } \\
\text { Semente } \\
\text { Secagem em temperatura ambiente }\end{array}$ & $\begin{array}{l}\text { Fenólicos totais: } 20380 \pm 770 \\
\text { Fenólicos totais: } 36940 \pm 960\end{array}$ & Myoda et al. (2010) \\
\hline $\begin{array}{l}\text { Casca e semente - Secagem em } \\
\text { leito fluidizado a } 45-55^{\circ} \mathrm{C}\end{array}$ & $\begin{array}{l}\text { Fenólicos: } 4007,95 \\
\text { Flavonoides: } 6,68 \pm 0,16 \\
\text { Proantocianidinas: } 64,19 \pm 0,55\end{array}$ & $\begin{array}{l}\text { Fracassetti et al. } \\
\text { (2013) }\end{array}$ \\
\hline $\begin{array}{l}\text { Casca e semente - Secagem em } \\
\text { bandeja a } 50^{\circ} \mathrm{C} \text { e } 4 \mathrm{~m} / \mathrm{s}\end{array}$ & $\begin{array}{l}\text { Ácido ascórbico: } 820 \pm 30 \\
\text { Ácido dehidroascórbico: } 60 \pm 4 \\
\text { Antocianinas: } 50 \pm 10 \\
\text { Fenólicos: } 18436,6 \pm 1,9 \\
\text { Proantocianidinas: } 23,8 \pm 0,5\end{array}$ & $\begin{array}{l}\text { De Azevêdo et al. } \\
\text { (2014) }\end{array}$ \\
\hline $\begin{array}{l}\text { Casca liofilizada - 85\% vermelha } \\
\text { (madura) }\end{array}$ & $\begin{array}{l}\text { Ácido ascórbico: } 5178,49 \\
\text { Antocianinas: } 120,0 \\
\text { Fenólicos: } 17500 \\
\text { Flavonoides }^{* \star *}: 45\end{array}$ & Neves et al. (2015)* \\
\hline
\end{tabular}

Sementes - secagem a 35으 C com Fenólicos totais: $4802 \pm 139 \quad$ Carmo et al. (2019) circulação de ar

Notas: * Valores expressos em $100 \mathrm{~g}$ de matéria fresca, ${ }^{* *}$ Valores expressos em gráfico, ${ }^{* * *} \mathrm{mg}$ quercetina/100g, ND: Não detectado

Unidade dos teores de compostos ativos: ácido ascórbico e ácido dehidroascórbico = mg/100g; antocianinas $=\mathrm{mg}$ cianidina 3-glicosídeo $/ 100 \mathrm{~g}$; fenólicos $=\mathrm{mg}$ equivalentes de ácido gálico $/ 100 \mathrm{~g}$; flavonoides $=\mathrm{mg}$ rutina $/ 100 \mathrm{~g}$ e proantocianidinas $=\mathrm{mg}$ equivalentes de tanino quebracho $/ 100 \mathrm{~g}$.

Além dos trabalhos de extração, identificação e quantificação dos compostos bioativos do resíduo do camu-camu, vem crescendo o número de 
estudos descrevendo os benefícios potenciais do uso de seu resíduo para a saúde.

Yapu et al. (2008), estudando 9 espécies de plantas da Amazônia Peruana, afirmaram que o camu-camu está dentro das espécies cujos os extratos (aquoso e etanólico) apresentaram atividade antiplasmódica. Sugerindo novos estudos para aplicá-los como alternativa ao tratamento da malária.

Do Carmo et al. (2020) avaliaram 5 extratos obtidos a partir da semente de camu-camu em relação aos seus efeitos antimaláricos, anti-esquistossomicidas, leishmanicidas e anti-hemolíticos in vitro e obtiveram resultados positivos quanto as atividades antimalárica e anti-esquistossomicida para os extratos hidroalcoolicos, indicando que estudos in vivo precisam ser realizados para avaliar as atividades antimalárica e anti-esquistossomicida de extratos de sementes de camu-camu.

Azevêdo et al. (2015) estudaram os efeitos neuroprotetores do resíduo de camu-camu seco a 50 C na neurodegeneração induzida experimentalmente em modelos de $C$. elegans para doença de Alzheimer e doença de Parkinson e alcançaram aumento de genes antioxidantes críticos e maior resistência contra o estresse oxidativo in vivo em $C$. elegans. Observaram também que o tratamento com extratos de camu-camu estendeu significativamente a expectativa de vida de C. elegans em $20 \%$ e que o resíduo de camu-camu seco promoveu diminuição significativa da neurotoxicidade em C. elegans.

Por outro lado, estudos evolvendo aplicações de resíduos do camu-camu em alimentos são incipientes. Fidelis et al. (2020) caracterizaram a composição fenólica e as propriedades antioxidantes e antiproliferativas in vitro do extrato de semente de camu-camu liofilizado e avaliaram os efeitos da adição do extrato nas propriedades antioxidantes e sensoriais do iogurte. Quando adicionado a iogurtes, diferentes concentrações de extrato de semente de camu-camu aumentaram a capacidade antioxidante dos iogurtes. Sendo o iogurte com $25 \%$ de extrato aceito sensorialmente, indicando que o extrato de semente de camucamu pode ser um ingrediente sustentável para adição a iogurtes potencialmente funcionais. 


\subsection{Administração oral de medicamentos}

A via mais comumente usada na administração de medicamentos é a via oral com absorção intestinal, uma vez que a via oral é mais fácil, não invasiva e conveniente (BORGES et al., 2015).

Há uma enorme variedade de formas farmacêuticas orais sólidas em uso ou em pesquisa e desenvolvimento. Formas de dosagem oral sólidas, como: pílulas, comprimidos e cápsulas são excelentes sistemas de administração de medicamentos, pois geralmente apresentam custo de produção menor para as empresas farmacêutica e fornecem medicamentos convenientemente para o corpo (LAU et al., 2018). A maioria das formas de dosagem sólidas é colocada na boca e deve ser engolida. No entanto, apresentam desvantagens significativas, estima-se que quase $28 \%$ da população em geral têm problemas frequentes para engolir medicamentos, o que costuma ser a causa da baixa adesão do paciente (SCHIELE et al., 2013). Outra desvantagem inclui a degradação enzimática da droga no estômago e no intestino, bem como o metabolismo de primeira passagem hepática (TEUBL et al., 2013).

Com isso, outras mucosas são consideradas locais potenciais para a administração de drogas. Os revestimentos mucosos das cavidades nasal, retal, vaginal, ocular e bucal oferecem vantagens distintas sobre a administração oral para efeito sistêmico (PATEL; LIU; BROWN, 2011). A mucosa bucal tem excelente acessibilidade, uma extensão de músculo liso e mucosa relativamente imóvel (CHINNA REDDY; CHAITANYA; MADHUSUDAN RAO, 2011). A mucosa bucal é uma região ricamente vascularizada e é relativamente permeável (PATEL et al., 2012). O acesso direto à circulação sistêmica através da veia jugular interna evita a hidrólise ácida no trato gastrointestinal e desvia as drogas do metabolismo de primeira passagem hepática, levando a alta biodisponibilidade (CHINNA REDDY; CHAITANYA; MADHUSUDAN RAO, 2011).

A fim de superar os problemas de deglutição e degradação enzimática no estômago, aliado a biodisponibilidade de absorção via mucosa bucal, os sistemas de entrega de rápida dissolução estão recebendo atenção considerável (PATEL; LIU; BROWN, 2011). Entre eles, os filmes orais surgiram e foram alavancados por essa necessidade do mercado (BORGES et al., 2015). Na 
literatura, diversos nomes são dados aos filmes orais: lâmina oral, filme fino oral, filme bucal, filme mucoadesivo, filme transmucosal, filme de rápida dissolução, filme orodispersível, filme de desintegração oral (termo adotado nesse trabalho).

\subsubsection{Filmes de desintegração oral}

Os filmes de desintegração oral (FDOs) apresentam uma forma de dosagem que emprega um polímero hidrofílico, permitindo assim, rápida hidratação, adesão e dissolução na cavidade oral visando promover uma rápida liberação local ou sistêmica do medicamento (VARUN et al., 2011). Os filmes de desintegração oral além de apresentarem as vantagens dos comprimidos (fácil administração e dosagem precisa) e das formas líquidas (fácil deglutição, biodisponibilidade rápida) são de grande importância para crianças, idosos e pacientes com dificuldade de deglutição (KATHPALIA; GUPTE, 2013).

É crescente o interesse em desenvolver FDOs como pode ser notado pelo número de marcas comerciais existentes relacionadas à veiculação de diversos princípios ativos (Tabela 11). 
Tabela 11 - Filmes de desintegração oral disponíveis comercialmente.

\begin{tabular}{|c|c|c|c|c|}
\hline Empresa & Nome da marca & Princípio ativo & Aplicação & Referência \\
\hline \multirow[t]{6}{*}{ Labtec Pharma } & Ondansetron & \multirow[t]{4}{*}{ Ondansentrona } & Controle de & \multirow{4}{*}{$\begin{array}{l}\text { DIXIT; } \\
\text { PUTHLI, } \\
\text { (2009) }\end{array}$} \\
\hline & Rapidfilm® & & náuseas e vômitos & \\
\hline & & & induzidos & \\
\hline & & & quimioterapia & \\
\hline & Donezepil & \multirow[t]{2}{*}{ Donepezila } & Tratamento de & \\
\hline & Rapidfilm® & & Alzheimer & \\
\hline Meda Pharmaceutical & Onsolis & Citrato de fentanil & Analgésico no & FDA (2012) \\
\hline \multirow[t]{2}{*}{ Inc. } & & & tratamento de & \\
\hline & & & câncer & \\
\hline Pfizer, Inc & $\begin{array}{l}\text { Listerine® } \\
\text { pocketpaks } \AA\end{array}$ & Menta & Refrescante bucal & \multirow[t]{2}{*}{$\begin{array}{l}\text { BALA et al. } \\
(2013)\end{array}$} \\
\hline Novartis & Theraflu & Dextrometorfano & Anti gripal & \\
\hline \multirow[t]{4}{*}{ Indivior Inc } & Suboxone ${ }^{\circledR}$ & Hidrocloreto de & Tratamento da & \multirow[t]{4}{*}{ FDA (2014) } \\
\hline & & buprenorfina & dependência de & \\
\hline & & Cloridrato de & opióides & \\
\hline & & naloxona & & \\
\hline \multirow[t]{5}{*}{ PharmFilm ${ }^{\circledR}$} & Sympazan & Clobazam & Tratamento de & \multirow[t]{5}{*}{ FDA (2018) } \\
\hline & & & convulsões & \\
\hline & & & associadas à & \\
\hline & & & Síndrome de & \\
\hline & & & Lennox-Gastaut & \\
\hline \multirow[t]{2}{*}{ Exeltis USA, Inc. } & Vitafol & Vitaminas B6, B12 e & Multivitamínico pré- & \multirow{2}{*}{$\begin{array}{l}\text { Vitafol } \\
(2019)\end{array}$} \\
\hline & & D e ácido fólico & natal & \\
\hline Aquestive & Exservan & Riluzol & Tratamento da & FDA (2019) \\
\hline \multirow[t]{2}{*}{ Therapeutics } & & & esclerose lateral & \\
\hline & & & amiotrófica & \\
\hline \multirow[t]{3}{*}{ Sunovion } & Kynmobi & Apomorfina & Tratamento agudo & \multirow[t]{3}{*}{ FDA (2020) } \\
\hline & & & de Mal de & \\
\hline & & & Parkinson & \\
\hline Endo Pharm. \& Bio & Belbuca ${ }^{\circledR}$ & Buprenorfina & Tratamento de dor & Belbuca \\
\hline Delivery Science & & & crônica & (2021) \\
\hline
\end{tabular}


Para a formulação dos filmes de desintegração oral, a primeira e uma das principais etapas, é a escolha da macromolécula já que esta será a responsável por importantes propriedades, tais como: propriedades para formação de filmes, resistência química, elevada hidrofilicidade, dentre outras (TEDESCO et al., 2016).

Entre a multiplicidade de polímeros biocompatíveis usados para projetar veículos para drogas macromoleculares, os polissacarídeos são preferidos na indústria farmacêutica devido à sua maior estabilidade, compatibilidade e facilidade de alterar suas propriedades físico-químicas quando misturado com outros biopolímeros (VUDDANDA et al., 2017a). E ainda devido às suas propriedades mucoadesivas, antimicrobianas e anti-inflamatórias (DRAGAN; DINU, 2019).

Exemplos dos polímeros utilizados na produção de filmes de desintegração oral podem ser observados na Tabela 12.

Amido, carboximetilcelulose (CMC) e Hidroxipropil metilcelulose (HPMC) são macromoléculas comumente utilizadas na elaboração de FDO, por apresentarem elevada disponibilidade comercial, baixo custo, baixa toxicidade, boa capacidade formadora de filme, entre outras. 
Tabela 12 - Polímeros e princípios ativos utilizados em filmes de desintegração.

\begin{tabular}{|c|c|c|c|}
\hline Polímero & Princípio ativo & Aplicação & Referência \\
\hline Hidroxipropil metilcelulose & Sulfato de salbutamol & Antiasmático & Prasanthi et al. (2011) \\
\hline \multicolumn{4}{|l|}{ Hidroxipropilcelulose } \\
\hline \multicolumn{4}{|l|}{ Alginato de sódio } \\
\hline Hidroxipropil metilcelulose & $\begin{array}{l}\text { Cloridrato de } \\
\text { amitriptilina }\end{array}$ & Antidepressivo & Salman et al. (2014) \\
\hline Hidroxipropil metilcelulose & Dicloridrato de & Antidepressivo & Abdelbary et al. (2014) \\
\hline Carboximetilcelulose & flupentixol & & \\
\hline Quitosana & Cloridrato de & Analgésico bucal & Castán et al. (2015) \\
\hline Hidroxipropilmetilcelulose de sódio & doxepina & & \\
\hline \multicolumn{4}{|l|}{ Carboximetilcelulose de sódio } \\
\hline Carboximetilcelulose de sódio & Cloridrato de & Terapia cardíaca & Wang et al. (2016) \\
\hline Polivinilpirrolidona K-30 & diltiazem & & \\
\hline \multicolumn{4}{|l|}{ Álcool polivinílico } \\
\hline Hidroxipropil metilcelulose & Nitrato de Miconazol & Tratamento de Candidíase oral & Tejada et al. (2017) \\
\hline \multicolumn{4}{|l|}{ Quitosana } \\
\hline Hidroxipropil metilcelulose & Ropinirol & Auxílio no tratamento de doença de & Lai et al. (2018) \\
\hline & & Parkinson & \\
\hline Hidroxipropil metilcelulose & Varfarina sódica & Anticoagulante & Niese \& Quodbach (2019) \\
\hline Quitosana & Axetilcefuroxima & Tratamento de infecções na cavidade & Timur et al. (2019) \\
\hline Hidroxipropil metilcelulose & & oral & \\
\hline
\end{tabular}




\subsubsection{Filmes de desintegração oral com compostos naturais}

Embora seja mais comum o estudos das propriedades funcionais de princípios ativos naturais, é crescente o número de trabalhos que os incorporam na formulação de filmes de desintegração oral.

Borges e de Carvalho (2015) adicionaram extrato de própolis em filmes de gelatina e colágeno hidrolisado, desenvolvendo bom carreador de componentes ativos para liberação na cavidade oral.

Tedesco, Monaco-Lourenco e Carvalho (2017) elaboraram filmes de desintegração oral a base de gelatina e HPMC, para veiculação de compostos fenólicos, incorporaram nos filmes extrato etanólico de pele de amendoim.

Garcia et al. (2018) estudaram filmes de desintegração oral de gelatina e amido com extrato da polpa de camu-camu seco e encapsulado com maltodextrina por spray dryer como alternativa para preservação de vitamina $\mathrm{C}$ e para administração e liberação dessa vitamina na mucosa bucal.

Bodini et al. (2020) desenvolveram FDOs com propriedades antioxidantes e antiinflamatórias a partir de matrizes poliméricas à base de amido e hidroxipropil metilcelulose aditivados com extrato de erva baleeira.

Mais trabalhos que incorporaram princípios ativos naturais em FDOs, podem ser observados na Tabela 13. 
Tabela 13 - Estudos de FDO incorporados com extratos de princípios ativos naturais.

\begin{tabular}{|c|c|c|c|}
\hline Polímeros & Extrato & Aplicação & Referência \\
\hline $\begin{array}{l}\text { Alginato, quitosana e } \\
\text { ágar }\end{array}$ & Própolis & $\begin{array}{l}\text { Doenças dentárias e } \\
\text { bucais. }\end{array}$ & $\begin{array}{l}\text { Juliano et al. } \\
\text { (2007) }\end{array}$ \\
\hline HPMC & Gengibre & $\begin{array}{l}\text { Problemas estomacais } \\
\text { como náuseas }\end{array}$ & $\begin{array}{l}\text { Daud et al. } \\
\text { (2011) }\end{array}$ \\
\hline CMC e HPMC & Mirra & Antisséptico bucal & $\begin{array}{l}\text { Auda et al. } \\
\text { (2017) }\end{array}$ \\
\hline $\begin{array}{l}\text { Polivinilpirrolidona, } \\
\text { Gelatina, Metilcelulose e } \\
\text { pectina }\end{array}$ & Murta & $\begin{array}{l}\text { Estomatite aftosa } \\
\text { recorrente }\end{array}$ & $\begin{array}{l}\text { Hashemi et al. } \\
(2017)\end{array}$ \\
\hline Amido de milho & Casca de manga & $\begin{array}{l}\text { Entrega de compostos } \\
\text { fenólicos }\end{array}$ & $\begin{array}{l}\text { Guerra et al. } \\
(2019)\end{array}$ \\
\hline $\begin{array}{l}\text { Quitosana e amido de } \\
\text { tapioca }\end{array}$ & Folha de gambier & Gengivite & $\begin{array}{l}\text { Miksusanti et } \\
\text { al. (2020) }\end{array}$ \\
\hline Amido e HPMC & Erva baleeira & $\begin{array}{l}\text { Entrega de compostos } \\
\text { bioativos }\end{array}$ & $\begin{array}{l}\text { Bodini et al. } \\
(2020)\end{array}$ \\
\hline $\mathrm{CMC}$ & Ginkgo biloba L. & Entrega de falvonoides & $\begin{array}{l}\text { Rimkiene et al. } \\
\text { (2021) }\end{array}$ \\
\hline $\begin{array}{l}\text { Quitosana e } \\
\text { maltodextrina }\end{array}$ & Alho & Antioxidante & $\begin{array}{l}\text { Himani et al. } \\
(2021)\end{array}$ \\
\hline
\end{tabular}

\subsubsection{Polímeros}

\subsection{Amido}

O amido é um dos polissacarídeos mais abundantes, sendo obtido facilmente de diversas fontes renováveis, como cereais e tubérculos (MAHMOOD et al., 2017). Além de serem matérias-primas não tóxicas, reconhecidamente como seguras (GRAS) e inclusos no guia de ingredientes inativos da FDA, possuem boa capacidade para formar filmes transparentes, insípidos, inodoros e biodegradáveis (DIXIT; PUTHLI, 2009). Permitem ainda modificações físicas, químicas e/ou enzimáticas em suas estruturas para melhorar propriedades funcionais como gelatinização, retrogradação, solubilidade, textura entre outros e que os fazem ter ampla aceitação e aplicação em diferentes áreas industriais (EGHAREVBA, 2019). Na indústria farmacêutica, por 
exemplo, é muito utilizado como incipiente pelo seu baixo custo, qualidade e segurança (BUILDERS; ARHEWOH, 2016), e na indústria alimentícia possuem ampla aplicação como emulsificantes e estabilizantes (STEPHEN; PHILLIPS; WILLIAMS, 2006).

Amilose e amilopectina (Figura 2), ambos polímeros da glicose, são os principais componentes do amido e sua razão depende principalmente de sua origem botânica (LOURDIN; VALLE; COLONNA, 1995). Filmes de amido sem plastificantes contém em média $75 \%$ e $25 \%$ dos respectivos biopolímeros e geralmente são quebradiços devido, principalmente, a suas diferenças estruturais; a amilose de cadeias lineares possui a capacidade de formar filmes mais resitentes devidos as ligações de hidrogênio que se formam mais facilmente em sua extensão, já a amilopectina possui cadeias altamente ramificadas e seus filmes geralmente são mais frágeis devido ao curto comprimento médio das cadeias e maior grau de emaranhamento causado pelo grande número de ramificações (KOCH et al., 2010).

Apesar da capacidade em formar filmes a partir de suas propriedades mecânicas e barreira ao oxigênio, os filmes de amido, geralmente, precisam de componentes plastificantes para garantir flexibilidade, como polióis como o glicerol, sendo este um dos mais utilizados (STADING; RINDLAV-WESTLING; GATENHOLM, 2001).

Como visto em Garcia et al. (2017), trabalhar com amidos modificados e ou prégelatinizados são, também, alternativas para alterar as propriedades dos filmes. A utilização de amido pré-gelatinizado em blenda polimérica com gelatina, pode contribuir para a diminuir o tempo de desintegração em testes in vitro e in vivo em filmes de desintegração oral. Garcia et al. (2017) desenvolveram FDO com blendas de amido pré-gelatinizado e gelatina com a função de carreadores de vitamina $C$ do extrato seco da polpa de acerola e avaliando o aumento da concentração de amido verificaram que nos FDO que possuíam as maiores concentrações de amido prégelatinizado houve alteração em suas propriedades de superfície, como uma maior hidrofilicidade, o que influenciou fortemente nos resultados, como a diminuição dos tempos de desintegração in vitro e in vivo. 
Figura 2. Estrutura amilose e amilopectina.
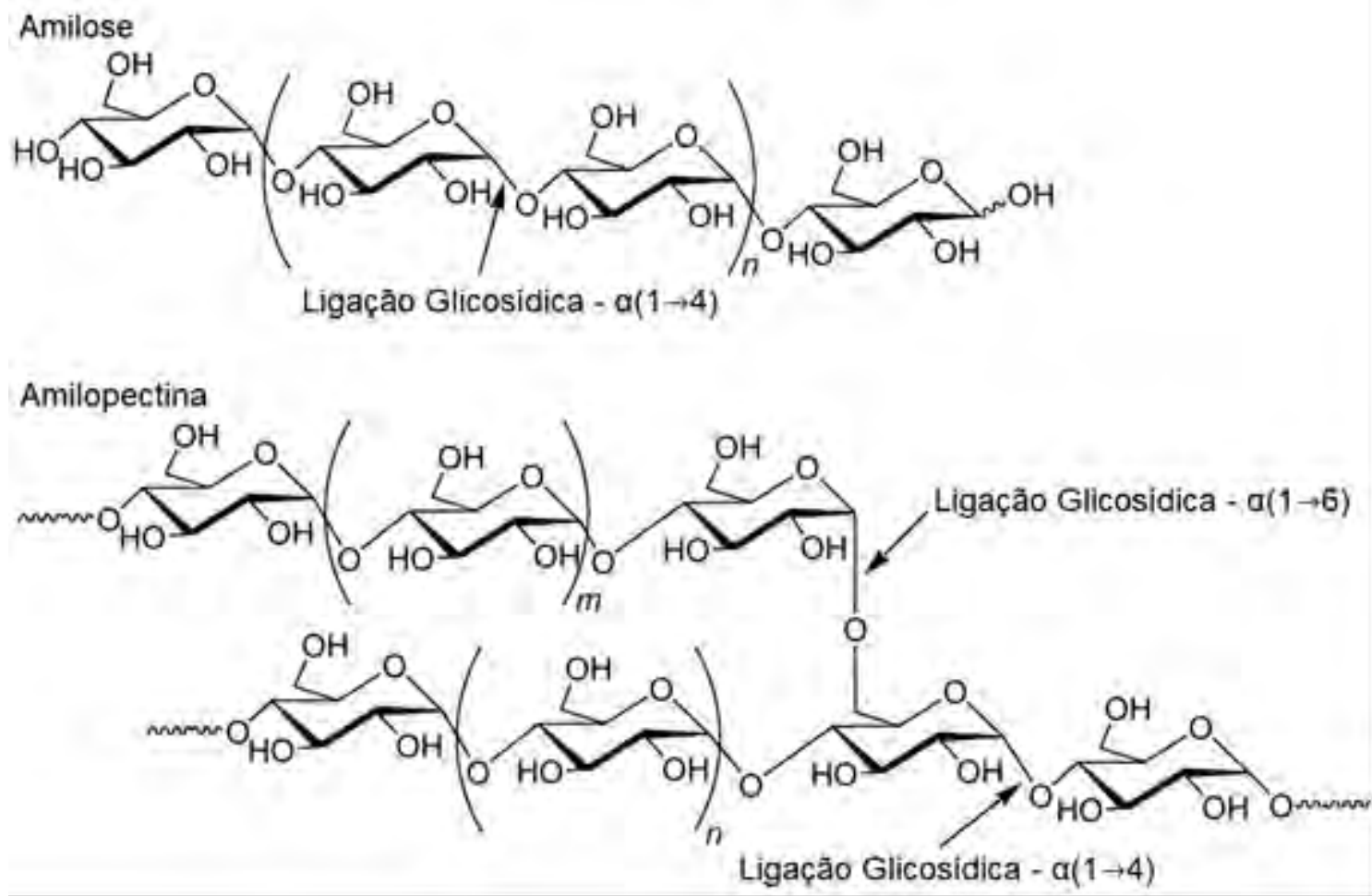

Fonte: Adaptado de Kadokawa (2012)

\subsection{Celulose e seus derivados}

A celulose é um polímero natural, o mais abundante da natureza, de origem vegetal com enorme e antigo interesse científico pois, além de uma matéria-prima renovável e biodegradável, sua estrutura versátil permite diversos tipos de modificações físico-químicas acarretando uma vasta área de aplicação como: materiais de construção e revestimento, papéis, têxteis, meios de sorção, reguladores de viscosidade, materiais funcionais avançado, entre outros (HEINZE, 2015)

A celulose é um polímero de cadeia linear com um grande número de hidroxilas $(-\mathrm{OH})$, mas especificamente três grupos por Unidade Anidroglucose (AGU) ligadas covalentemente por ligações $\beta-1,4$-glicosídicas que determinam o comprimento da cadeia de celulose (Figura 3), expresso em termos de AGUs constituintes ou grau de polimerização (DP) e que variam com a origem e o tratamento recebido pela matéria prima (KLEMM et al., 2005). A capacidade de reter seu estado semicristalino de agregação, mesmo em um meio aquoso, é que permite propriedades estruturais incomuns nos polissacarídeos, como a elevada resistência mecânica (ATALLA, 1990). Os elementos básicos de sua estrutura supramolecular, as fibras e fibrilas de celulose 
dependem do grau de linearidade e da presença dos grupos hidroxilas ao longo da cadeia e são responsáveis pela formação das ligações de hidrogênio inter e intramolecular, fazendo com que as cadeias de celulose se organizem em arranjos paralelos de cristalitos e filamentos de cristalitos (KLEMM et al., 2005). Esse arranjo, das fibras e fibrilas, determina sua estrutura supramolecular e possuem influência em sua estrutura física e propriedades químicas (KLEMM et al., 2005). Essa estrutura, bem como a de outros polissacarídeos, possuem algumas desvantagens como: baixa solubilidade em solventes comuns, alta hidrofilicidade e falta de termoplasticidade e de propriedades antimicrobianas (ARAVAMUDHAN et al., 2014).

Figura 3. Estrutura da celulose.

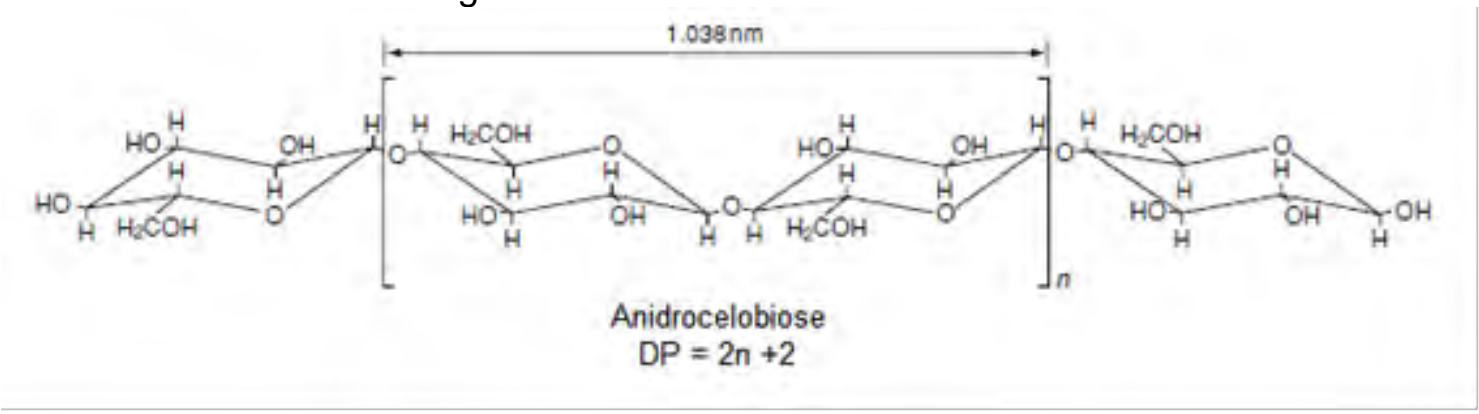

Fonte: Adaptado de Holtzapple (2003)

Os derivados de celulose, em especiais, os éteres de celulose como; carboximetilcelulose (CMC), hidroxipropil metilcelulose (HPMC), metilcelulose (MC), entre outros são ótimas opções pois, além de boas propriedades para formação de filmes, podem agregar outras propriedades aos mesmos (BOURTOOM, 2008).

\subsection{Carboximetilcelulose (CMC)}

O CMC é um dos derivados mais importantes da celulose e possui aplicação na indústria farmacêutica, têxtil (BISWAL; SINGH, 2004) e de alimentos (TOĞRUL; ARSLAN, 2004). Apresenta biocompatibilidade, não toxicidade, biodegradabilidade e hidrofilicidade, além de características anfifílicas por apresentar uma estrutura polissacarídica hidrofóbica e muitos grupos carboxilas hidrofílicos (Figura 4) (SU et al., 2010). Uma das principais aplicações é como espessante ou modificador de viscosidade, e apresenta excelentes propriedades filmogênicas devido à sua 
biocompatibilidade com polissacarídeos solúveis em água, proteínas, surfactantes e plastificantes, (BALLESTEROS et al., 2018).

CMC é um polímero aniônico linear e suas cadeias são resíduos lineares de glucopiranose com ligações $\beta(1 \rightarrow 4)$ (SU et al., 2010). Geralmente encontrado na forma de sal de sódio, solúvel em água e produzido por reações de celulose alcalina com monocloroacetato de sódio sob condições controladas, com grau médio de substituição (GS) variando de 0.4 a 1.5 , sendo 0.4 o mínimo necessário para solubilização e formação de goma em água, sendo que para aplicação em alimentos o GS geralmente se encontra entre 0.6 a 0.95 (DU et al., 2009)

Figura 4. Estrutura química do CMC.

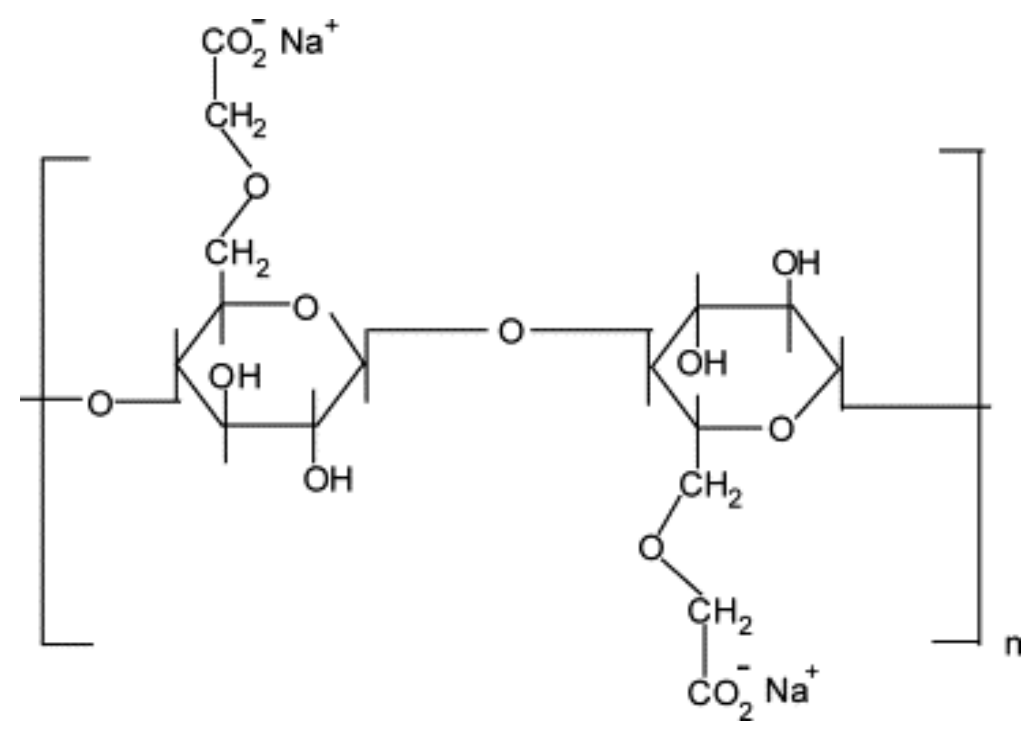

Fonte:BISWAL \& SINGH (2004)

\subsection{HPMC}

O HPMC é um éter de propilenoglicol de metilcelulose e suas propriedades físico-químicas são afetadas fortemente pela estrutura química que o compõe, como o conteúdo dos grupos metoxi, hidroxipropil e massa molar, conforme Figura 5. (SIEPMANN; PEPPAS, 2012). 
Figura 5. Estrutura química do HPMC.

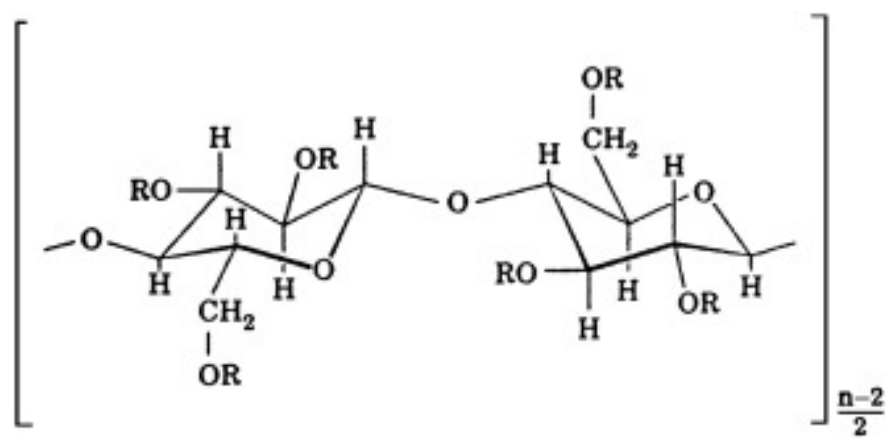

Fonte: SIEPMANN \& PEPPAS (2012)

O substituinte $\mathrm{R}$ representa um grupo de $-\mathrm{CH}_{3}$, ou um grupo de $-\mathrm{CH}_{2} \mathrm{CH}\left(\mathrm{CH}_{3}\right)$ $\mathrm{OH}$, ou um átomo de hidrogênio (SIEPMANN; PEPPAS, 2012)

Por possuir características anfifílica (hidrofílica e hidrofóbica, simultaneamente), possui uma variedade de aplicações, tais como: modificador reológico, aditivo em alimentos com diferentes funcionalidades e excipiente em medicamentos de liberação controlada (MARANI, 2015). Além disso, o HPMC é atóxico, fácil de manusear, relativamente baixo custo e de fácil compactação, sendo um dos materiais mais utilizados como transportadores em matrizes hidrofílicas (VIRIDÉN; WITTGREN; LARSSON, 2009).

\subsubsection{Produção dos filmes de desintegração oral}

Os filmes de desintegração oral são produzidos a partir da solubilização de diferentes ingredientes, formando a solução filmogênica que pode ser composta por: polímero solúvel em água, plastificante, princípio ativo e outros ingredientes como agente estimulador de saliva, aromatizante e saborizantes (BALA et al., 2013; IRFAN et al., 2015).

A combinação de polímeros e plastificantes desempenha um papel importante na preparação de FDOs, plastificantes são normalmente adicionados à solução filmogênica para se obter filmes menos quebradiços (MÜLLER; LAURINDO; YAMASHITA, 2009). A concentração de plastificante geralmente varia de $0 \%$ a $20 \%$ $\mathrm{p} / \mathrm{p}$ (IRFAN et al., 2015). Exemplos de plastificantes comumente utilizados na produção de FDOs são: polietilenoglicol, glicerol, sorbitol e dibutilftlato (BALA et al., 2013). O uso inadequado ou excessivo de plastificante pode resultar em filmes de 
baixa qualidade com alteração no tempo de desintegração, devido à separação de fases parcial ou total. O tempo de desintegração dos FDOs é importante, pois pode afetar significativamente a liberação do medicamento e, posteriormente, a absorção e a biodisponibilidade (VUDDANDA et al., 2017a).

Em relação aos métodos de produção de filmes de desintegração oral, o método de casting é o método mais comumente utilizado (IRFAN et al., 2015). Pezik et al. (2021) prepararam e caracterizaram filmes de desintegração oral à base de pululano contendo besilato de amlodipina, um medicamento anti-hipertensivo. Pornpitchanarong et al. (2020) desenvolveram filmes mucoadesivos orais a base de uma mistura de polímero de ácido hialurônico funcionalizado com catecol e álcool polivinílico contendo nanosuspensão de clotrimazol para tratamento de candidíase oral. Prajapati et al. (2018) formularam filmes orais carregado com zolmitriptano, fármaco utilizado para enxaqueca, à base de pululano.

No entanto, a produção de filmes por casting apresenta algumas desvantagens como longo tempo de secagem, dificuldade no controle das condições de produção, produção em pequena escala, dentre outras (LOW et al., 2013). Uma alternativa que vem ganhando interesse na produção de filmes em geral, a fim de viabilizar a produção com tempo menor e em larga escala, é a técnica de espalhamento, na qual consiste em uma lâmina de fita contínua espalhar a solução filmogênica sobre o suporte, e secagem por circulação de ar quente (convecção de calor), condução de calor, ou infravermelho (DE MORAES et al., 2013). Para controle da espessura dos filmes pode-se ajustar o espaço entre a lâmina e a superfície do suporte (TANIMOTO; HAYAKAWA; NEMOTO, 2004).

O espalhador automático de filme é bastante utilizado nas indústrias de fabricação de papel, plástico, cerâmica e tintas, porém ainda pouco explorado para a produção de filmes de desintegração oral. Tabela 14 reúne alguns desses estudos. 
Tabela 14 - Estudos de filmes desenvolvidos pela técnica de espalhamento.

\begin{tabular}{lll}
\hline Polímero & Princípio Ativo & Referências \\
\hline HPMC & Prednisolona & $\begin{array}{l}\text { Brniak, Maślak \& } \\
\text { Jachowicz (2015) }\end{array}$ \\
HPMC e HPC & $\begin{array}{l}\text { Cloridrato de } \\
\text { loperamida }\end{array}$ & $\begin{array}{l}\text { Woertz \& Kleinebudde } \\
(2015)\end{array}$ \\
HPMC & Tadalafil & $\begin{array}{l}\text { Vuddanda et al. } \\
\text { (2017b) }\end{array}$ \\
HPMC & Extrato etanólico & Tedesco (2018) \\
& do resíduo de & \\
acerola & \\
Maltodextrina & Melatonina & Musazzi et al. (2019) \\
CMC & Extrato de romã & Borges et al. (2019) \\
HPMC & Diclofenaco de & Speer et al. (2019) \\
HPMC & sódio & \\
\hline
\end{tabular}

A técnica de espalhamento vem sendo utilizada também na impressão de extratos pela tecnologia de jato de tinta "inkjet" (BORGES et al., 2019; BUANZ et al., 2015). E há ainda trabalhos que utilizam a técnica para desenvolvimento de filmes utilizados como embalagem alimentícia (ZHANG et al., 2020) e filmes comestíveis (DE MORAES et al., 2013). 


\section{Objetivos}

\subsection{Objetivos Gerais}

Extrair compostos ativos dos resíduos industriais de camu-camu e desenvolver filmes de desintegração oral como sistema carreador dos princípios ativos presentes no extrato.

\subsection{Objetivos Específicos}

- Obtenção de extratos utilizando-se como solventes: água e solução de etanol hidroalcóolica 70\% e 80\%. Caracterização dos extratos em relação a concentração de compostos fenólicos e capacidade antioxidante visando-se a definição do melhor solvente para extração;

- Caracterização do extrato produzido com o solvente escolhido em relação à cor, $\mathrm{pH}$, vitamina $\mathrm{C}$, flavonoides e capacidade antioxidante;

- Produção de filmes de desintegração oral com três diferentes macromoléculas: amido pré-gelatinizado de milho, HPMC e CMC, e incorporação do extrato;

- Caracterização dos filmes controle e com incorporação do extrato: espessura, propriedades mecânicas, ângulo de contato, tempo de desintegração, pH de superfície, cor, opacidade, microscopia de força atômica e espectroscopia de infravermelho com transformada de Fourier) e quantificação dos compostos ativos (fenólicos totais e capacidade antioxidante);

- Estudo do perfil de liberação de compostos fenólicos com as diferentes macromoléculas estudadas.

- Avaliação do efeito protetivo do filme utilizando-se ensaios de estabilidade de compostos fenólicos e capacidade antioxidante. 


\section{Materiais e métodos}

\subsection{Materiais}

O resíduo de camu-camu (Myrciaria dubia) proveniente do processamento do camu-camu para produção da polpa desidratada (pó) foi gentilmente cedido pela empresa Doce Fruta (São Pedro do Turvo, SP, Brasil). As macromoléculas hidroxipropil metilcelulose (HPMC E15) e carboximetilcelulose (CMC) (Denvercel PH40A) foram doadas pelas empresas Colorcon (Midland, USA) e Denver (Cotia, SP, Brasil), respectivamente. $O$ amido de milho pré-gelatinizado (Snow Flake) foi adquirido da empresa Daxia (São Paulo, SP, Basil). Os reagentes utilizados foram: álcool etílico (Synth, Diadema, Brasil), ácido ascórbico (Sigma-Aldrich, St Louis, MO, USA), ácido clorídrico (Synth, Diadema, Brasil), ácido gálico (Sigma-Aldrich, St Louis, MO, USA), ácido sulfúrico $\left(\mathrm{H}_{2} \mathrm{SO}_{4}\right.$, Merck, Darmstadt, Germany, carbonato de sódio (Synth,Diadema, Brasil), cloreto de alumínio (Synth, Diadema, Brasil), dihydrochloride (AAPH) (Sigma-Aldrich, St Louis, MO, USA), ditiotreitol (DTT) (Sigma-Aldrich, St Louis, MO, USA), Folin-Ciocalteu (Sigma-Aldrich, St Louis, MO, USA), 2,20-azobis(2methylpropionamidine), fluoresceína (Sigma-Aldrich, St Louis, MO, USA), quercetina (Sigma-Aldrich, St Louis, MO, USA) e Trolox (Sigma-Aldrich, St Louis, MO, USA).

\subsection{Métodos}

$\mathrm{Na}$ Figura 6 pode-se observar o fluxograma do delineamento deste projeto de pesquisa. 
Figura 6 - Fluxograma de produção e execução do projeto de filmes de desintegração oral a partir do resíduo industrial de camu-camu (RCC).

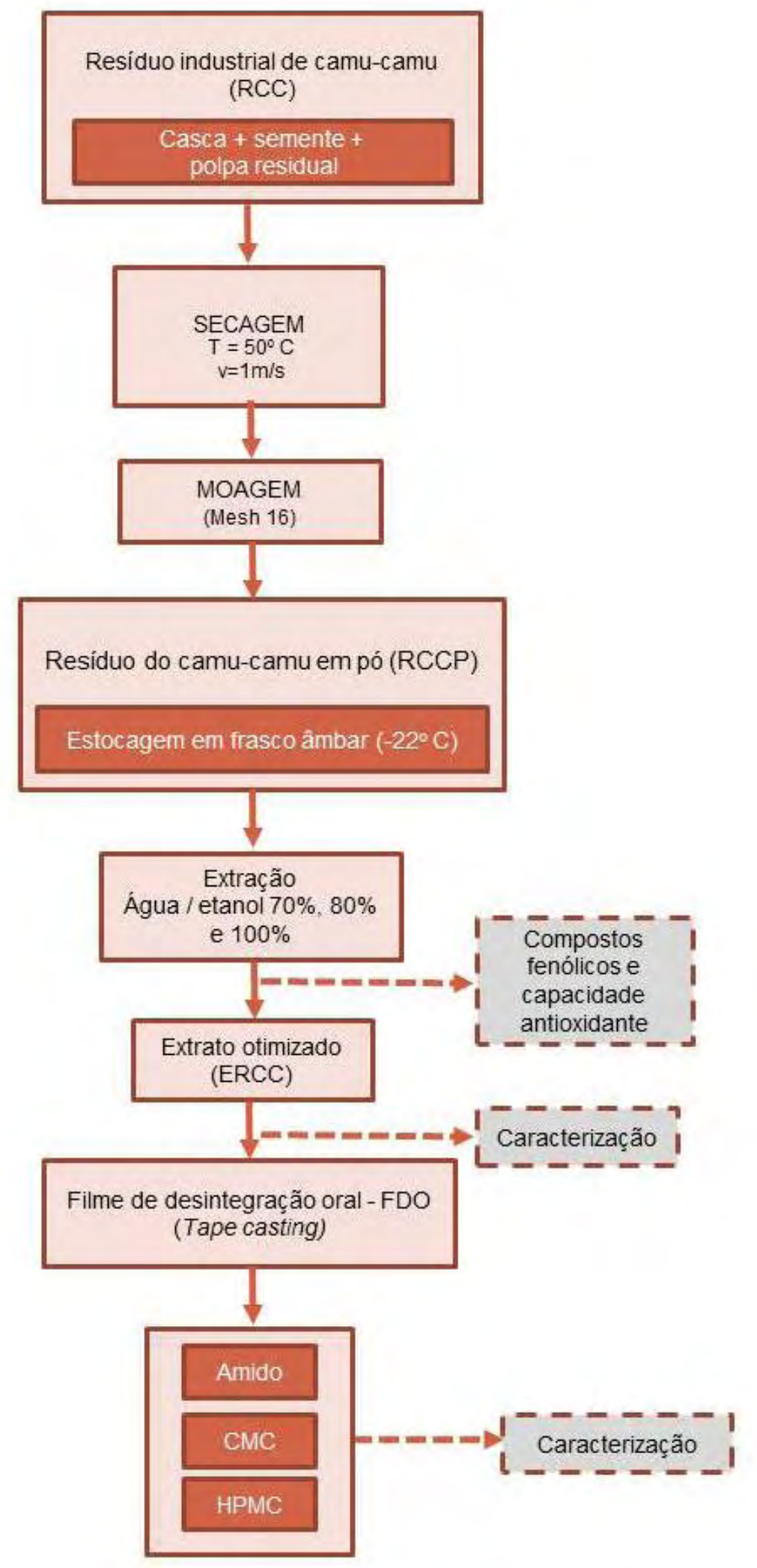

Fonte: Própria autoria 


\subsubsection{Obtenção do resíduo de camu-camu em pó (RCCP)}

A indústria Doce Fruta processa camu-camu para produção de extrato em pó, como resíduo é gerado uma mistura de casca, semente e polpa. Esse resíduo é esmagado em um processador de rosca e em seguida passa por um filtro rotativo, obtendo-se um resíduo homogêneo (Figura 7), sendo este o resíduo utilizado. O lote utilizado no trabalho foi coletado em 10/05/2017.

Figura 7. Resíduo de camu-camu in natura doado pela empresa Doce Fruta em São Pedro do Turvo - SP.

Fonte: Própria autoria

Após a recepção desse resíduo cedido pela indústria Doce Fruta, estes foram ensacados e congelados (Freezer Brastemp, BVR28HBBNA) a temperatura de $-22^{\circ}$ C para posterior secagem. Anteriormente a secagem o resíduo foi mantido sob refrigeração para o descongelamento. A secagem do resíduo foi realizada de acordo com Araújo (2019), utilizou-se estufa de circulação de ar forçada a temperatura de $50^{\circ} \mathrm{C}$ com velocidade do ar de $1 \mathrm{~m} / \mathrm{s}$ por 9 horas, e os resíduos, cerca $250 \mathrm{~g}$, foram distribuídos uniformemente em bandejas (espessura do resíduo na bandeja $=6 \mathrm{~mm}$ ), conforme testes preliminares. Os resíduos secos passaram por moagem e 
padronização de granulometria (Mesh 16) e então foram armazenados em frascos âmbar sob refrigeração $\left(-25^{\circ} \mathrm{C}\right)$ até extração (Figura 8).

Figura 8. Pó do resíduo industrial de camu-camu após secagem e padronização da granulometria (RCCP).

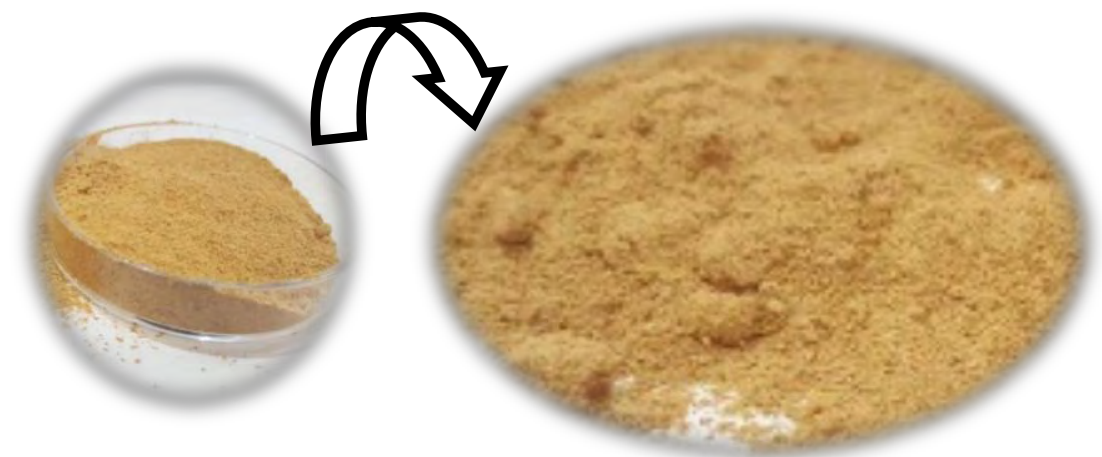

Fonte: Própria autoria

\subsubsection{Produção e caracterização do extrato do resíduo de camu-camu (ERCC)}

Para produção de ERCC, a extração foi realizada de acordo com metodologia adaptada de Correia et al. (2012), amostras de RCCP $(1,0 \mathrm{~g})$ foram dispersas em $40 \mathrm{ml}$ de solvente (soluções hidroalcóolicas de 70 e $80 \%$ etanol e água). A dispersão foi mantida sob agitação magnética a 500 rpm (agitador magnético IKA Topolino) por um período de 5, 10, 20, 40 e 60 min em banho de gelo. Em seguida a dispersão foi submetida à filtração a vácuo em papel de filtro (Whatman no. 1). Uma segunda extração foi realizada, adicionando-se mais $40 \mathrm{~mL}$ do solvente e mantendo-se em agitação magnética de 5, 10, 20, 40 e 60 min em banho de gelo, sendo em seguida a solução filtrada.

A determinação do tempo das extrações, bem como a escolha do solvente mais adequado foram realizadas considerando-se a concentração de compostos fenólicos totais e capacidade antioxidante pelos métodos de DPPH• e ORAC. O extrato otimizado, definido a partir dos testes preliminares (quantificação de compostos fenólicos e capacidade antioxidante) foi caracterizado em relação a cor, pH, vitamina C, fenólicos totais, flavonoides e capacidade antioxidante. 


\subsubsection{Cor}

Com o auxílio de um colorímetro Miniscan XE (HunterLab) avaliou-se os parâmetros de cor (luminosidade $\left(L^{*}\right)$, chroma $a^{*}$ e chroma $\left.b^{\star}\right)$. D65 foi o iluminante utilizado, sendo controlado pelo programa computacional Universal Software e abertura de $10^{\circ}$ utilizando-se as coordenadas CIELab*. Para as leituras, alíquotas do ERCC $(5 \mathrm{ml})$ foram colocadas em placa de pettri.

\subsubsection{2 $\mathrm{pH}$}

Para determinação do $\mathrm{pH}$, utilizou-se uma alíquota de $20 \mathrm{~mL}$ do $\mathrm{ERCC}$, sendo a determinação realizada utilizando-se o pHmetro WTW 3210 (WTW Com., Weilheim, Alemanha).

\subsubsection{Vitamina C}

A concentração total de vitamina $C$ no ERCC foi obtida a partir da quantificação de ácido ascórbico e ácido dehidroascórbico, de acordo com Sánchez-Mata et al. (2000) utilizando-se cromatógrafo Shimatzu Promenience (injetor automático: SIL20HT, bomba: LC 20 AD e detector de UV-visível a 245 nm (Thermo Separation Spectra UV100). A coluna cromatográfica utilizada foi Shim-pack GIST C18 (250 mmL. x 4.6 mml.D., $5 \mu \mathrm{m}$, Shimadzu, Japão) e a fase móvel foi solução tampão 1,8 mM de $\mathrm{H}_{2} \mathrm{SO}_{4}$ $(\mathrm{pH} 2,6)$ a uma taxa de fluxo 0,9 ml/min. Para quantificação do ácido ascórbico, o extrato foi filtrado antes da injeção no sistema cromatográfico (Millipore 0,45 mm, Bedford, Md., EUA). E para quantificar o ácido dehidroascórbico, alíquotas de $1 \mathrm{~mL}$ do ERCC filtrado foram reduzidas com $0,2 \mathrm{~mL}$ de solução de ditiotreitol (DTT) (20 mg/ml), a solução foi mantida ao abrigo de luz por 2 h e então, injetadas no sistema. Como padrão utilizou-se o ácido ascórbico e os resultados expressos em base seca mg de ácido ascórbico/100 g de resíduo seco.

\subsubsection{Compostos fenólicos totais}

A concentração de compostos fenólicos totais foi determinada de acordo com a metodologia proposta por Singleton et al. (1998), utilizando a curva padrão de ácido gálico. Adicionou-se $0,5 \mathrm{~mL}$ das soluções de ERCC em 2,5 mL de reagente de Folin- 
Ciocalteu ( $1: 10 ; \mathrm{v} / \mathrm{v})$. As soluções foram homogeneizadas por 10 segundos e mantidas ao abrigo de luz por 5 minutos em temperatura ambiente. Em seguida, adicionou-se 2,0 $\mathrm{mL}$ de carbonato de sódio (7,5\%), homogeneizou-se e manteve novamente a solução em repouso e ausência de luz por 2 horas em temperatura ambiente. Com o auxílio de um espectrofotômetro Lambda 35 (Perkin-Elmer, Waltham, MA, USA) à 760 $\mathrm{nm}$ realizou-se a leitura das absorbâncias e os valores foram expressos em $\mathrm{mg}$ de ácido gálico/g de resíduo seco.

\subsubsection{Flavonoides totais}

A concentração de flavonoides totais nos ERCCs foi determinada de acordo com Neves et al. (2015). Amostras de $3 \mathrm{~mL}$ de ERCC foram adicionados a $2 \mathrm{~mL}$ de solução de cloreto de alumínio (5\%), em seguida as soluções foram homogeneizadas em agitador de tubos (ika, Vortex) e mantidas em repouso por 30 minutos. Após esse período, com o auxílio de um espectrofotômetro Lambda 35 (Perkin-Elmer, Waltham, MA, USA) à $441 \mathrm{~nm}$ realizou-se a leitura das absorbâncias. Como padrão utilizou-se quercetina, e os resultados expressos em base seca $\mathrm{mg}$ de quercetina $/ 100 \mathrm{~g}$ de resíduo seco.

\subsubsection{Capacidade antioxidante}

\subsection{Sequestro do radical DPPH}

Para determinação da capacidade antioxidante empregou-se o método do radical DPPH conforme proposto por Brand-Williams et al. (1995) com modificações. As alíquotas de amostras ( $400 \mu \mathrm{L}$ de extrato diluído) foram adicionadas a solução de $\mathrm{DPPH} \bullet(0,004 \%, 2,0 \mathrm{~mL})$. As soluções foram agitadas e mantidas a abrigo de luz por 1 hora. A absorbância foi determinada a $517 \mathrm{~nm}$ utilizando-se espectrofotômetro Lambda 35, (Perkin-Elmer, Waltham, MA, USA). Como padrão externo utilizou-se o trolox $(5-50 \mu \mathrm{M})$ e os resultados foram expressos em $\mu \mathrm{mol}$ equivalente de trolox/g de amostra. 


\subsection{ORAC}

A capacidade antioxidante pelo método de ORAC foi determinada conforme descrito por Ou, Hampsch-Woodill e Prior (2001), utilizando-se o fluorímetro FLUOstar Optima (BMG Labtech, Germany). Alíquotas dos ERCCs diluídos (25 $\mu \mathrm{L}$ ) foram adicionadas a $150 \mu \mathrm{L}$ de fluoresceína $(81 \mathrm{mM})$ e incubadas por 10 minutos a $37^{\circ} \mathrm{C}$ em microplacas de 96 poços. Em seguida, $25 \mu \mathrm{L}$ da solução AAPH (152 mM) foi adicionada. A fluorescência foi determinada por um período de $60 \mathrm{~min}$ (excitação= $493 \mathrm{~nm}$; emissão= $515 \mathrm{~nm})$. Como padrão externo utilizou-se o trolox $(8,12,16,24$, 32, 48, 64 e $96 \mu \mathrm{M})$ e para preparo de todas as soluções utilizou-se tampão fosfato (75 mM, pH 7,4). Três diluições de cada amostra foram analisadas. Os resultados foram expressos em equivalente de trolox ( $\mu$ molET /g de amostra) calculado de acordo com a equação 1.

$$
\text { ORAC }=\frac{(A \cup C a-A U C b) M t}{(A \cup C t-A \cup C b) M a}
$$

Onde:

AUC = área líquida sob a curva

$\mathrm{AUCa}=\mathrm{AUC}$ da amostra

$\mathrm{AUCb}=\mathrm{AUC}$ branco

AUCt= AUC Trolox

Mt = Molaridade do Trolox

$\mathrm{Ma}=$ Molaridade da amostra

\subsubsection{Produção dos filmes de desintegração oral}

Para produção dos filmes de desintegração oral foram utilizadas três macromoléculas: amido pré-gelatinizado (Amido), carboximetilcelulose (CMC) e hidroxipropil metilcelulose (HPMC), e como plastificante, sorbitol. Após testes preliminares, as concentrações de macromoléculas foram fixadas em $5,2,5$ e 7,5 g /100 g de solução filmogênica para o amido, CMC e HPMC, respectivamente. Fixou-se a concentração de sorbitol em $0,4 \mathrm{~g}$ de sorbitol / $\mathrm{g}$ de macromolécula, e a concentração de ERCC em $30 \mathrm{~g} / 100 \mathrm{~g}$ de macromolécula, sendo esta a máxima 
concentração de extrato possível de incorporação sem prejuízo da manuseabilidade dos FDOs.

Para a produção dos FDO à base de amido, homogeneizou-se água, sorbitol e a macromolécula com agitação mecânica (IKA RW20 digital, Staufen, Alemanha) a $600 \mathrm{rpm}$. A solução foi aquecida até $83^{\circ} \mathrm{C}$, em seguida, desligou-se o aquecimento e a solução foi mantida em agitação até atingir temperatura ambiente.

Para a produção dos FDOs à base de CMC e HPMC, homogeneizou-se, inicialmente, água e sorbitol em agitador mecânico (IKA RW20 digital, Staufen, Alemanha) a $600 \mathrm{rpm}$ com aquecimento a $60 \stackrel{\circ}{\circ} \mathrm{C}$. Em seguida, desligou-se 0 aquecimento e cada macromolécula foi adicionada lentamente, mantendo-se a agitação até a completa solubilização do polímero. As soluções filmogênicas de CMC e HPMC ainda foram colocadas em repouso em temperatura ambiente por 24 horas na ausência de luz para remoção de bolhas de ar.

A incorporação do extrato etanólico do resíduo do camu-camu (EERCC) nas três formulações filmogênica, ocorreu à temperatura ambiente, mantendo-se a agitação mecânica (600 rpm) até a total incorporação do EERCC (30 minutos).

Os FDOs foram produzidos utilizando-se a técnica de espalhamento. As soluções filmogênicas foram espalhadas utilizando-se um aplicador de filme automático (Zehntner ZAA 2300H) (Figura 9) com o auxílio do aplicador universal de $220 \mathrm{~mm}$ de comprimento (ZUA 220) a uma velocidade de $10 \mathrm{~mm} / \mathrm{s}$. Após testes preliminares, e visando obter FDOs com espessura média de $60 \mu \mathrm{m}$, a espessura do espalhador foi fixada em 1400, 2000 e $900 \mu \mathrm{m}$ para amido, CMC e HPMC, respectivamente nos filmes controle. E para as soluções filmogênicas com adição do extrato a espessura do espalhador foi fixada em: 1150, 2000 e $1000 \mu \mathrm{m}$ para os filmes com amido, CMC e HPMC, respectivamente. Os filmes foram submetidos à secagem em estufa de ar de circulação forçada a $40^{\circ} \mathrm{C}$ (Marconi, MA 035/5, Piracicaba, Brasil). 
Figura 9. Espalhador automático de filme Zehntner ZAA2300.

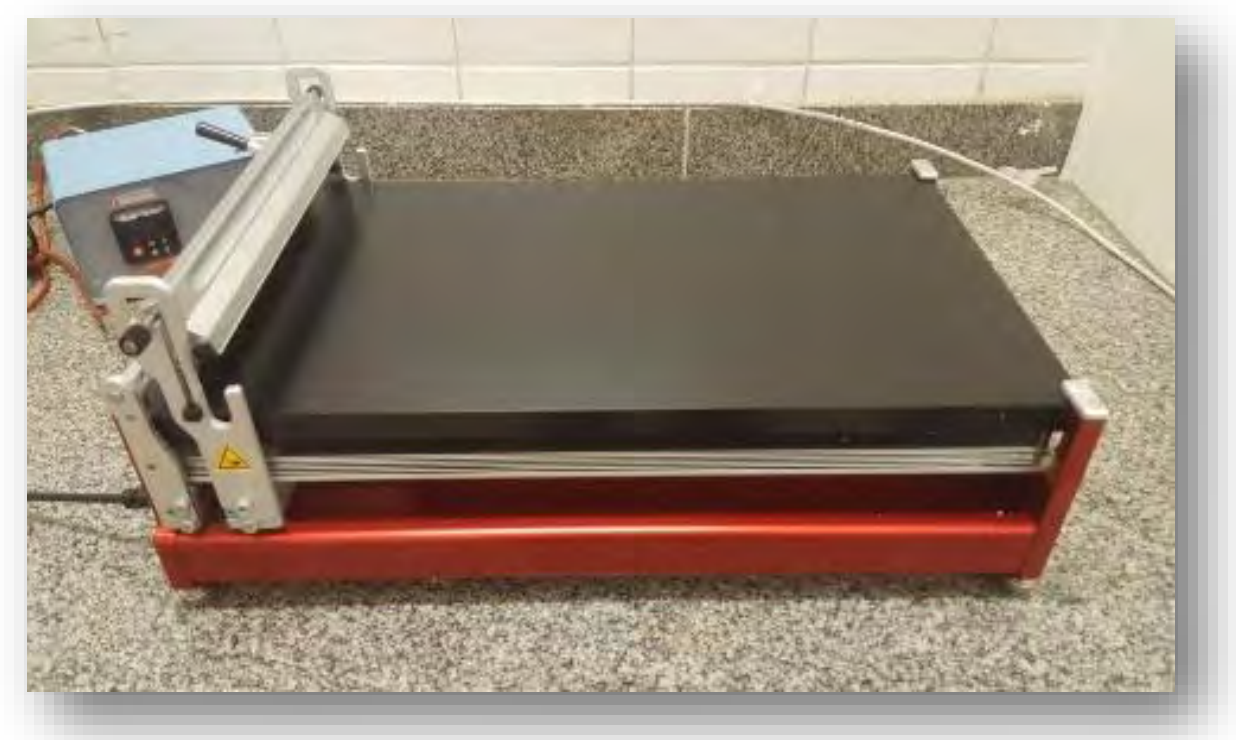

Fonte: Própria autoria

Os FDOs foram caracterizados e armazenados em diferentes condições conforme descrito na Tabela 15.

Tabela 15 - Condições de armazenamento dos FDOs para ensaios de caracterização.

\section{Caracterização}

Caracterizaçăo

Espessura

Propriedades mecânicas

Cor e opacidade

$\mathrm{pH}$ de superfície

Ângulo de contato

Tempo de desintegração

Perfil de liberação

FTIR

Microscopia de Força

atômica
Armazenamento em dessecador

\begin{tabular}{lll} 
Dias & Meio & Umidade relativa (\%) \\
\hline 4 & $\mathrm{NaBr}$ & $50-60$
\end{tabular}

5




\subsubsection{Caracterização dos filmes de desintegração oral}

\subsubsection{Espessura}

Para determinação da espessura dos filmes de desintegração oral utilizou-se o micrômetrodigital Mitutoyo $(0,001 \mathrm{~mm})$. E a média aritmética de 10 medidas aleatórias sobre a área do filme foi calculada.

\subsubsection{Propriedades mecânicas}

Para caracterização das propriedades mecânicas dos FDOs, determinou-se tensão na ruptura e elongação de acordo com o método da ASTM D882-10 (ASTM, 2010), utilizando-se o texturômetro TA.XT plus (StableMicroSystems, Godalming, Surrey, UK). Os FDOs $(10 \times 2,5 \mathrm{~cm})$ foram fixados na sonda de tração e os parâmetros de realização do teste foram: $100 \mathrm{~mm}$ para distância de separação da probe e a velocidade do teste foi de $50 \mathrm{~mm} / \mathrm{min}$. A partir da curva de tensão versus deformação, foram obtidas diretamente a tensão e a elongação.

\subsubsection{Parâmetros de cor e opacidade}

Os filmes de desintegração oral foram cortados em quadrados $5 \times 5 \mathrm{~cm}$ para determinação da cor e opacidade. Os parâmetros de cor $\left(L^{*}, a^{*}\right.$ e $\left.b^{\star}\right)$ e opacidade foram obtidos da leitura de 5 pontos em cada amostra, apoiada sobre uma placa branca, utilizando-se o colorímetro Miniscan XE (HunterLab) (GENNADIOS et al., 1996). A opacidade foi determinada pelo software do equipamento (equação 2), onde calculou-se a razão entre a opacidade do filme sobreposto no padrão preto $\left(P_{p}\right)$ e no padrão branco $\left(\mathrm{P}_{\mathrm{b}}\right)$ (SOBRAL 2000).

$$
\text { Opacidade }=(\mathrm{Pp} / \mathrm{Pb}) \times 100
$$

\subsubsection{4 $\quad \mathrm{pH}$ de superficie}

Para determinar o pH de superfície, utilizou-se tampão fosfato salino $\mathrm{pH} 6,75$ como solução simuladora de saliva produzido de acordo com Wong et al. (1999) $(8,00$ g NaCl, 2,38 $\mathrm{g} \mathrm{Na}_{2} \mathrm{HPO}_{4}$ e 0,19 $\mathrm{g} \mathrm{KH}_{2} \mathrm{PO}_{4}$ por litro de água destilada ajustado com ácido fosfórico). Após 30 segundos de imersão das amostras dos filmes (3x2 cm) na 
solução tampão, colocou-se o eletrodo em contato com a superfície do FDO, e o pH (WTW, pH3210, Alemanha) determinado após 1 minuto de contato do eletrodo com a amostra de FDO.

\subsubsection{5 Ângulo de contato}

As medidas do ângulos de contato dos FDOs foram realizadas em um tensiômetro ótico (Attension, Theta Lite Optical Tensiometer). Amostras dos filmes $(3 \times 2 \mathrm{~cm})$ foram fixadas com fita adesiva e uma gota de água ultrapura ( $5 \mu \mathrm{l})$ despejada. Após 10 segundos, registrou-se a imagem da superfície do filme com a gota, e o ângulo de contato foi calculado pelo software Attension Theta (Versão 4.1.9.8).

\subsubsection{Espectroscopia de Infravermelho com Transformada de Fourier}

Para avaliar as interações entre os componentes dos filmes utilizou-se 0 espectrofotômetro Spectrum One (Perkin-Elmer, Waltham, MA, USA), aplicando-se a técnica de espectroscopia na região do infravermelho com transformada de Fourier, a partir de 16 varreduras para cada amostra na faixa espectral de 650 a $4000 \mathrm{~cm}^{-1} \mathrm{com}$ resolução de $2 \mathrm{~cm}^{-1}$.

\subsubsection{Microscopia de força atômica}

A avaliação da estrutura superficial dos filmes de desintegração foi realizada utilizando-se o microscópio de força atômica Solver Next, NT-MDT (Russia), de acordo com Valencia et al. (2019). Os filmes $(1,5 \times 1,5 \mathrm{~cm})$ foram fixados com fita adesiva dupla face em um suporte e as imagens foram obtidas analisando três posições aleatórias (com 50 x 50 $\mu$ m cada), utilizando o modo semi-contato, com taxas de digitalização de $0,5 \mathrm{~Hz}$ e resolução de $0.1 \mu \mathrm{m} / \mathrm{px}$. A constante da mola e frequência de ressonância nominal das ponteiras utilizadas foram de $5 \mathrm{~N} / \mathrm{m}$ e $150 \mathrm{kHz}$, respectivamente.

\subsubsection{Tempo de desintegração}

O tempo de desintegração foi avaliado de acordo com a metodologia proposta por Garsuch e Breitkreutz (2010) com adaptações. Amostras de filmes (3,5 x 4,0 cm) 
foram fixadas a um slide frame sobreposto em uma placa de petri (Figura 10). Depositou-se sobre o filme uma gota de água destilada $(250 \mu \mathrm{L})$ e o tempo necessário para formar um furo no filme foi definido como o tempo de desintegração.

Figura 10. Slide frame com filme oral utilizado para a realização do tempo de desintegração.

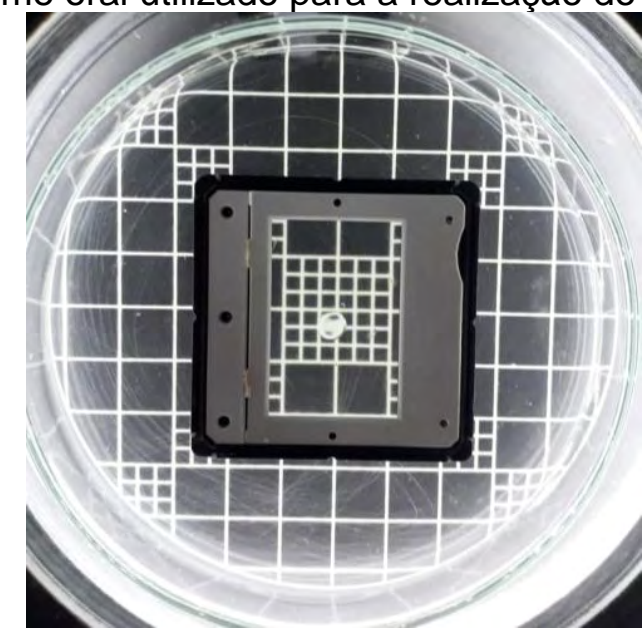

Fonte: Própria autoria

\subsubsection{Perfil de liberação in vitro}

Para determinar o perfil de liberação in vitro de compostos fenólicos nos filmes de desintegração oral, amostras de filmes $(3 \times 2 \mathrm{~cm})$ foram imersas em $5 \mathrm{~mL}$ de solução

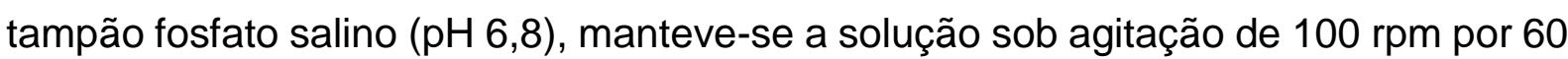
minutos em incubadora a $37^{\circ} \mathrm{C}$ (shaker, MA 420, Marconi, Piracicaba, SP, BR). Alíquotas de $0,5 \mathrm{~mL}$ da solução em agitação foram retiradas nos intervalos de tempo de $0,1,3,5,10,15,30$ e 60 minutos, para determinação de compostos fenólicos totais, conforme metodologia de SINGLETON; ORTHOFER; LAMUELA-RAVENTÓS (1998), descrita no item 4.2.2.4. A fim de manter o volume do teste constante, a cada retirada de amostra, um volume igual de solução tampão era reposto.

\subsubsection{Estabilidade}

Os FDOs $(3 \times 2 \mathrm{~cm})$ foram embalados em papel alumínio e armazenados em câmaras incubadoras BOD (MA 415, Marconi) sob duas condições controladas como proposto por Shimoda et al. (2009), condição normal: $25^{\circ} \mathrm{C}$ e $50-60 \%$ de umidade (solução salina de $\mathrm{NaBr}$ ) e condição acelerada: $40^{\circ} \mathrm{C}$ e $75 \%$ de umidade (solução salina de $\mathrm{NaCl}$ ), por um período de 20 semanas. Ao longo desse período, os filmes 
foram avaliados em relação aos compostos fenólicos totais e a capacidade antioxidante pelo método de ORAC (descritos nos itens 4.2.2.4 e 4.2.2.6.2, respectivamente), em intervalos de 7 dias. O teor de umidade das amostras também foi determinado em função do tempo de armazenamento.

Para quantificar os compostos fenólicos totais, amostras dos filmes $(0,5 \mathrm{~g})$ foram imersas em $10 \mathrm{~mL}$ de água destilada e a solução mantida sob agitação de 100 rpm por 90 minutos em incubadora a $37^{\circ} \mathrm{C}$ (shaker, MA 420, Marconi, Piracicaba, SP, BR), em seguida a solução foi homogeneizada em banho ultrassônico (Ultra clear, $1400 \mathrm{~A}$, Unique) a temperatura ambiente por 30 minutos e alíquotas de 0,5 mL foram retiradas para realizar o ensaio de determinação da concentração de compostos fenólicos.

Para extração dos filmes para determinação da capacidade antioxidante pelo método de ORAC, $0,1 \mathrm{~g}$ de amostra foi solubilizada em $10 \mathrm{~mL}$ tampão fosfato $(75 \mathrm{mM}$, pH 7,4), a solução mantida sob agitação de 100 rpm por 90 minutos em incubadora a $37^{\circ} \mathrm{C}$ (shaker, MA 420, Marconi, Piracicaba, SP, BR), em seguida a solução foi homogeneizada em banho ultrassônico (Ultra clear, 1400 A, Unique) a temperatura ambiente por 30 minutos e alíquotas de $25 \mu \mathrm{L}$ foram retiradas para realização das análises.

\subsubsection{Análise estatística}

Utilizou-se o software SAS (Versão 9.2, SAS, Inc.) para realizar as análises estatísticas. E o teste de Duncan com intervalo de confiança de 95\% foi empregado para determinar a diferença entre as médias.

Todos os ensaios de caracterização do EERCC foram realizados em triplicata. Para as análises de caracterização dos FDOs foram realizadas três formulações distintas (tempos diferentes) cada macromolécula e cada análise foi realizada em triplicata (totalizando-se 9 amostras), com exceção dos ensaios para propriedades mecânicas, ângulo de contato e estabilidade. O ensaio para propriedades mecânicas foi realizado a partir de 10 repetições de cada triplicata, totalizando 30 amostras para cada macromolécula. Enquanto que para as análises do ângulo de contato, de cada triplicada da formulação foram realizadas 5 análises de cada triplicata (totalizando-se 15 amostras para cada macromolécula). $\mathrm{E}$ os ensaios realizados para avaliar a estabilidade dos FDOs foram realizados a partir de 6 repetições da triplicata das formulações totalizando-se 18 amostras para cada macromolécula analisada. 


\section{Resultados e discussões}

\subsection{Tempo de extração e escolha do solvente}

Em testes preliminares, observou-se que o solvente etanol $100 \%$ extraiu quantidades menores de compostos fenóilicos quando comparado aos outros três solventes, por isso os resultados para esse solvente não foram apresentados.

Observando-se a Tabela 16, verificou-se que o tempo de extração não afetou significativamente a concentração de compostos fenólicos independente do solvente utilizado. Por outro lado, a concentração de compostos fenólicos nos extratos foi significativamente afetada pelo tipo de solvente. Verificou-se (Tabela 16), que os extrados produzidos utilizando-se como solvente etanol $70 \%$ apresentaram maior concentração de compostos fenólicos.

Tabela 16 - Concentrações de compostos fenólicos ( $\mathbf{C}_{\text {compostos fenólicos }}$ ) mg EAG /g resíduo seco) dos extratos obtidos com diferentes solventes (água, etanol $70 \%$ e etanol $80 \%$ ) e diferentes tempos de extração ( $\left.t_{\text {extração }}\right)$.

\begin{tabular}{llll}
\hline textração (min) & \multicolumn{3}{c}{ C $_{\text {compostos fenólicos }}$} \\
\cline { 2 - 4 } & Água & Etanol 70\% & Etanol 80\% \\
\hline 5 & $36,35 \pm 2,24^{\mathrm{Ca}}$ & $59,99 \pm 4,04^{\mathrm{Aa}}$ & $43,45 \pm 2,93^{\mathrm{Ba}}$ \\
10 & $35,67 \pm 1,88^{\mathrm{Cab}}$ & $59,25 \pm 6,47^{\mathrm{Aa}}$ & $43,90 \pm 3,30^{\mathrm{Ba}}$ \\
20 & $34,80 \pm 1,36^{\mathrm{Cb}}$ & $64,73 \pm 5,35^{\mathrm{Aa}}$ & $45,85 \pm 3,93^{\mathrm{Ba}}$ \\
40 & $36,61 \pm 0,86^{\mathrm{Ca}}$ & $63,64 \pm 8,71^{\mathrm{Aa}}$ & $50,31 \pm 4,87^{\mathrm{Ba}}$ \\
60 & $36,55 \pm 0,53^{\mathrm{Ca}}$ & $64,22 \pm 7,09^{\mathrm{Aa}}$ & $48,28 \pm 2,70^{\mathrm{Ba}}$ \\
\hline
\end{tabular}

Nota: $\mathrm{C}_{\text {compostos fenólicos }}=\mathrm{mg}$ equivalente de ácido gálico / $\mathrm{g}$ resíduo seco; letras maiúsculas diferentes na mesma linha diferem entre si ao nível de $5 \%$ de significância pelo teste Duncan. Letras minúscula diferentes na mesma coluna, diferem entre si ao nível de $5 \%$ de significância pelo teste Duncan.

Considerando-se os resultados apresentados na Tabela 16, o tempo de extração foi fixado em 5 min de forma a otimizar o processo de extração dos ERCCs, Para a escolha do solvente, os ERCCs foram ainda avaliados quanto à capacidade antioxidante. Os resultados para os métodos de DPPH• e ORAC seguem apresentados na Tabela 17. 
Tabela 17 - Atividade antioxidante determinada pelos métodos DPPH• e ORAC, dos extratos do resíduo de camu-camu obtidos utilizando-se diferentes solventes (tempo de extração = $5 \mathrm{~min})$.

\begin{tabular}{lll}
\hline Solvente & DPPH $\bullet$ & ORAC \\
\hline Água & $220,54 \pm 16,54^{\mathrm{b}}$ & $216,14 \pm 10,55^{\mathrm{a}}$ \\
Etanol $70 \%$ & $273,93 \pm 16,24^{\mathrm{a}}$ & $224,59 \pm 21,38^{\mathrm{a}}$ \\
Etanol $80 \%$ & $246,83 \pm 63,82^{\mathrm{ab}}$ & $193,78 \pm 14,32^{\mathrm{b}}$
\end{tabular}

Nota: $\mathrm{DPPH}$ e ORAC $=\mu \mathrm{Mol}$ Trolox Equivalente/g de resíduo seco \pm DP; letras diferentes na mesma coluna, diferem entre si ao nível de $5 \%$ de significância pelo teste Duncan.

Sendo que valores mais elevados de DPPH e ORAC indicam maior capacidade antioxidante, em ambas as análises a extração com o solvente etanol $70 \%$ foi a que resultou em valores significativamente maiores, justificando-se assim a escolha desse solvente para a realização das extrações.

$\mathrm{Na}$ literatura é possível encontrar trabalhos com extrações hidroalcoólicas: Zimmer et al. (2021) investigaram os efeitos antioxidantes, antibacterianos e antitumorais dos extratos hidroalcoólicos da polpa e das sementes de Physalis pubescens. Rimkiene et al. (2021) avalariam a biodisponibilidade de flavonoides de filmes sublinguias a base de CMC incorporados com extrato etanólico $70 \%$ de Ginkgo biloba $L$.

Carmo et al. (2019) avaliaram diferentes extratos hidroalcoólicos de sementes de camu-camu em relação à sua composição fenólica, atividade antioxidante, citotóxica e avaliaram a capacidade dos extratos em inibir aberrações cromossômicas, obtendo os melhores resultados para o extrato obtido com soluções hidroalcóolicas com 50\% etanol obtendo valores de concentração de composto fenólicos de $4802 \mathrm{mg}$ EAG/100 g e capacidade antioxidante pelo método de DPPH de $3694 \mathrm{mg}$ ácido ascórbico equivalente $/ 100 \mathrm{~g}$.

\subsection{Caracterização do extrato etanólico de camu-camu}

\subsubsection{Cor e pH}

A caracterização do extrato etanólico do resíduo do camu-camu em relação à cor e pH, pode ser observada na Tabela 18. 
Tabela 18 - Caracterização do extrato etanólico de camu-camu (EERCC) em relação ao pH, luminosidade $\left(L^{*}\right)$, croma $a^{*}\left(a^{*}\right)$ e croma $b^{*}\left(b^{*}\right)$.

\begin{tabular}{ll}
\hline Análises & EERCC \\
\hline $\mathrm{pH}$ & $3,97 \pm 0,00$ \\
$\mathrm{~L}^{*}$ & $59,00 \pm 0,54$ \\
$\mathrm{a}^{*}$ & $0,44 \pm 0,06$ \\
$\mathrm{~b}^{*}$ & $13,03 \pm 0,62$ \\
\hline
\end{tabular}

Verificou-se que o extrato apresenta caráter ácido, o que era esperado em função das características intrínsecas do fruto. Maeda et al. (2006) ao estudarem polpa e néctar de camu-camu observaram valores de $\mathrm{pH}$ de 2,64 e 2,89, respectivamente. Souza et al. (2019) estudando néctares de camu-camu submetidos a diferente tratamentos térmicos $\left(40,50\right.$ ou $60^{\circ} \mathrm{C}$ de termosonicação por 30 ou 60 minutos), não verificaram diferença significativa entre os tratamentos em relação ao $\mathrm{pH}$, sendo os valores observados próximos a 3,5. Chagas (2019) verificaram valores de $\mathrm{pH}$ de 3,30 para o resíduo úmido e 2,90 para a farinha seca, ambos provenientes do resíduo do processamento de camu-camu. De Azevêdo et al. (2014a) encontraram valores de 3,3 e 3,8 para o resíduo de camu-camu seco a 50 e $80 \cong \mathrm{C}$, respectivamente.

Em relação aos parâmetros de cor, avaliando o sólido de cor (Figura 11), verificou-se que o EERCC apresentou elevados valores de $L^{*}$ e valores positivos para os parâmetros de $a^{*}$ e $b^{*}$ (Tabela 18), indicando coloração amarelada. O valor de b*, relacionado com a coloração amarela escura do EERCC, pode ocorrer devido à presença de compostos bioativos (ZANATTA et al., 2005). 
Figura 11. Sólido de cor do sistema CIELab.

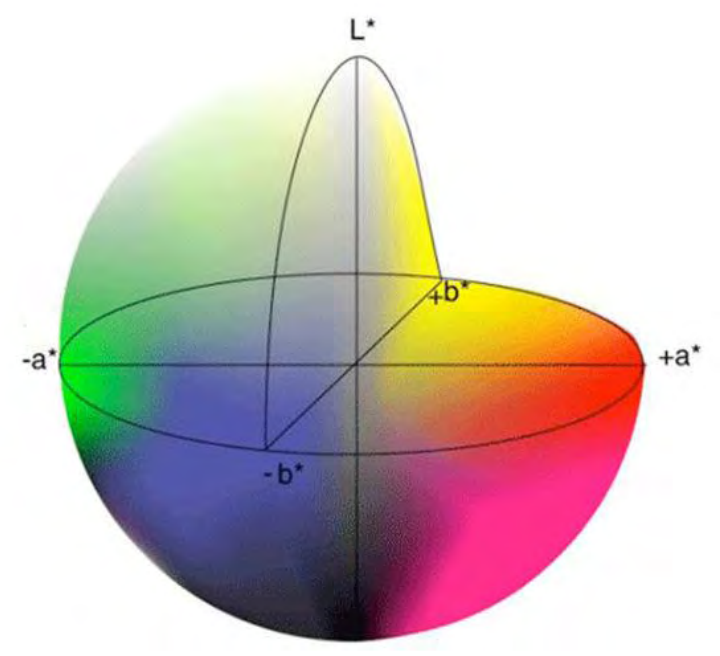

Fonte: FARRAHI MOGHADDAM et al., 2013

\subsubsection{Compostos bioativos}

Na Tabela 19 encontram-se os resultados da caracterização do extrato etanólico do resíduo de camu-camu em relação à concentração de compostos fenólicos totais, flavonoides, vitamina $\mathrm{C}$ e atividade antioxidante pelos métodos de DPPH• e ORAC.

Tabela 19 - Concentração de compostos fenólicos totais, concentração de flavonoides, vitamina $\mathrm{C}$ e atividade antioxidante (DPPH• e ORAC) do extrato etanólico obtido do resíduo industrial de camu-camu (EERCC).

\begin{tabular}{ll}
\hline Análises & EERCC \\
\hline Compostos fenólicos totais (mg EAG / g resíduo seco) & $39,71 \pm 1,17$ \\
Flavonoides (mg quercetina / 100g resíduo seco) & $217,12 \pm 8,16$ \\
Vitamina C (mg AA Total/100g resíduo seco) & $1621,29 \pm 172,08$ \\
Atividade Antioxidante - DPPH• ( $\mu$ mol Trolox eq./g resíduo seco) & $262,88 \pm 20,96$ \\
Atividade Antioxidante - ORAC ( $\mu$ mol Trolox eq./g resíduo seco) & $232,18 \pm 17,25$
\end{tabular}

Os resultados observados para a concentração de compostos fenólicos foram similares aos observados na literatura. Carmo et al. (2019) reportaram valor similares de concentração de compostos fenólicos totais $(43,54 \pm 1,15 \mathrm{mg}$ EAG/g) para extrato etanólico $(75 \%)$ da semente de camu-camu. O resultado obtido também corrobora 
com o encontrado por Fidelis et al. (2018) no extrato a base de água do revestimento da semente do camu-camu (aproximadamente $40 \mathrm{mg}$ EAG / g resíduo). Tedesco (2018) avaliou no seu trabalho com secagem do resíduo de acerola valores próximo de $25 \mathrm{mg}$ EAG/g de amostra seca para o resíduo de acerola seca a $50 \stackrel{\circ}{\mathrm{C}}$.

Quanto à concentração de flavonoides, o teor observado no presente trabalho foi superior ao encontrado por Neves et al. (2015) estudando diferentes estágios de maturação do camu-camu, que observaram valores entre 38,96 e 60,75 mg quercetina/100 g amostra seca referente a flavonoides presentes na polpa e na casca do camu-camu, sendo o maior valor referente a casca do camu-camu totalmente maduro. E também foi superior ao valor observado por Tedesco (2018), que alcançou valores próximo de $60 \mathrm{mg}$ quercetina/100 g amostra seca na quantificação de flavonoides.

Em relação a capacidade antioxidante, os valores verificados no presente trabalho também foram superiores aos valores observados na literatura. Neves et al. (2015) avaliaram a atividade antioxidante pelo método do DPPH• e ORAC e verificaram valores de 51,59 e 58,48 $\mu \mathrm{mol}$ Trolox eq./g amostra seca pelo método do DPPH•, e 50,36 e 58,10 $\mu \mathrm{mol}$ Trolox eq./g amostra seca pelo método do ORAC para polpa e casca, respectivamente. Chirinos (2010) também estudando diferentes estágios de maturação do camu-camu observou, utilizando-se o método do DPPH•, o valor máximo de $185 \mu \mathrm{mol}$ Trolox eq./g amostra fresca. Chagas (2019) ao avaliar secagem do resíduo em pó do camu-camu em diferentes temperaturas observou para o resíduo seco a 50 C e extraído com metanol, atividade antioxidante pelo método de ORAC 229,58 $\pm 23 \mu \mathrm{mol}$ Trolox eq./g resíduo seco. Tedesco (2018) alcançou valor de 176,85 $\mu \mathrm{mol}$ Trolox eq./g resíduo seco para o resíduo de acerola seco a 40 ํ. Os valores superiores encontrados no presente trabalho podem ser devido a heterogeneidade da matéria-prima, bem como estágio de maturação do resíduo do fruto de camu-camu e métodos e/ou solventes diferentes empregados na extração.

O valor observado em relação à concentração de vitamina $C$ foi semelhante aos valores reportados por Villanueva-Tiburcio et al. (2010), que verificaram valores de $1641 \pm 364$ e $1538 \pm 581 \mathrm{mg}$ ácido ascórbico / $100 \mathrm{~g}$ amostra seca na casca verde e madura do camu-camu, respectivamente; e foi inferior ao valor que esse autores observaram para a casca do fruto com estágio de maturação intermediário (entre verde e maduro) de $5349 \pm 940 \mathrm{mg}$ ácido ascórbico / $100 \mathrm{~g}$ amostra seca. Tedesco 
(2018) em seu trabalho com secagem do resíduo de acerola, encontrou valor máximo de vitamina $C$ de $300 \mathrm{mg} \mathrm{AA}$ Total $/ 100 \mathrm{~g}$ resíduo seco. Com isso, comprando os resultados obtidos nesse presente trabalho com os valores observados por Tedesco (2018) é possível confirmar que o resíduo de camu-camu apresenta maior teor de compostos fenólicos totais, flavonoides, atividade antioxidante e vitamina $\mathrm{C}$, quando comparado ao resíduo de acerola.

\subsection{Caracterização dos filmes de desintegração oral}

\subsubsection{Espessura e propriedades mecânicas}

Verificou-se (Tabela 20) que a adição de extrato não provocou alteração no contéudo de água (CA), sendo que os filmes de CMC apresentaram o maior $\mathrm{CA}$ e HPMC o menor. Também não verificou-se alteração significativa da espessura com a adição do EERCC nos FDO, independente da macromolécula. Porém, os FDOs a base de CMC apresentaram espessura inferior, enquanto os FDOs a base de amido e HPMC não diferiram significativamente entre si. Essa diferença de espessura pode ter ocorrido devido a diferença das concentrações de macromoléculas utilizadas nas formulações, sendo a concentração de CMC a menor $(2,5 \mathrm{~g} / 100 \mathrm{~g}$ de solução filmogênica), embora tenha sido ajustadas diferentes espessuras do espalhador para tentar igualar a espessura final dos FDOs secos.

Tabela 20 - Conteúdo de água (CA), espessura, tensão de ruptura (TR) e elongação (E) dos filmes de desintegração oral à base de amido pré-gelatinizado (Amido), carboximetilcelulose (CMC) e hidroxipropil metilcelulose (HPMC), sem e com incorporação extrato etanólico obtido do resíduo industrial de camu-camu (EERCC).

\begin{tabular}{llllll}
\hline C eercc & Polímero & CA $(\mathbf{g} / \mathbf{1 0 0 g}$ de água) & Espessura $(\boldsymbol{\mu m})$ & TR $(\mathbf{M P a})$ & E (\%) \\
\hline 0 & Amido & $10,95 \pm 1,76^{\mathrm{aB}}$ & $64,93 \pm 8,16^{\mathrm{aA}}$ & $4,97 \pm 0,68^{\mathrm{aC}}$ & $44,49 \pm 9,78^{\mathrm{aA}}$ \\
& CMC & $15,61 \pm 2,49^{\mathrm{aA}}$ & $43,25 \pm 4,22^{\mathrm{aB}}$ & $21,04 \pm 3,61^{\mathrm{aB}}$ & $39,80 \pm 6,53^{\mathrm{aB}}$ \\
& HPMC & $10,04 \pm 1,87^{\mathrm{aB}}$ & $73,16 \pm 3,34^{\mathrm{aA}}$ & $30,77 \pm 5,10^{\mathrm{bA}}$ & $31,26 \pm 7,00^{\mathrm{aC}}$ \\
30 & Amido & $10,13 \pm 0,45^{\mathrm{aB}}$ & $64,54 \pm 3,61^{\mathrm{aA}}$ & $5,48 \pm 0,97^{\mathrm{aC}}$ & $50,51 \pm 11,76^{\mathrm{aA}}$ \\
& CMC & $14,67 \pm 0,72^{\mathrm{aA}}$ & $46,58 \pm 4,21^{\mathrm{aB}}$ & $20,98 \pm 5,00^{\mathrm{aB}}$ & $37,87 \pm 6,28^{\mathrm{aB}}$ \\
& HPMC & $8,80 \pm 0,47^{\mathrm{aC}}$ & $67,06 \pm 10,67^{\mathrm{aA}}$ & $36,50 \pm 4,00^{\mathrm{aA}}$ & $18,43 \pm 4,06^{\mathrm{bC}}$
\end{tabular}

Nota: $\mathrm{C}_{\text {EERCC }}=$ Concentração de extrato etanólico obtido do resíduo industrial de camu-camu (g EERCC $/ 100 \mathrm{~g}$ solução filmogênica); Letras minúsculas diferentes na mesma coluna para filmes com a mesma macromolécula sem e com incorporação de EERCC diferem entre si ao nível de $5 \%$ de significância pelo teste Duncan. Letras maiúsculas diferentes na mesma coluna para filmes com a mesma CeERcc diferem entre si ao nível de 5\% de significância pelo teste Duncan. 
A incorporação de EERCC nos FDOs provocou alterações significativas apenas nas propriedades mecânicas dos FDOs a base de HPMC, sendo responsável pelo aumento da tensão de ruptura e diminuição da elongação.

É desejável que os filmes de desintegração oral possuam resistência mecânica adequada para resistir ao manuseio sem ser danificado. A resistência determinada pela TR é importante para manusear e empacotar os FDO (Alhayali et al. 2019). Visser et al. (2015a) definiram como Atributos críticos de qualidade para filmes orodispersiveis TR $>2 \mathrm{MPa}$ e $\mathrm{E}>10 \%$. De um modo geral, os FDOs estudados no presente trabalho atendem a esses atributos, embora pode-se afirmar que os FDOs à base de HPMC (sem e com incorporação de EERCC) apresentaram a maior tensão na ruptura e a menor elongação, enquanto os FDOs a base de amido apresentaram a menor TR e maior elongação.

Os valores observados para TR e elonganção no presente trabalho foram semelhantes aos observados na literatura. Bodini et al. (2019) encontraram valor para tensão na ruptura de filme a base de HPMC sem adição de extrato 24,3 $\pm 2,4 \mathrm{MPa}$, porém elongação de $7,4 \pm 3.0 \%$.

Ju e Song (2019) variando a concentração de extrato de camu-camu em filmes a base de amido de teff (Eragrostis tef) encontraram valores de tensão na ruptura entre 8,75 \pm 0,49 e 31,38 \pm 0,64 MPa e para elongação valores entre 26,33 \pm 1,60 e $73,30 \pm 5,91 \%$. Essa variação ocorreu conforme o aumento da concentração de extrato de camu-camu na formulação, para concentrações maiores, menor a tensão de ruptura e maior a elongação.

Takeuchi et al. (2020) estudando propriedades mecânicas de FDO a base de HPMC observaram que a redução de HPMC e aumento da concentração do principio ativo Paracetamol (PA) na formulação provocou redução na TR e aumento na elongação. Sendo os valores de tensão de ruptura de 58,2; 11,5; 6,4 e 4,7MPa; e elongação de 19,6; 5,2; 3,7 e 3,2\% para as formulações: 100:0; 80:20; 70:30 e 60:40 HPMC:PA, respectivamente. Em ambos os trabalhos de Ju e Song (2019) e Takeuchi et al. (2020) a redução da TR e aumento da elongação podem estar associados a redução da concentração da macromolécula nas formulações, o que não ocorreu no presente trabalho, uma vez que o EERCC foi incorporado mantendo-se a concentração inicial das macromoléculas dos FDO controle. 
Visser et al. (2015b) estudando diversas soluções para formação de FDO, avaliaram as propriedades mecânicas de filmes controles, filmes com adição de princípios ativos sintéticos e FDO comerciais. Alguns dos resultados obtidos referente a TR e E foram: FDO controle a base de HPMC 4,32 $\pm 0,0 \mathrm{MPa}$ e 15,62 $\pm 2,55 \%$; FDO a base de HPMC com $1 \mathrm{~g}$ de prednisolona 2,85 $\pm 0,53 \mathrm{MPa}$ e 11,11 $\pm 3,41 \%$; Listerine Pocketpaks ${ }^{\circledR} 0,34 \pm 0,08 \mathrm{MPa}$ e $10,06 \pm 4,05 \%$.

Dessa forma, pode-se afirmar que os FDO desenvolvidos no presente trabalho apresentam propriedades mecânicas compativeis com FDOs disponíveis na literatura e comercialmente.

\subsubsection{Cor e opacidade}

De um modo geral, verificou-se que a incorporação do EERCC provocou alterações significativas no parâmetro croma b* (amarelo (+) ao azul (-)) em todas as macromoléculas (Tabela 21), que possivelmente está associado à coloração do extrato. Essas alterações são também perceptíveis analisando a Figura 12, os filmes incorporados com EERCC (Figura 12a', b', c') apresentaram coloração alaranjada. Embora o camu-camu apresente coloração avermelhada intensa, devido à heterogeneidade (frutos verdes presentes, sementes, etc.) o extrato do resíduo possui coloração alaranjada o que justifica os valores de b* observados. Zanatta et al. (2005) justificaram que a cor vermelha para roxa na casca do camu-camu é proveniente da concentração de antocianinas presentes no fruto. Comparando-se os FDO entre as diferentes macromoléculas na mesma concentração de EERCC, embora observa-se algumas diferenças significativas nos parâmetro de cor, visualmente não são observadas diferenças (Figura 12a, b, c).

De maneira similar, Garcia et al. (2018) obtiveram valores médios de 96,4 $\pm 1,1$, $-0,92 \pm 0,04,1,73 \pm 0,08$ e 0,36 $\pm 0,05$ para luminosidade, croma $a^{*}$, croma $b^{*} e$ opacidade, respectivamente, para filmes de desintegração oral a base de amido e gelatina incorporados com extrato em pó de camu-camu (obtido pela secagem da polpa do fruto em spray dryer).

Rojas-Bravo et al. (2019) adicionando diferentes concentrações do pó da casca de manga em filmes comestíveis a base de amido de milho obtiveram também, alterações no parâmetro croma $b^{*}$; sendo $-4,51 \pm 0,26$ para o filme controle, 
aumentando para 30,72 $\pm 1,88$ e 44,53 $\pm 1,96$ nas concentrações de 2 e $4 \%$ de pó da casca de manga, respectivamente.

Quanto à opacidade, pode-se afirmar que a adição de EERCC alterou significativamente apenas a opacidade dos FDOs a base de amido, a qual reduziu $50 \%$. Bertuzzi et al. (2007) correlacionaram opacidade dos filmes de amido com zonas cristalinas, ou seja, maior a transparência do filme quanto maior a zona cristalina. Portanto, é possível que o EERCC tenha aumentado a zona cristalina dos FDO a base de amido.

Independente da macromolécula, nenhuma diferença significativa foi encontrada para a opacidade quando comparado os FDOs com as diferentes macromoléculas na mesma concentração de EERCC. 
Figura 12. Exemplos de filmes de desintegração oral à base de diferentes macromoléculas sem e com incorporação extrato etanólico obtido do resíduo industrial de camu-camu (EERCC): (a) amido, (a') amido + EERCC; (b) carboximetilcelulose (CMC), (b') CMC + EERCC; (c) hidroxipropil metilcelulose (HPMC), (c') HPMC + EERCC.

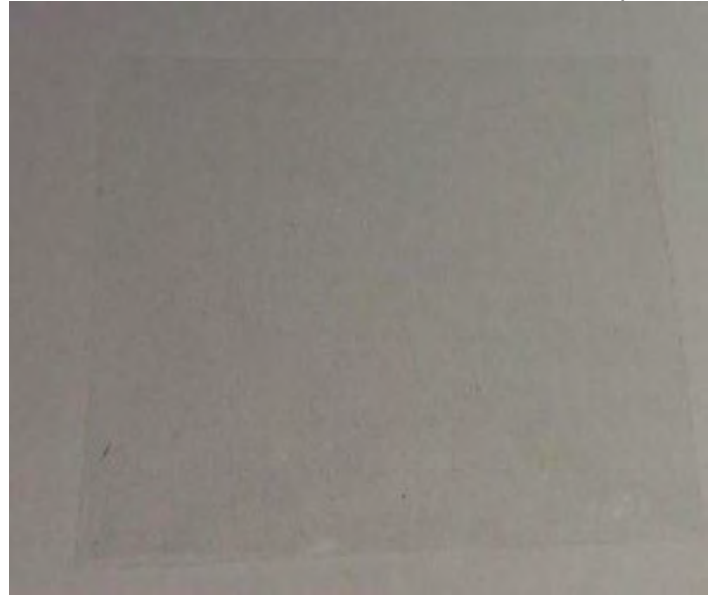

(a)

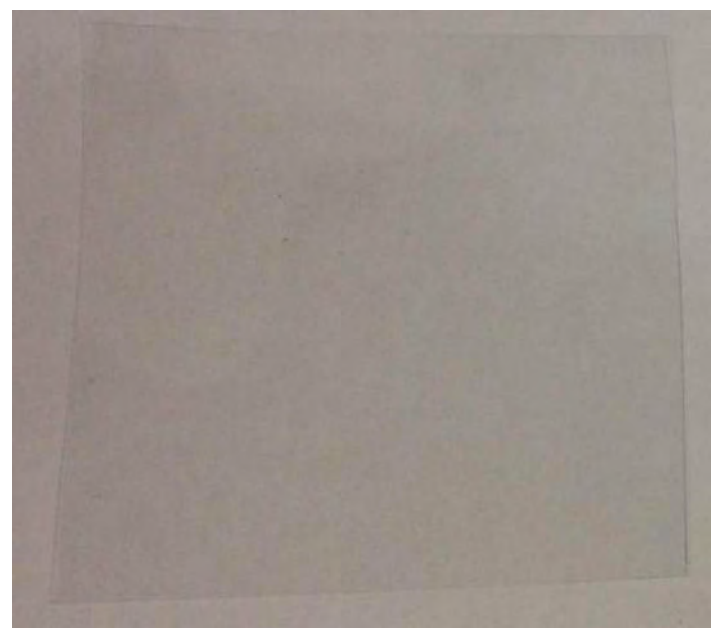

(b)

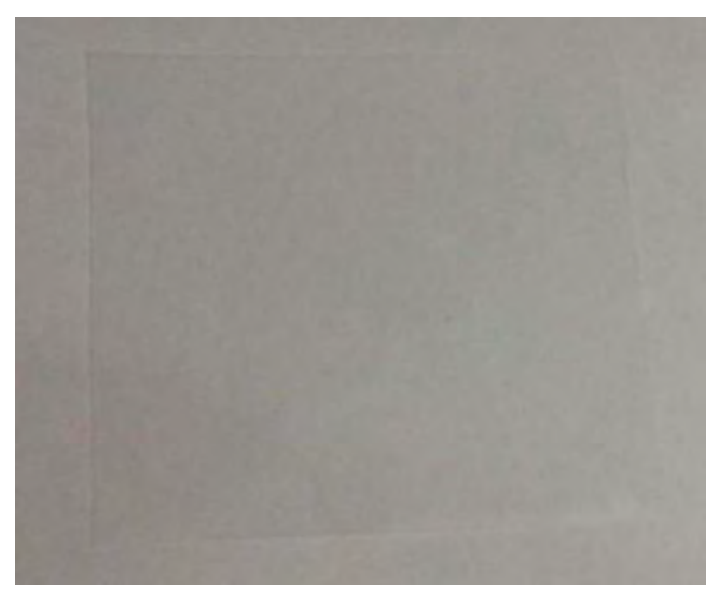

(c)

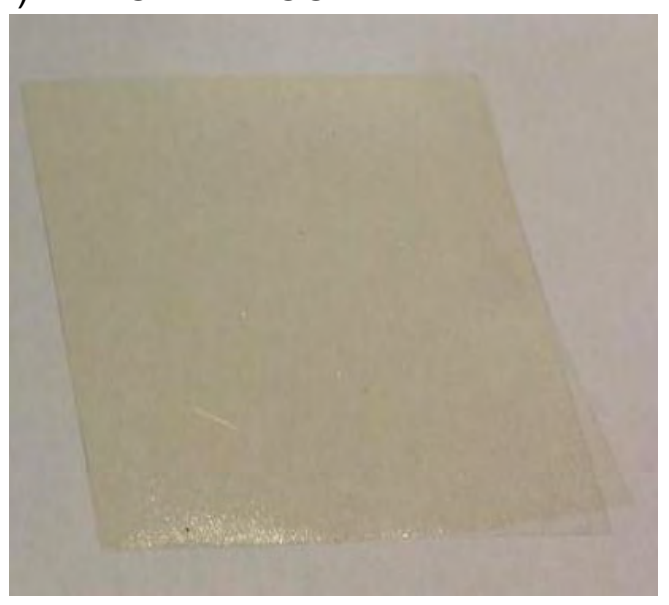

$\left(a^{\prime}\right)$

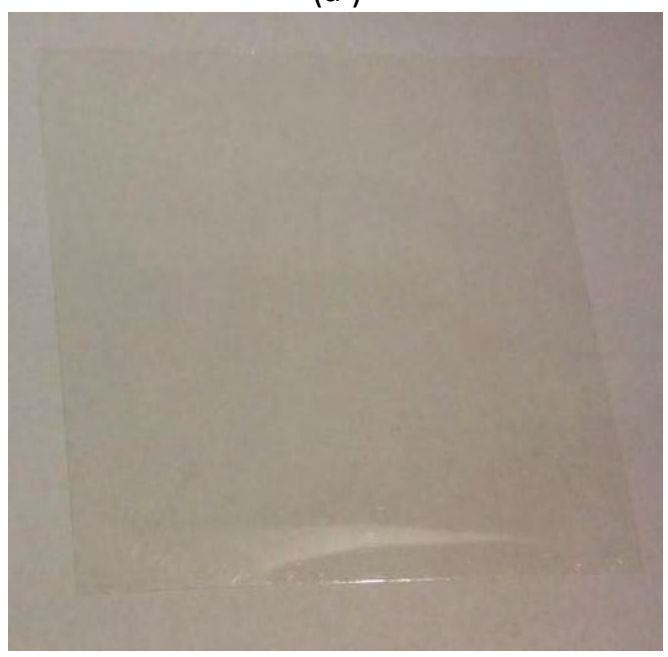

$\left(b^{\prime}\right)$

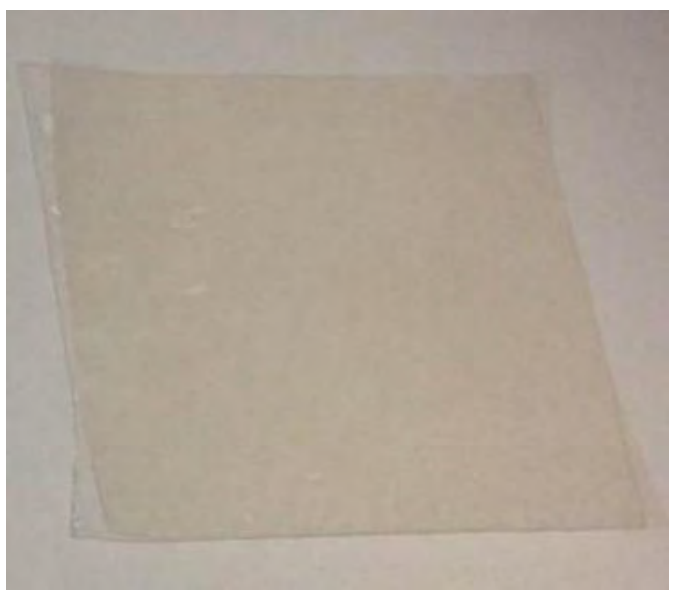

$\left(c^{\prime}\right)$

Fonte: Própria autoria 
Tabela 21 - Luminosidade $\left({ }^{*} L\right)$, croma $a^{*}\left(a^{*}\right)$, croma $b^{*}\left(b^{*}\right)$ dos filmes de desintegração oral à base de amido pré-gelatinizado (Amido), carboximetilcelulose (CMC) e hidroxipropil metilcelulose (HPMC), sem e com extrato etanólico obtido do resíduo industrial de camu-camu (EERCC).

\begin{tabular}{|c|c|c|c|c|c|}
\hline $\mathbf{C}_{\text {EeRcC }}$ & Macromolécula & $L^{*}$ & $a^{*}$ & $\mathbf{b}^{\star}$ & Opacidade \\
\hline \multirow[t]{3}{*}{0} & Amido & $90,91 \pm 0,31^{\mathrm{aA}}$ & $-0,95 \pm 0,06^{\mathrm{aA}}$ & $1,69_{ \pm 0,01^{\mathrm{aB}}}$ & $2,58 \pm 0,31^{\mathrm{bA}}$ \\
\hline & $\mathrm{CMC}$ & $91,21 \pm 0,99^{a A}$ & $-0,98 \pm 0,04^{\mathrm{bA}}$ & $1,89 \pm 0,06^{\mathrm{aA}}$ & $1,06 \pm 0,54^{\mathrm{aA}}$ \\
\hline & HPMC & $91,12 \pm 1,16^{\mathrm{aA}}$ & $-0,97 \pm 0,04^{\mathrm{bA}}$ & $1,87 \pm 0,13^{\mathrm{aA}}$ & $1,42 \pm 1,15^{\mathrm{aA}}$ \\
\hline \multirow[t]{3}{*}{30} & Amido & $87,80 \pm 0,27^{\mathrm{bB}}$ & $-0,71 \pm 0,78^{a \mathrm{~B}}$ & $6,49 \pm 0,78^{\mathrm{bB}}$ & $1,27 \pm 0,42^{\mathrm{aA}}$ \\
\hline & CMC & $87,97 \pm 0,28^{\mathrm{bB}}$ & $-1,38 \pm 0,40^{\mathrm{aA}}$ & $8,74 \pm 0,40^{\mathrm{bA}}$ & $0,60 \pm 0,19^{a A}$ \\
\hline & HPMC & $89,97 \pm 0,16^{\mathrm{aA}}$ & $-1,32 \pm 0,30^{\mathrm{aA}}$ & $4,14 \pm 0,30^{\mathrm{bC}}$ & $1,32 \pm 0,65^{a A}$ \\
\hline
\end{tabular}

Nota: $C_{\text {EERCC }}=$ Concentração de extrato etanólico obtido do resíduo industrial de camu-camu (g EERCC $/ 100 \mathrm{~g}$ solução filmogênica); Letras minúsculas diferentes na mesma coluna para filmes com a mesma macromolécula sem e com incorporação de EERCC diferem entre si ao nível de $5 \%$ de significância pelo teste Duncan. Letras maiúsculas diferentes na mesma coluna para filmes com a mesma CEeRcC diferem entre si ao nível de 5\% de significância pelo teste Duncan.

\subsection{3 $\mathrm{pH}$ de superfície}

A incorporação do EERCC (Tabela 22) provocou redução significativa do pH de superfície. Os resultados estão relacionados ao valor reduzido do $\mathrm{pH}$ do extrato. Os valores do $\mathrm{pH}$, independente da incorporação ou não do EERCC ficaram na faixa de 6,2 a 6,6, ou seja próximo a neutralidade. Diversos trabalhos na literatura, envolvendo o desenvolvimento de filmes de desintegração oral relatam que valores de $\mathrm{pH}$ próximos a 7,0 não provocam irritações na mucosa bucal, como seguem alguns exemplos: AUDA et al. (2019) estudando formulações de FDO a base de HPMC incorporados com isradipina (medicamento para tratamento de pressão alta) encontraram valores de pH de superfície entre 5,9 e 7,0. Garcia et al. (2020) produziram FDOs a base de amido pré-gelatinizado e gelatina incorporados com extrato seco de acerola e obtiveram valores entre 5,6 e 6,1. Tedesco (2018) alcançou valores de $\mathrm{pH}$ entre de 6,56 e 6,70 para FDO a base de amido, CMC e HPMC incorporados com extrato etanólico de resíduo de acerola. Borges et al. (2019) obtiveram pH de 6,8 para filmes a base $\mathrm{CMC}$ impressos com extrato etanólico do mesocarpo de romã. Portanto, pode-se considerar aceitável o pH encontrado. 
Tabela 22 - pH de superfície dos filmes de desintegração oral à base de amido prégelatinizado (Amido), carboximetilcelulose (CMC) e hidroxipropil metilcelulose (HPMC), sem e com incorporação de extrato etanólico obtido do resíduo industrial de camu-camu (EERCC).

\begin{tabular}{lll}
\hline Cencc $_{\text {enc }}$ & Macromolécula & pH de superfície \\
\hline 0 & Amido & $6,61 \pm 0,05^{\mathrm{aA}}$ \\
& CMC & $6,58 \pm 0,12^{\mathrm{aA}}$ \\
30 & HPMC & $6,60 \pm 0,14^{\mathrm{aA}}$ \\
& Amido & $6,20 \pm 0,11^{\mathrm{bA}}$ \\
& CMC & $6,20 \pm 0,15^{\mathrm{bB}}$ \\
& HPMC & $6,36 \pm 0,12^{\mathrm{bB}}$
\end{tabular}

Nota: $C_{\text {EERCC }}=$ Concentração de extrato etanólico obtido do resíduo industrial de camu-camu (g EERCC $/ 100 \mathrm{~g}$ solução filmogênica); Letras minúsculas diferentes para filmes com a mesma macromolécula sem e com incorporação de EERCC diferem entre si ao nível de 5\% de significância pelo teste Duncan. Letras maiúsculas diferentes na mesma coluna para filmes com a mesma $\mathrm{C}_{\text {EERCC }}$ diferem entre si ao nível de $5 \%$ de significância pelo teste Duncan.

\subsection{4 Ângulo de contato}

Na Tabela 23 pode-se observar os resultados obtidos de ângulo de contato para filmes de desintegração oral à base de amido pré-gelatinizado (Amido), carboximetilcelulose (CMC) e hidroxipropil metilcelulose (HPMC) com e sem adição de extrato do resíduo industrial de camu-camu. De acordo com Arkles (2006), valores inferiores a $90^{\circ}$ para ângulo de contato indicam uma superfície hidrofílica, enquanto valores maiores $\left(\theta>90^{\circ}\right)$ são característicos de superfícies hidrofóbicas. Em relação aos filmes controles, o filme a base de CMC foi o que apresentou menor ângulo de contato, ou seja, maior hidrofilicidade, característica importante para desintegração oral. Porém a adição do EERCC resultou em um ângulo de contato maior, ou seja, um filme menos hidrofílico. Possivelmente, esse resultado está relacionado com o aumento de rugosidade na superfície do filme. Para as demais macromoléculas (amido e HPMC), a adição de extrato não resultou em alterações significativas, e os ângulos de contatos de todos os FDOs incorporados com ERCC não apresentam diferenças significativas entre si. 
Tabela 23 - Ângulo de contato dos filmes de desintegração oral de amido pré-gelatinizado (Amido), carboximetilcelulose (CMC) e hidroxipropil metilcelulose (HPMC), sem e com incorporação de extrato etanólico obtido do resíduo industrial de camu-camu (EERCC).

\begin{tabular}{lll}
\hline C $_{\text {eercc }}$ & Macromolécula & Ângulo de contato $\left(^{\circ}\right)$ \\
\hline 0 & Amido & $67,71 \pm 7,01^{\mathrm{aA}}$ \\
& CMC & $49,94 \pm 8,33^{\mathrm{aB}}$ \\
30 & HPMC & $66,52 \pm 4,10^{\mathrm{aA}}$ \\
& Amido & $74,40 \pm 13,52^{\mathrm{aA}}$ \\
& CMC & $70,09 \pm 3,69^{\mathrm{bA}}$ \\
& HPMC & $60,93 \pm 3,50^{\mathrm{aA}}$ \\
\hline
\end{tabular}

Nota: $C_{\text {EERCC }}=$ Concentração de extrato etanólico obtido do resíduo industrial de camu-camu (g EERCC $/ 100 \mathrm{~g}$ solução filmogênica); Letras minúsculas diferentes para filmes com a mesma macromolécula sem e com incorporação de EERCC diferem entre si ao nível de 5\% de significância pelo teste Duncan. Letras maiúsculas diferentes na mesma coluna para filmes com a mesma $\mathrm{C}_{\text {EERCC }}$ diferem entre si ao nível de $5 \%$ de significância pelo teste Duncan.

Garcia et al. (2018) estudando diferentes formulações de filmes de desintegração oral incorporados com camu-camu em pó (polpa seca por spray dryer) obtiveram valor de $86^{\circ}$ para o FDO 100\% gelatina, 45 para FDO 100\% amido prégelatinizado e valores intermediários para blendas das macromoléculas, concluindo que o aumento da concentração de amido nas formulações reduziu o ângulo de contato, indicando aumento nas características hidrofílicas dos FDOs com maiores concentrações de amido.

Alopaeus et al. (2020) prepararam filmes bucais utilizando um copolímero de enxerto (Soluplus $\AA$ ) como solubilizante e formador de filme e suplementados com polímeros hidroxipropil metilcelulose (HPMC) ou hidroxipropilamido de ervilha modificado (Lycoat $\AA$ ) para aumentar a hidrofilicidade e obter propriedades mucoadesivas. O menor ângulo de contato foi observado para os filmes com Soluplus $\AA^{\circledR}$ à base de HPMC $\left(24,5^{\circ} \pm 6,9\right)$, enquanto filmes apenas com Soluplus ${ }^{\circledR}$ (sem HPMC) o ângulo de contato foi de 52,0 $\pm 2,9$.

Tedesco et al. (2021) também encontraram valores próximos aos obtidos na

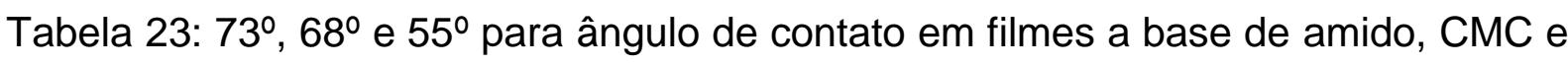
HPMC, respectivamente, incorporados com extrato do resíduo de acerola. 


\subsubsection{Espectroscopia de Infravermelho com Transformada de Fourier}

A espectroscopia FTIR foi utilizada para investigar as interações intermoleculares e alterações estruturais dentro da matriz dos filmes em nível molecular através da análise espectral (Figura 13).

Como visto em Villacrés et al. (2014) filmes de amido possuem bandas características: $3100-3600 \mathrm{~cm}^{-1}$, com minímo de $3324 \mathrm{~cm}^{-1}$, que correspondem ao estiramento de grupos $\mathrm{O}-\mathrm{H}$ livres ou ligados através de ligações de hidrogênio intra e intermolecular. Outra banda típica, em $2929 \mathrm{~cm}^{-1}$, está associada ao estiramento C$\mathrm{H}$ no anel de glicose. Os picos entre 1016 e $1078 \mathrm{~cm}^{-1}$ são característicos do estiramento C-O do anel anidroglicose. Outra banda típica entre 920 e $1145 \mathrm{~cm}-1$ está associada ao estiramento da ligação C-O (ZHANG \& HAN, 2006).

De acordo com Fiori et al. (2019) filmes de CMC possuem bandas características em: $3360 \mathrm{~cm}^{-1}$ que está associada a estiramento da ligação $\mathrm{O}-\mathrm{H}$, a banda próxima de $2880 \mathrm{~cm}^{-1}$ é atribuída as ligações $\mathrm{C}-\mathrm{H}$, sendo a banda mais forte na CMC em torno de 1010 e $1100 \mathrm{~cm}^{-1}$ correspondente ao estiramento das ligações C-O presentes no esqueleto de polissacarídeos. A banda do grupo assimétrico COOpode ser observada em $1590 \mathrm{~cm}^{-1}$, e as bandas em 1425 e $1325 \mathrm{~cm}^{-1}$ são atribuídas a conformação tesoura $-\mathrm{CH} 2$ e vibração de flexão do grupo $-\mathrm{OH}$, respectivamente (CHOl et al., 2017).

O espectro para os filmes de HPMC (Figura 13a) apresenta bandas características da macromolécula, como descrito por Palla-Papavlu et al. (2014) ao caracterizar filmes de etilcelulose e hidroxipropil metilcelulose. O pico em $3465 \mathrm{~cm}^{-1}$ está associado ao estiramento do grupo $\mathrm{O}-\mathrm{H}$, enquanto o pico próximo de $2900 \mathrm{~cm}^{-1}$ ao estiramento $\mathrm{C}-\mathrm{H}$ e grupo metil. O pico em $1460 \mathrm{~cm}^{-1}$ e a banda entre $900-1300$ $\mathrm{cm}^{-1}$ estão associados aos estiramentos $\mathrm{C}-\mathrm{H}$ e C-O-C, respectivamente.

De um modo geral, a adição do EERCC nos filmes não resultou em alterações nas bandas específicas características das macromoléculas, sugerindo que o extrato adicionado não acarretou em mudanças estrututais nas matrizes poliméricas a nível molecular. 
Figura 13. Espectros de absorção de infravermelho de filmes de desintegração oral à base de: (a) amido pré-gelatinizado (Amido), (b) carboximetilcelulose (CMC) e (c) hidroxipropil metilcelulose (HPMC), sem e com incorporação de extrato etanólico obtido do resíduo industrial de camu-camu (EERCC).

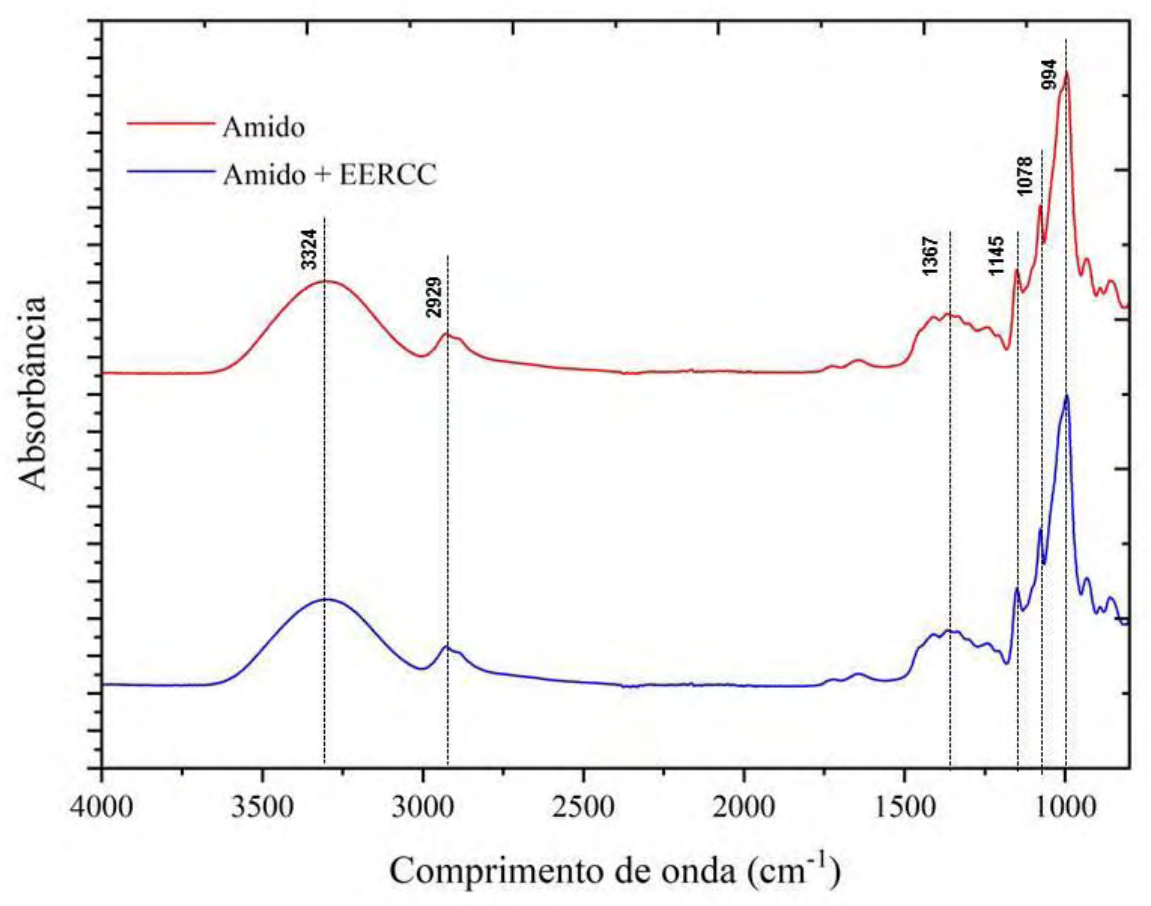

(a) 


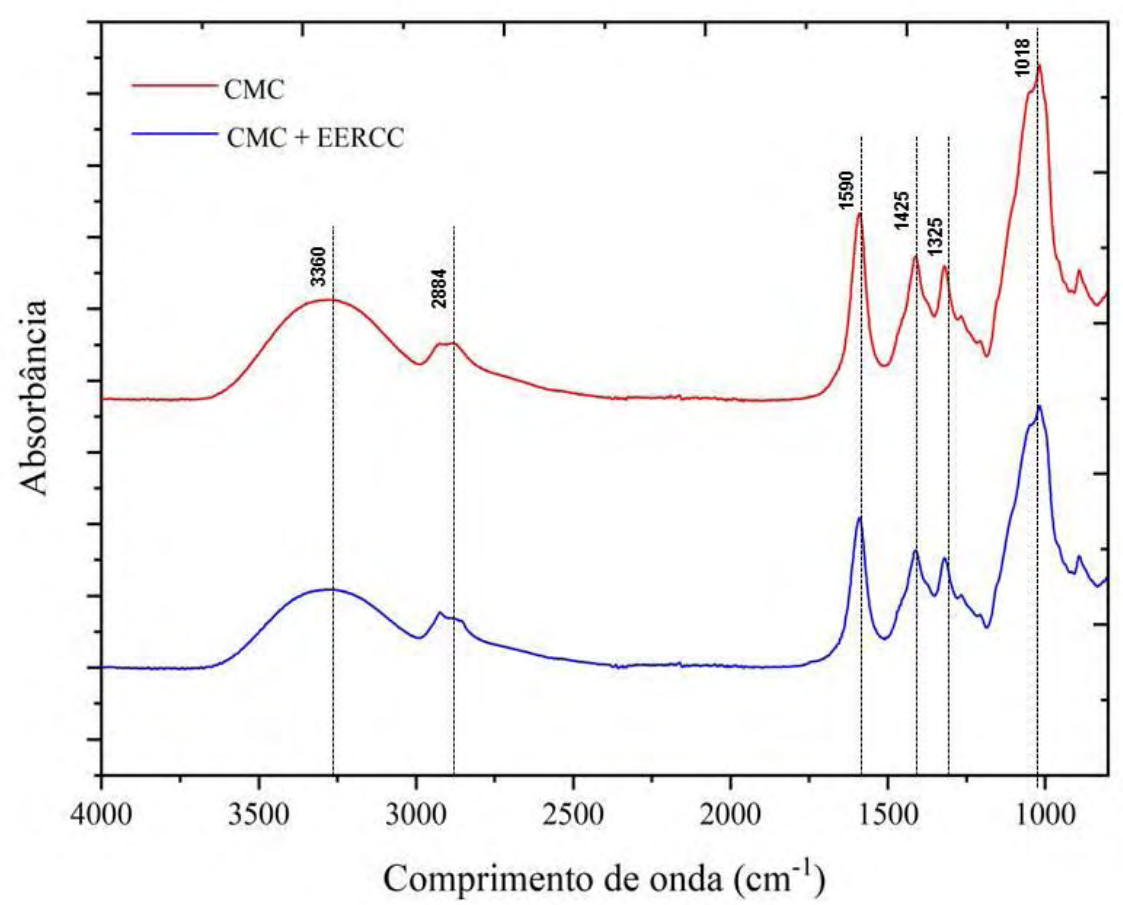

(b)

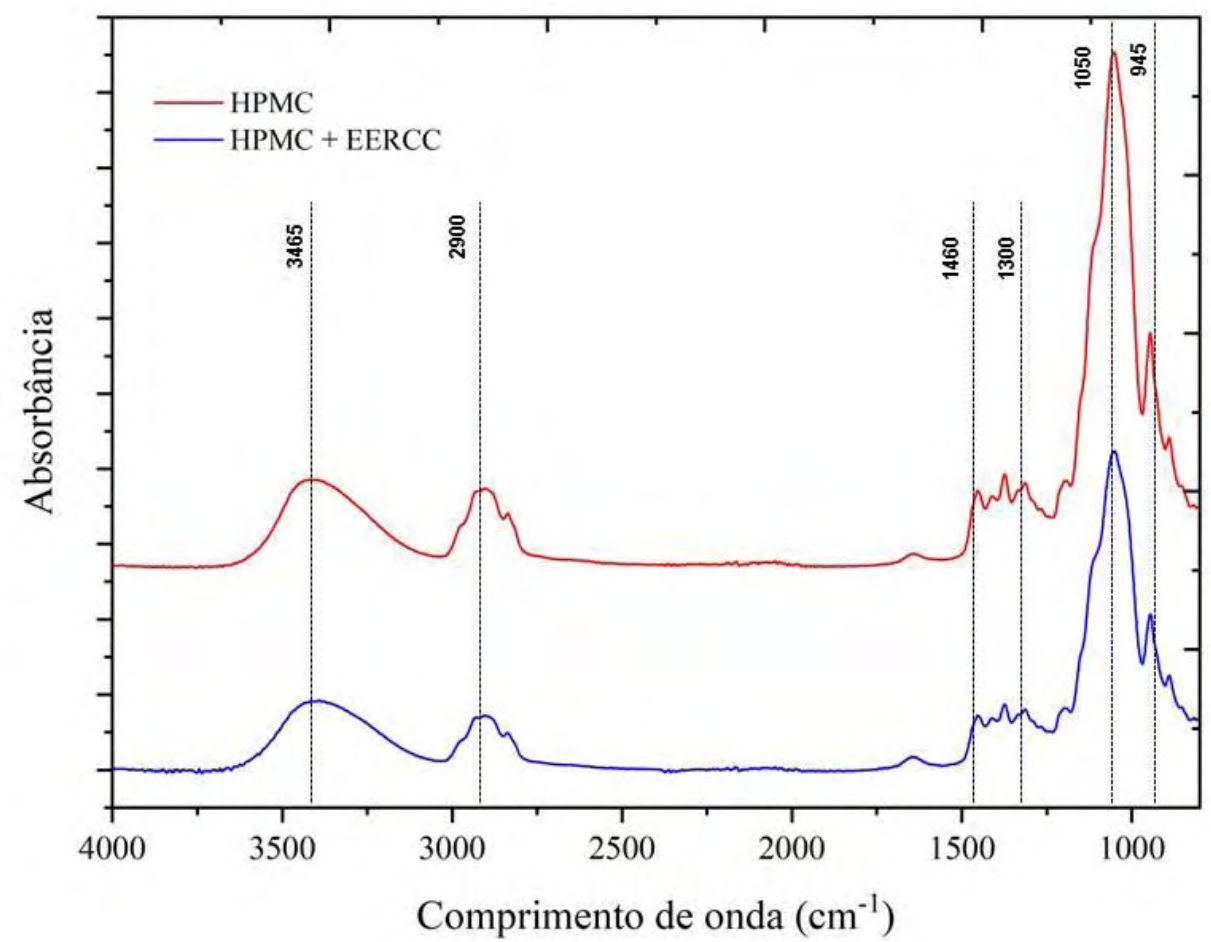

(c)

Fonte: Própria autoria 


\subsubsection{Microscopia de força atômica}

A avaliação do efeito da incorporação do extrato do resíduo do camu-camu na topografia dos filmes de desintegração oral pode ser observada através das imagens 2D (Figura 14), 3D (Figura 15) e valores de rugosidade média (Ra) (Tabela 24). A adição do EERCC acarretou em alterações da rugosidade apenas no FDO a base de $\mathrm{CMC}$, que apresentou um aumento de cerca de 50\%. De modo geral, avaliando as micrografias e os valores de rugosidade média dos FDOs com as diferentes macromoléculas, é significativa a diferença de rugosidades entre eles, sendo os FDOs à base amido (Figuras 14 a e a', Figuras 15 a e a') os que apresentaram superfície mais rugosa e o HPMC (Figuras $14 \mathrm{c} \mathrm{e} \mathrm{c}$ ', Figuras $15 \mathrm{c}$ e c') a mais lisa.

Li et al. (2021) encontraram resultados similares quanto à rugosidade no estudo de filmes comestíveis à base de $\mathrm{CMC}$ com mucilagem de inhame e nanopartículas de $\mathrm{ZnO}$; para o filme controle de CMC obtiveram rugosidade média de 26,6nm, e com a adição da mucilagem e das nanopartículas de $\mathrm{ZnO}$ os valores de rugosidade foram superiores que variaram entre 59,40-198,3nm dependo da formulação.

Erbil et al. (2003) relacionaram a rugosidade da superfície de um material com sua hidrofobicidade, mostrando que quanto maior a rugosidade, maior a hidrofobicidade, uma vez que a rugosidade aumenta a fração de ar aprisionado na superfície, aumentando assim o ângulo de contato com a água. Com isso, é possível correlacionar os resultados obtidos de ângulo de contato (Tabela 23) com os resultados de rugosidade média podendo observar tanto o aumento da rugosidade do FDO a base de CMC, bem como aumento do seu ângulo de contato após incorporação de EERCC. Assim, como não foram observadas diferenças significativas nos ângulos de contato para os FDOs com as demais macromoléculas, também não se observou diferença significativa para as rugosidades desses FDOs (amido e HPMC). 
Tabela 24 - Rugosidade média $(\mathrm{Ra})$ dos filmes de desintegração oral à base de amido prégelatinizado (Amido), carboximetilcelulose (CMC) e hidroxipropilmetilcelulose (HPMC) sem com e incorporação de extrato etanólico obtido do resíduo industrial de camu-camu (EERCC).

\begin{tabular}{lll}
\hline CeERCC & Macromolécula & $\mathbf{R a}(\mathbf{n m})$ \\
\hline 0 & Amido & $126,93 \pm 19,56^{\mathrm{aA}}$ \\
& CMC & $20,36 \pm 2,24^{\mathrm{aB}}$ \\
30 & HPMC & $4,51 \pm 1,20^{\mathrm{aC}}$ \\
& Amido & $144,91 \pm 14,14^{\mathrm{aA}}$ \\
& CMC & $44,02 \pm 3,45^{\mathrm{bB}}$ \\
& HPMC & $5,75 \pm 0,62^{\mathrm{aC}}$
\end{tabular}

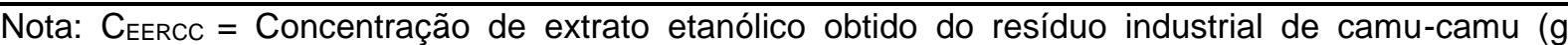
EERCC $/ 100 \mathrm{~g}$ solução filmogênica); Letras minúsculas diferentes para filmes com a mesma macromolécula sem e com incorporação de EERCC diferem entre si ao nível de $5 \%$ de significância pelo teste Duncan. Letras maiúsculas diferentes na mesma coluna para filmes com a mesma $\mathrm{C}_{\text {EERCC }}$ diferem entre si ao nível de $5 \%$ de significância pelo teste Duncan. 
Figura 14. Microscopia de força atômica 2D da superfície dos filmes de desintegração oral à base de diferentes macromoléculas sem e com incorporação de extrato etanólico obtido do resíduo industrial de camu-camu (EERCC): (a) amido, (a') amido + EERCC; (b) carboximetilcelulose (CMC), (b') CMC + EERCC; (c) hidroxipropil metilcelulose (HPMC), (c') HPMC + EERCC.

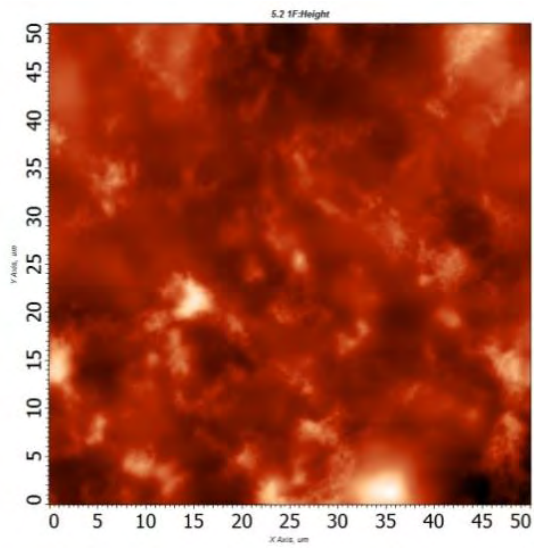

(a)

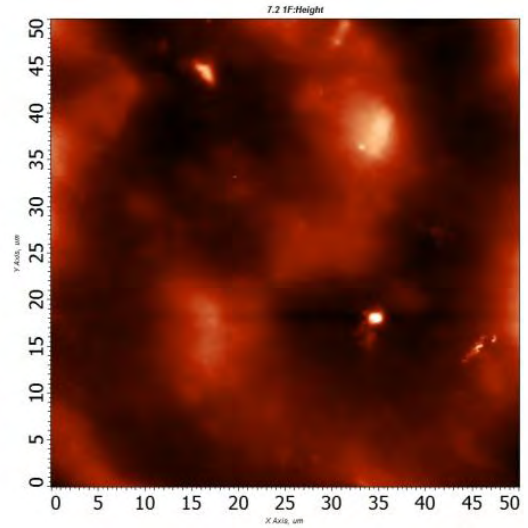

(b)

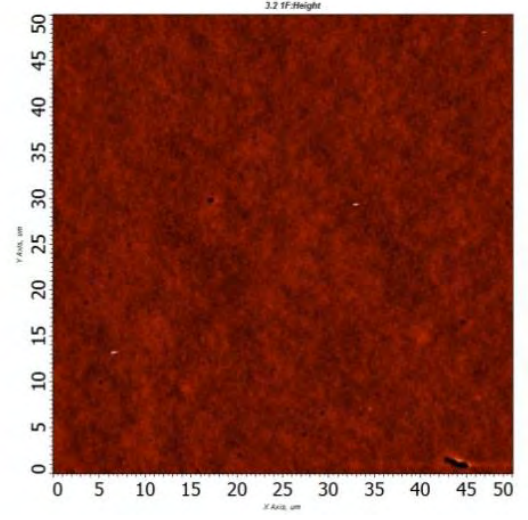

(c)
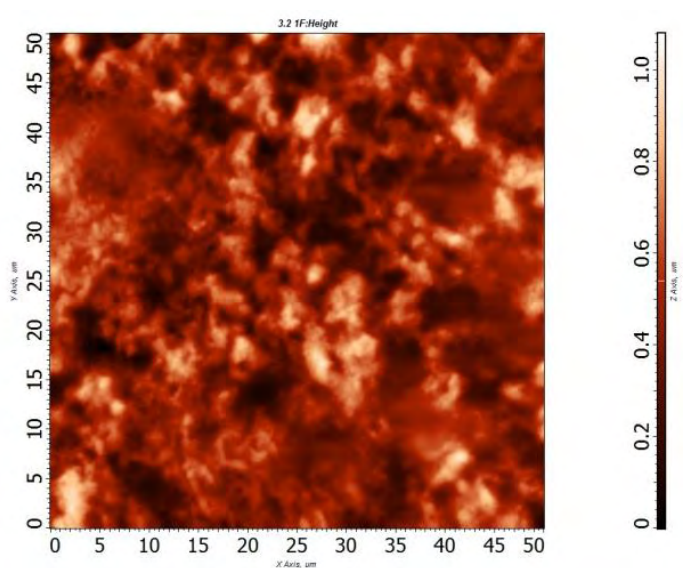

(a')

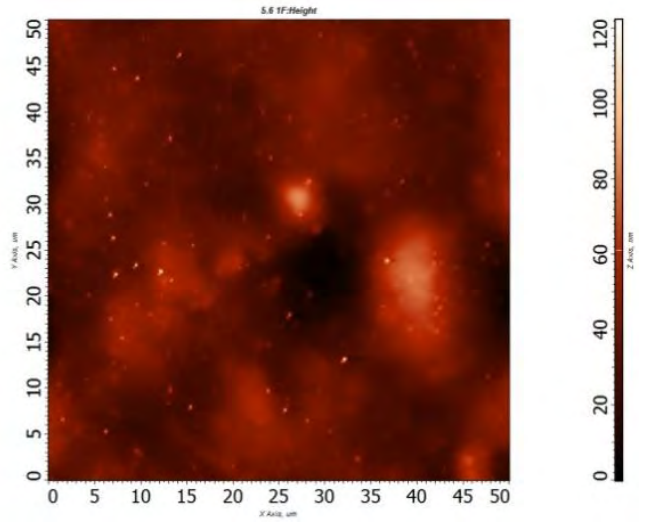

(b')

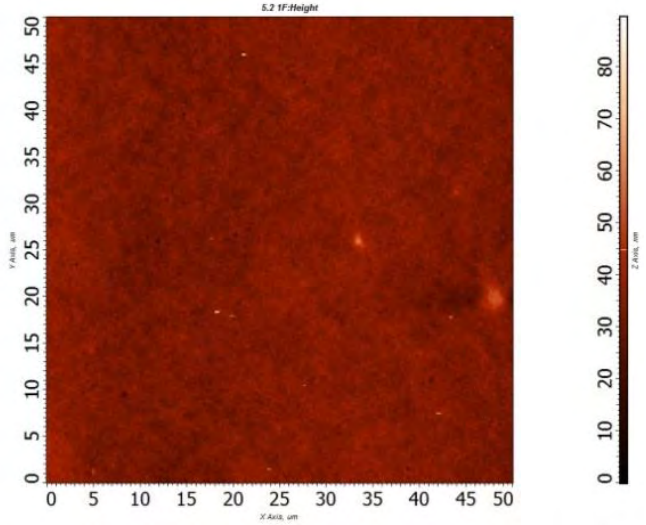

$\left(c^{\prime}\right)$

Fonte: Própria autoria

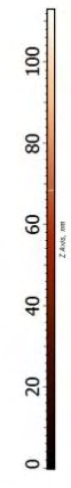


Figura 15. Microscopia de força atômica 3D da superfície de filmes de desintegração oral à base de diferentes macromoléculas sem e com incorporação de extrato etanólico obtido do resíduo industrial de camu-camu (EERCC): (a) amido, (a') amido + EERCC; (b) carboximetilcelulose (CMC), (b') CMC + EERCC; (c) hidroxipropil metilcelulose (HPMC), (c') HPMC + EERCC.

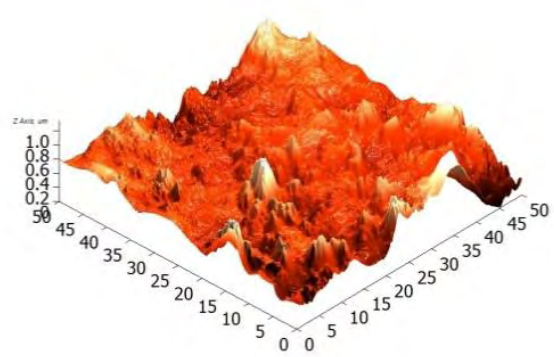

(a)

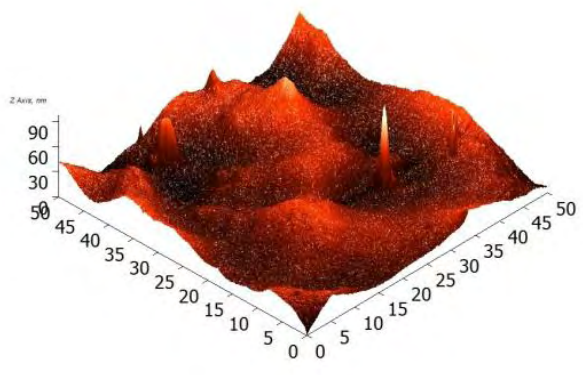

(b)

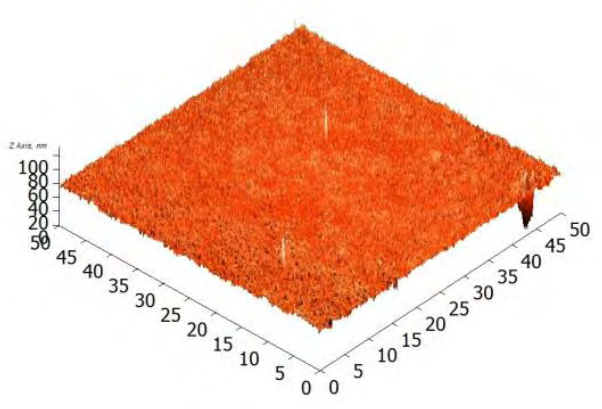

(c)

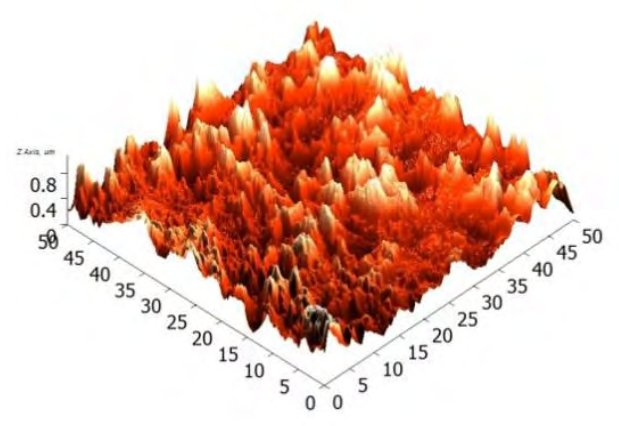

(a')

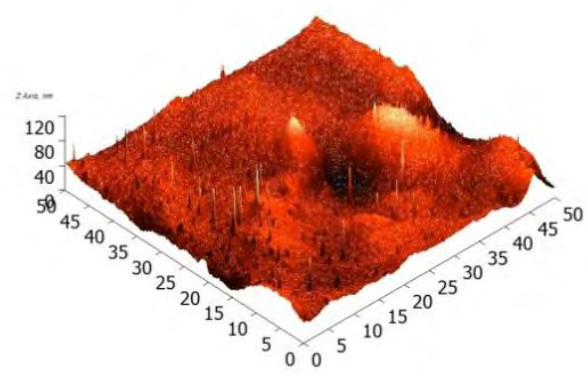

(b')

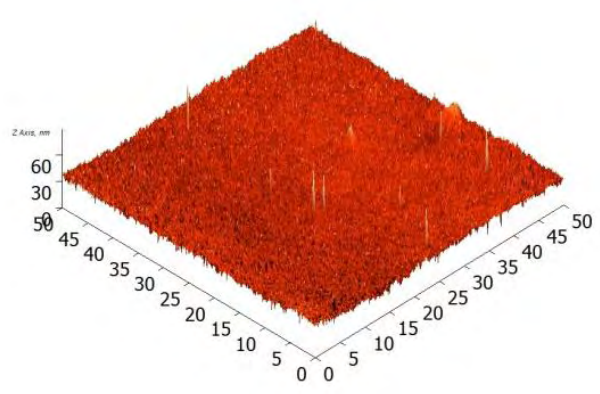

$\left(c^{\prime}\right)$

Fonte: Própria autoria 


\subsubsection{Tempo de desintegração}

Avaliando-se os dados da Tabela 25, apenas o FDO a base de HPMC sofreu alteração significativa, a adição de EERCC provocou redução significativa do tempo de desintegração. Ainda que essa redução tenha ocorrido, o FDO a base de HPMC foi o que apresentou maior tempo de desintegração. De uma maneira geral, comparando-se as macromoléculas, os filmes à base de CMC (sem e com adição de EERCC) apresentaram o menor tempo de desintegração. É possível que isso esteja relacionado com as espessuras dos FDOs a base de CMC, as quais foram as menores entre os filmes das três macromoléculas (Tabela 20). Como visto em Rimkiene et al. (2021) que estudaram filmes sublinguais a base de CMC com extrato etanólico de Ginkgo biloba L. e obtiveram aumento da espessura conforme aumento da concentração de extrato e afirmaram que filmes mais espessos são mais resistentes à penetração de água do que os filmes com espessura reduzida e, portanto, tempos de desintegração mais longos.

Abdelbary et al. (2014) avaliaram FDO a base de CMC com incorporação de dicloridrato de flupentixol para tratar a depressão com ansiedade. Nas formulações desenvolvidas variou-se as concentrações de CMC (1, 2 e 4\%), obtendo-se filmes com $0.09 \pm 0.1,0.18 \pm 0.06$ e $0.27 \pm 0.22 \mathrm{~mm}$ de espessura e tempos de desitegração de $50.3 \pm 0.56,66.0 \pm 0.91$ e $120.0 \pm 0.82 \mathrm{~s}$, respectivamente. Ou seja, filmes com espessuras menores resultaram em menor tempo de desintegração.

Tabela 25 - Tempo de desintegração dos filmes de desintegração oral incorporados com extrato etanólico obtido do resíduo industrial de camu-camu (EERCC).

\begin{tabular}{ccc}
\hline CeercC & Macromolécula & Tempo de desintegração (s) \\
\hline \multirow{2}{*}{0} & Amido & $60 \pm 9^{\mathrm{aA}}$ \\
& CMC & $48 \pm 4^{\mathrm{aA}}$ \\
& HPMC & $119 \pm 24^{\mathrm{aB}}$ \\
\multirow{2}{*}{30} & Amido & $62 \pm 4^{\mathrm{aB}}$ \\
& CMC & $50 \pm 5^{\mathrm{aC}}$ \\
& HPMC & $92 \pm 16^{\mathrm{bA}}$
\end{tabular}

Nota: $C_{\text {EERCC }}=$ Concentração de extrato etanólico obtido do resíduo industrial de camu-camu (g EERCC $/ 100 \mathrm{~g}$ solução filmogênica); letras minúsculas diferentes para filmes com a mesma macromolécula sem e com incorporação de EERCC diferem entre si ao nível de 5\% de significância pelo teste Duncan. Letras maiúsculas diferentes para filmes com a mesma $\mathrm{C}_{\text {EERCC }}$ diferem entre si ao nível de $5 \%$ de significância pelo teste Duncan. 
De acordo com a farmacopeia europeia (Ph.Eur, 2017) o tempo limite de desintegração requerido para comprimidos orodispersíveis é de 180s. Segundo Jyoti et al. (2011) filmes com tempo máximo de desintegração de 60s foram classificados como rápidos. Assim, considerando-se os tempos de desintegração observados na Tabela 25, os FDOs à base de amido e CMC são classificados como filmes de rápida desintegração.

De um modo geral, os tempos de desintegração dos filmes com e sem adição de EERCC foram superiores aos observados na literatura. Bodini et al. (2019) observaram para filmes de amido com HPMC com espessuras próximas das utilizadas no presente trabalho $(60 \pm 6 \mu \mathrm{m})$ tempos inferiores a 35 segundos.

Tedesco et al. (2017) observaram valores entre 16,96 e 27,41s para filmes de desintegração oral a base de HPMC e gelatina com espessura média de $50 \pm 5 \mu \mathrm{m}$ incorporados com diferentes concentrações de extrato etanólico da pele de amendoim.

Auda et al. (2019) observaram tempos de desintegração entre $38 \pm 3$ e $92 \pm 3$ s para filmes orais de desintegração rápida a base de HPMC incorporados com isradipina, um bloqueador de cálcio comumente utilizado para hipertensão.

Garsuch \& Breitkreutz (2010) compararam FDOs produzidos a base de CMC e HPMC incorporados com cafeína, e também observaram menor tempo de desintegração para os FDOs a base de CMC (<10 s).

\subsubsection{Perfil de liberação in vitro}

Os perfis de liberação in vitro de compostos fenólicos dos FDOs incorporados com EERCC (Figura 16), indicaram que a maior liberação dos compostos fenólicos ocorreu no FDO à base de $\mathrm{CMC}$ no tempo de 30 minutos, sendo que com 15 minutos já ocorria liberação de cerca de 83\%. Enquanto que para o FDO a base de HPMC após 30 minutos apresentou liberação de cerca de $70 \%$ de compostos feenólicos e com 1 hora a liberação máxima atingida foi de $83 \%$. Para o FDO a base de amido a liberação máxima alcançada com 1 hora foi de 67,5\%. De acordo com Bodini et al. (2020) uma matriz constituída principalmente por amido (80\%), não se solubiliza em meio aquoso dificultando a desintegração do filme e, portanto, interfere na liberação do princípio ativo. 
Castro et al. (2017) em estudo visando a otimização de filmes orais a base de CMC e gelatina para administração de cafeína verificaram que o $\mathrm{CMC}$ foi o mais indicado para liberação imediata, uma vez que a liberação máxima de cafeína $(81,1 \%$ $\pm 2,14$ ) ocorreu após 4 minutos.

Tedesco; Monaco-Lourenco; Carvalho (2017) estudando o perfil de liberação de composto fenólicos em filmes de HPMC incorporados com extrato de casca de amendoim observaram liberação máxima de compostos fenólicos totais em 5 min. Alhayall et al. (2019) em filmes de HPMC com silodosina, para o tratamento sintomático da hiperplasia prostática benigna em homens, alcançaram liberação de $80 \%$ do principio ativo em 10 minutos.

Figura 16. Perfil de liberação in vitro de compostos fenólicos de filme de desintegração oral (FDO) à base de (a) Amido pré gelatinizado, (b) Carboximetilcelulose (CMC) e (c) Hidroxipropil metilcelulose (HPMC); todos com extrato etanólico obtido do resíduo industrial de camu-camu em concentração de $30 \mathrm{~g} / 100 \mathrm{~g}$ de solução filmogênica.

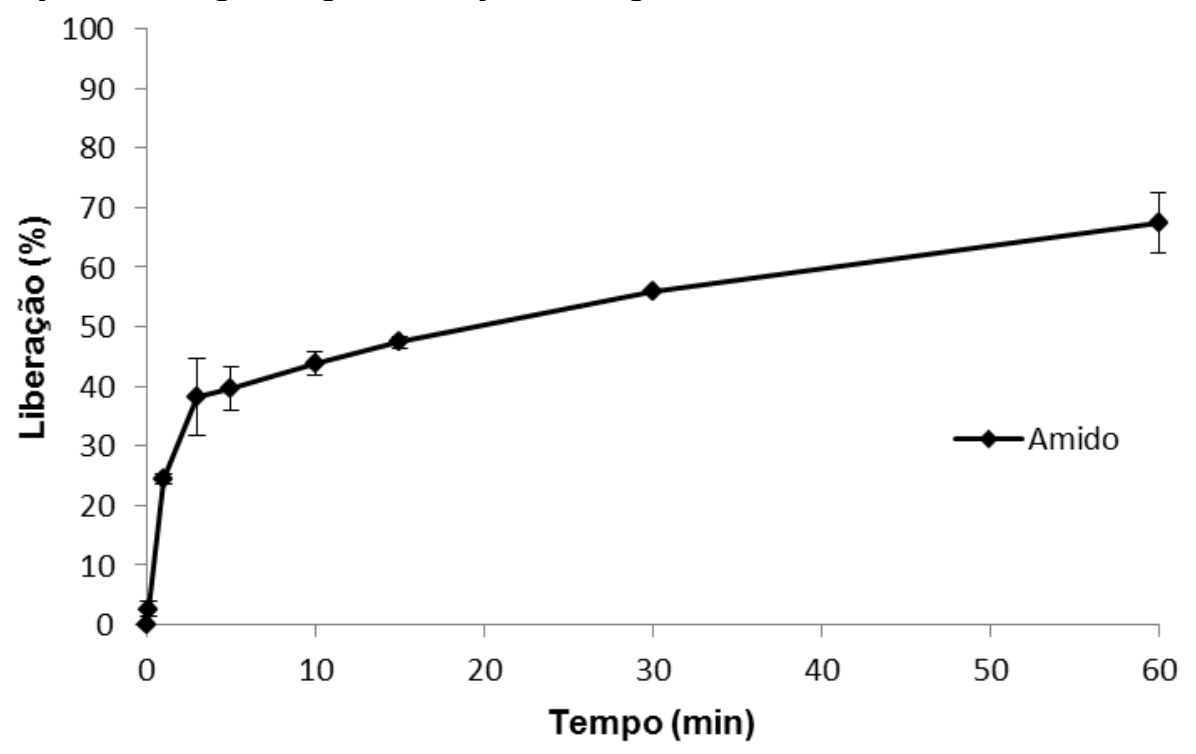

(a) 


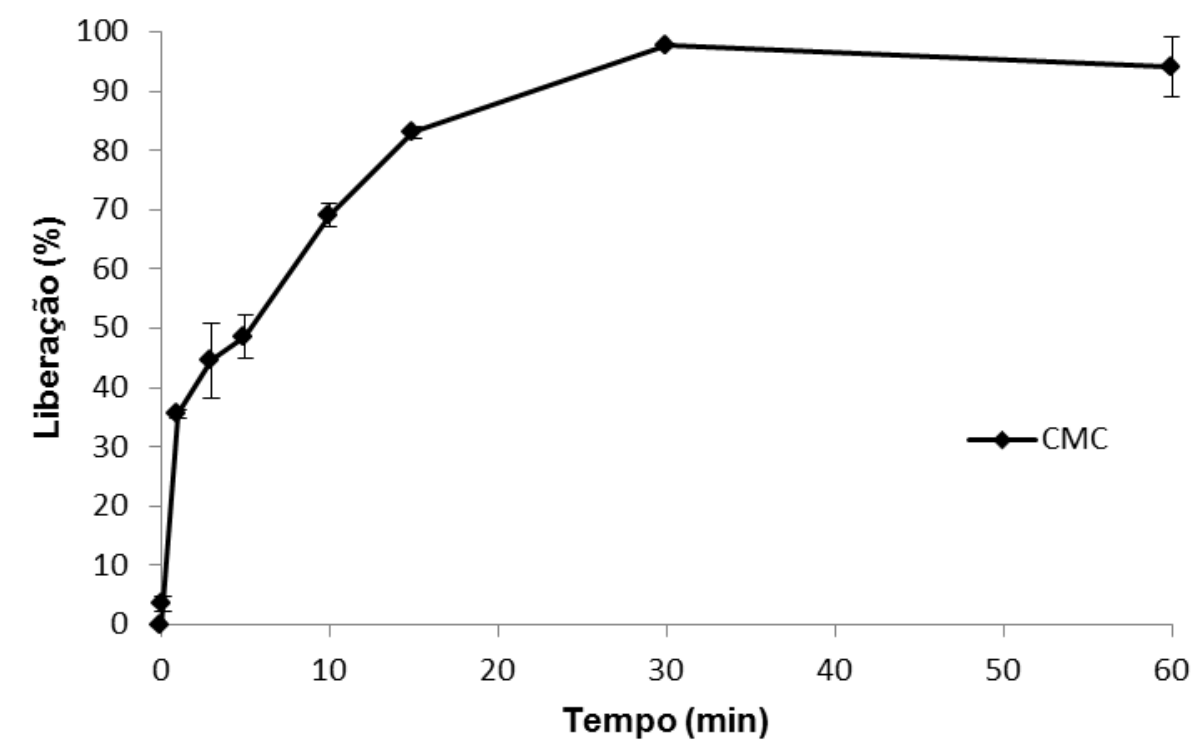

(b)

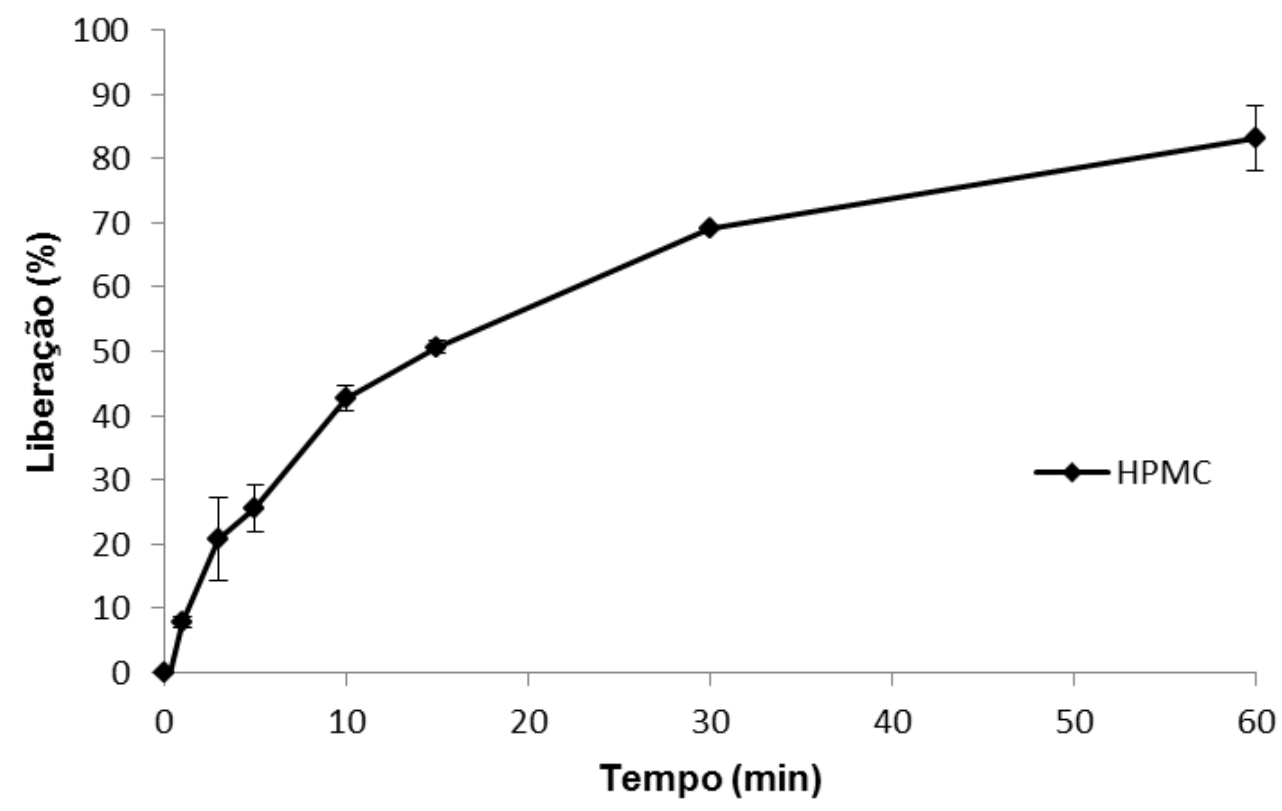

(c)

Fonte: Própria autoria

\subsubsection{Estabilidade}

Nas Figura 17 eFigura 18 pode-se observar a variação das concentrações de compostos fenólicos totais e da capacidade antioxidante nos filmes de desintegração 
ao longo de 20 semanas, armazenados em condição normal (25ㄷ e $60 \%$ UR) e acelerada $\left(40^{\circ} \mathrm{C}\right.$ e $\left.75 \% \mathrm{UR}\right)$.

Verificou-se, em ambas as condições de armazenamento, variações tanto da concentração de compostos fenólicos como da capacidade antioxidante (Figura 17 eFigura 18). Entretanto, não foi possível estabelecer uma correlação, as variações observadas podem estar relacionadas com a distribuição do extrato na matriz polimérica. Adicionalmente, as variações também podem estar associadas à extração dos compostos da matriz polimérica.

Tanto a quantificação de compostos fenólicos quanto a capacidade antioxidante não sofreram decaimento brusco no final do período de armazenagem (20 semanas) quando comparado ao valor inicial ( $\mathrm{Dia}$ ), indicando que os compostos ativos foram relativamente estáveis ao longo do período, isso pode ter ocorrido devido à estabilidade das matrizes poliméricas, ou ainda, devido ao armazenamento dos filmes embalados em papel alumínio.

Garcia et al. (2018) estudando estabilidade de filmes de camu-camu em pó a base de gelatina e amido, não embalados e armazenados a $30 \stackrel{\circ}{\circ}$ e $75 \%$ UR encontraram redução gradual da capacidade antioxidante pelo método DPPH• ao longo de 39 dias.

Shimoda et al. (2009) avaliando a estabilidade de filmes de desintegração oral com dexametasona armazenados por 24 semanas em embalagem de alumínio, obtiveram conteúdo de dexametasona estável, variando de $92,4 \%$ a $102,7 \%$ para condição normal de armazenamento $\left(25^{\circ} \mathrm{C}\right.$ e 50 a UR $60 \%$ ) e de $98,0 \%$ a $103,4 \%$ após o armazenamento em condição acelerada ( $40^{\circ} \mathrm{C}$ e UR $75 \%$ ).

Comparando-se os FDO de mesma macromolécula nas duas condições, podese afirmar que os filmes das três macromoléculas apresentaram comportamento semelhante ao longo do período, porém no último ponto (Dia 140) a condição acelerada acarretou em redução de cerca de $55 \%$ dos compostos fenólicos em relação ao ponto anterior (Dia 105) para o filme a base de CMC.

Aumentos significativos na quantificação dos compostos fenólicos e atividade antioxidante dos filmes a base de CMC e amido foram observados, é possível que as variações nas análises tenham ocorrido devido à heterogeneidade dos filmes, onde uma avaliação da distribuição dos compostos ativos torne-se necessário para estudos futuros. 
Figura 17. (a) Variação da concentração de compostos fenólicos totais ( $C_{\text {Fenólicos totais }}$ e (b) Variação da atividade antioxidante pelo método de ORAC ( $\mu$ mol Trolox Equivalente / grama de filme seco) em função do tempo de armazenamento a 25ㄷ e $60 \%$ UR nos filmes de desintegração a base de amido, CMC e HPMC com incorporação de extrato etanólico obtido do resíduo industrial de camu-camu.

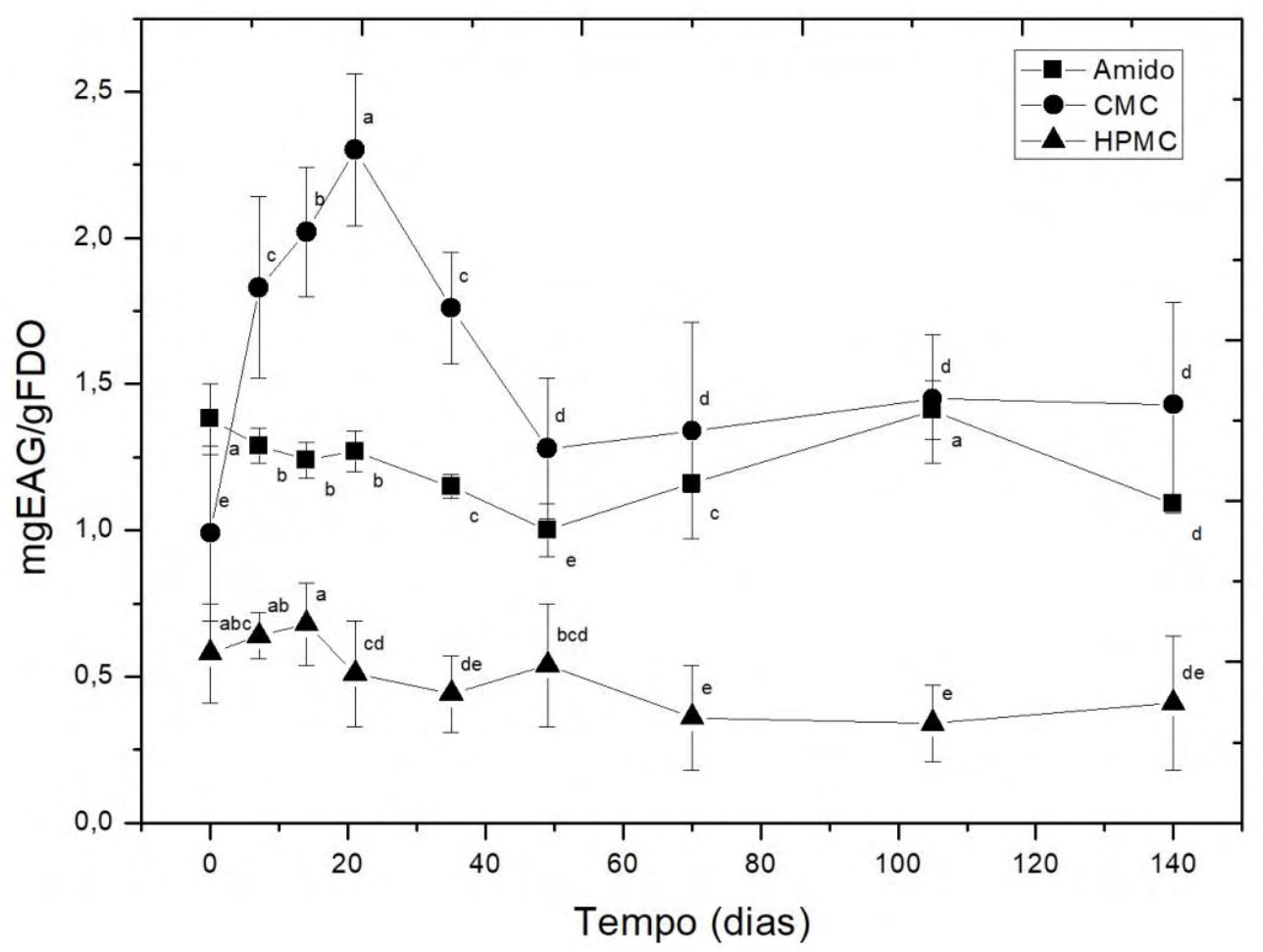

(a)

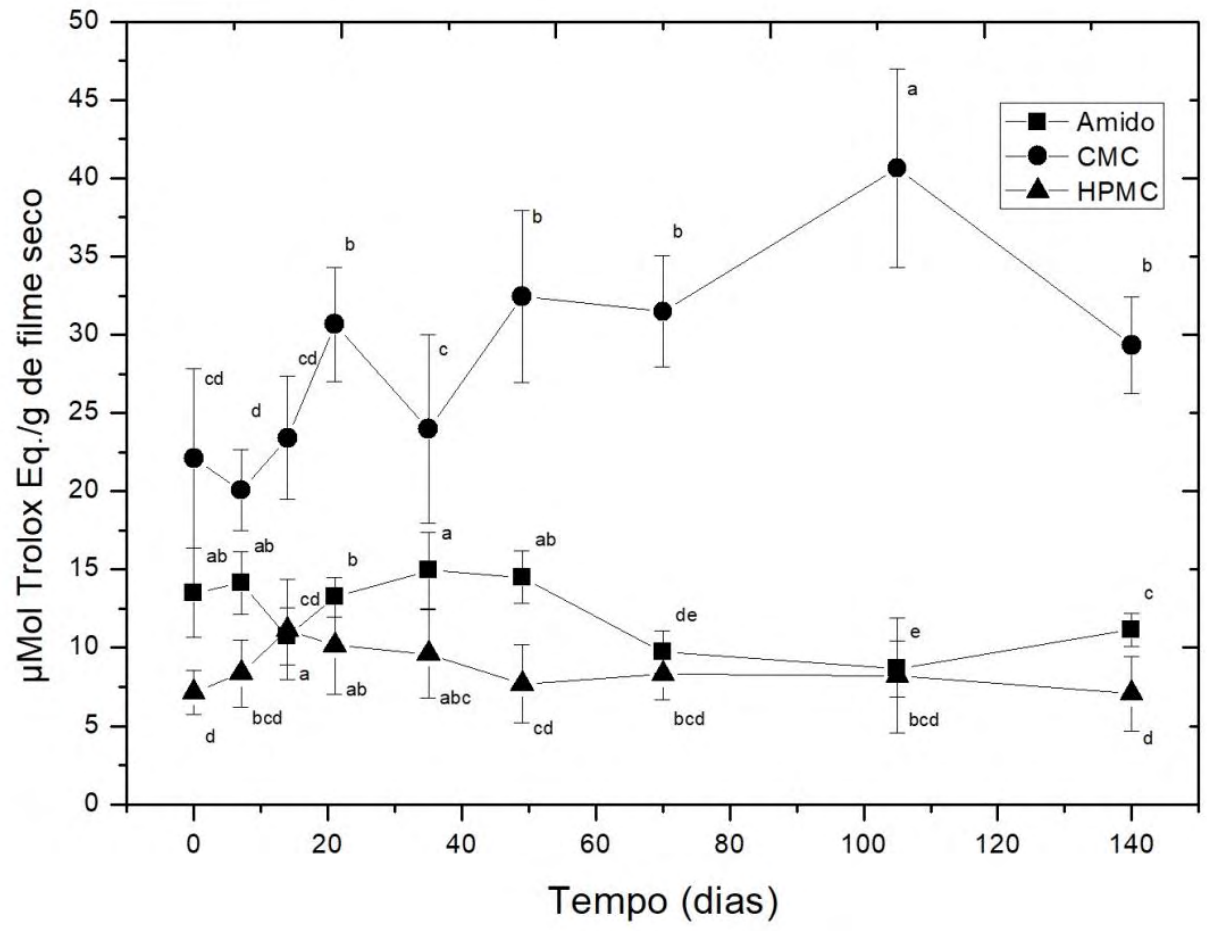

(b) 
Figura 18. (a) Variação da concentração de compostos fenólicos totais ( $\mathrm{C}_{\text {Fenólicos totais }}$ ) e (b) Variação da atividade antioxidante pelo método de ORAC ( $\mu \mathrm{mol}$ Trolox Equivalente / grama de filme seco) em função do tempo de armazenamento a $40^{\circ} \mathrm{C}$ e $75 \%$ UR nos filmes de desintegração a base de amido, CMC e HPMC com incorporação de extrato etanólico obtido do resíduo industrial de camu-camu.

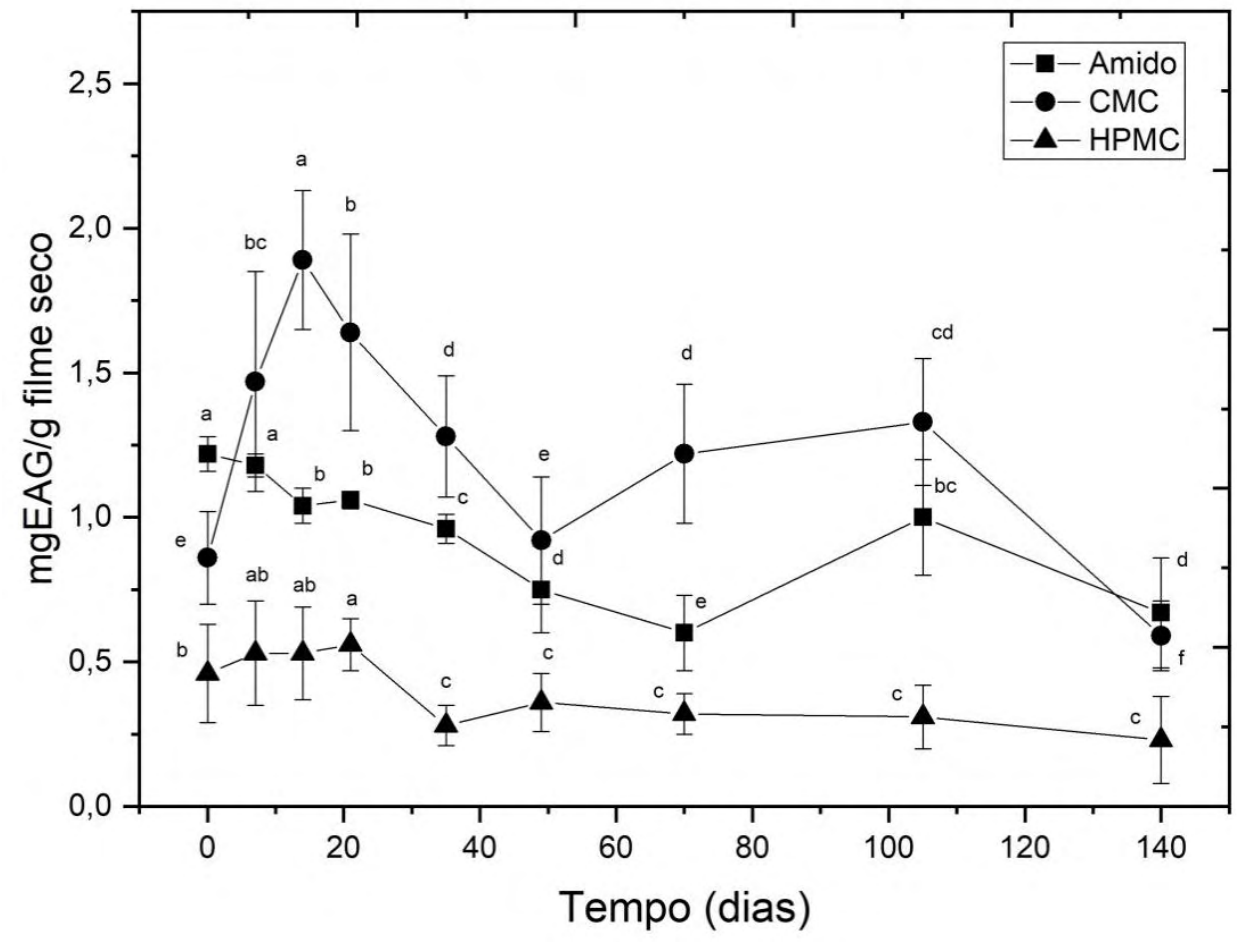

(a)

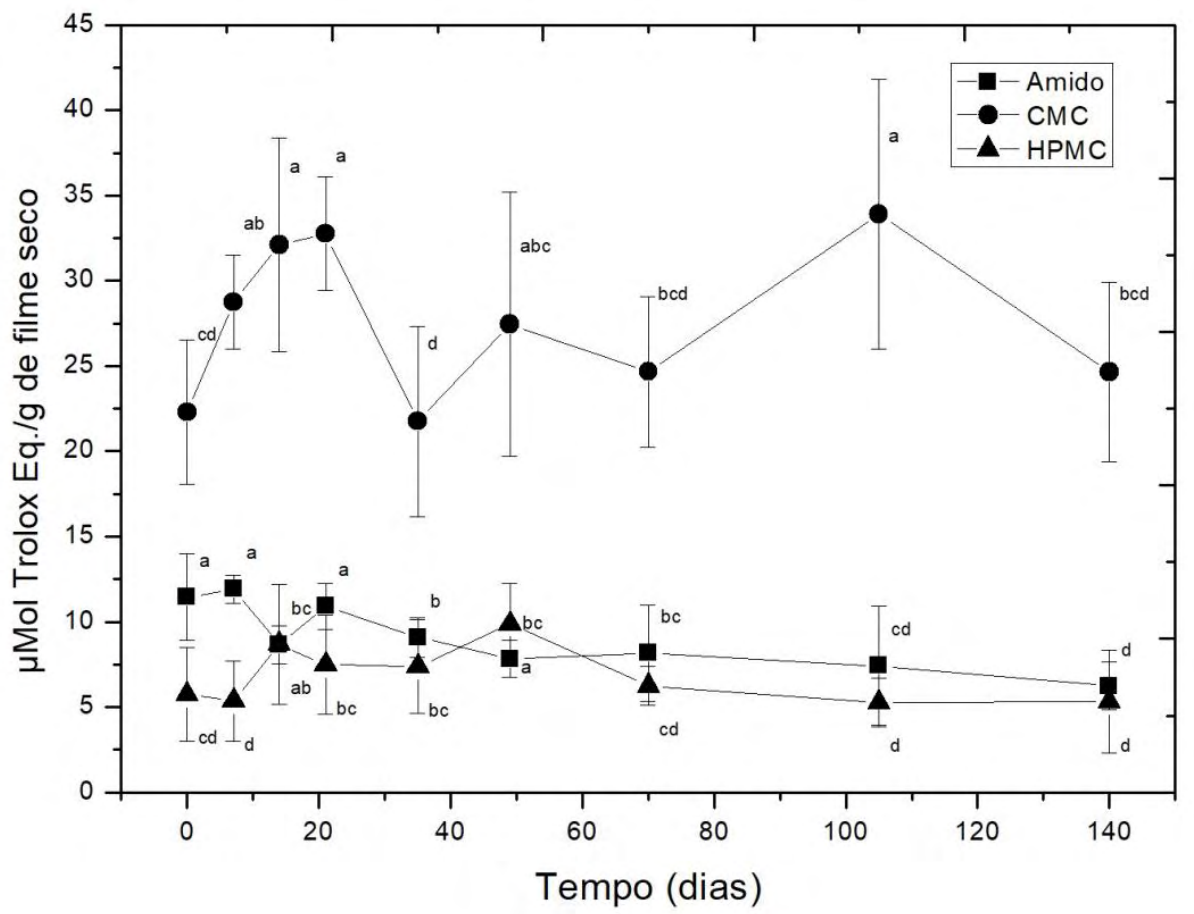

(b)

Fonte: Própria autoria 


\section{Conclusões}

Dentre os solventes testados, a solução hidroalcóolica $70 \%$ foi mais eficiente para extração de compostos fenólicos. Em relação ao tempo, verificou-se que extrações consecutivas com tempos de 5 minutos cada foram tão eficazes quanto extrações testadas em tempo maiores. O resíduo em pó do camu-camu apresentou teores de vitamina $\mathrm{C}$, flavonoides, compostos fenólicos e capacidade antioxidante, podendo, portanto ser aproveitado e utilizado como aditivo para funcionalizar alimentos e reduzir ou até substituir o uso de ingredientes sintéticos.

A incorporação do EERCC provocou alterações nas propriedades dos FDOs para os três polímeros utilizados, sendo o aumento do valor de croma $b^{*}$ e redução do $\mathrm{pH}$ esperados, devido a coloração e pH do extrato, respectivamente. Ainda que o $\mathrm{pH}$ tenha sido reduzido, os FDOs apresentaram pH próximo da neutralidade, o que assegura a ingestão sem irratibilidade na mucosa bucal. A incorporação do EERCC acarretou ainda na redução do tempo de desintegração do FDO a base de HPMC. E para os FDOs a base de CMC, mesmo com aumentos no ângulo de contato e na rugosidade média, apresentaram menor tempo de desintegração, menor tempo de liberação dos compostos fenólicos e maior teor de liberação de compostos fenólicos.

Em relação a estabilidade, embora durante 0 armazenamento tenha sido observada variações na concentração de compostos fenólicos, e da atividade antioxidante, após o período de armazenamento verificou-se que os FDOs ainda apresentaram concentração de compostos de fenólicos e atividade antioxidante.

Este trabalho pode contribuir com estudos futuros para incorporação de compostos ativos obtidos de outras fontes naturais e ainda sugere-se que a distribuição dos compostos ativos torne-se necessário, bem como a avaliação dos FDOs como veiculação de vitamina $\mathrm{C}$ obtida do resíduo de camu-camu. 


\section{Referências bibliográficas}

ABDELBARY, A. et al. Pharmaceutical and Pharmacokinetic Evaluation of a Novel Fast Dissolving Film Formulation of Flupentixol Dihydrochloride. AAPS PharmSciTech, v. 15, n. 6, p. 1603-1610, 2014.

AGUIAR, J. P. L. Table of Nutrient Composition of Amazonian Foods. Acta Amazonica, v. 26, n. 1/2, p. 121-126, 1996.

AKTER, M. S. et al. Nutritional compositions and health promoting phytochemicals of camu-camu (myrciaria dubia) fruit: A review. Food Research International, v. 44, n. 7, p. 1728-1732, 2011.

ALBUQUERQUE, J. G. D. E. et al. INTEGRAL UTILIZATION OF SERIGUELA FRUIT (Spondias purpurea L.) IN THE PRODUCTION OF COOKIES. Revista Brasileira de Fruticultura, v. 38, 2016.

ALHAYALI, A.; VUDDANDA, P. R.; VELAGA, S. Silodosin oral films: Development, physico-mechanical properties and in vitro dissolution studies in simulated saliva. Journal of Drug Delivery Science and Technology, v. 53, n. June, p. 101122, 2019.

ALOPAEUS, J. F. et al. Mucoadhesive buccal films based on a graft co-polymer - A mucin-retentive hydrogel scaffold. European Journal of Pharmaceutical Sciences, v. 142, p. 105142, 2020.

ALVES, R. E. et al. Camu-Camu (Myrciaria dubia Mc Vaugh): A Rich Natural Source of Vitamin C. Proceedings of the Interamerican Society for Tropical Horticulture, v. 46, n. October, p. 11-13, 2002.

ANSELMO, A. A. S. Resíduos de frutos amazônicos como ingredientes alternativos em rações extrusadas para juvenis de tambaqui, Colossoma macropomum. [s.I.] Universidade Federal do Amazonas, 2008.

ARAÚJO, P. A. DA C. et al. Caracterização de resíduo industrial de camu-camu e extração de compostos fenólicos por líquido pressurizadoCongresso Brasileiro de Ciência e Tecnologia de Alimentos. Sociedade Brasileira de Ciência e Tecnologia de Alimentos/SBCTA, , 2018. Disponível em: $<$ http://icongresso.pauta.itarget.com.br/arquivos/trabalhos_completos/pauta/9/3825_ 31072018_185806.pdf PP - Campinas>

Araújo, P. A. C. (2019). Estudo da cinética de secagem de resíduo industrial de camu-camu (Myrciaria dubia), caracterização e extração por líquido pressurizado de seus compostos ativos. Dissertação de Mestrado, Faculdade de Zootecnia e Engenharia de Alimentos, Universidade de São Paulo, Pirassununga. doi:10.11606/D.74.2019.tde-22102019-152424. Recuperado em 2021-09-20, de www.teses.usp.br

ARAVAMUDHAN, A. et al. Natural Polymers: Polysaccharides and Their Derivatives for Biomedical Applications. [s.I.] Elsevier Inc., 2014. 
ARKLES, B. Hydrophobicity, hydrophilicity and silanes: Water, water everywhere is the refrain from the rhyme of the ancient mariner and a concern of every modern coatings technologist. Pramana, n. Paint \& Coatings Industry, 1, 2006.

ATALLA, R. H. The Structures of Cellulose. MRS Proceedings, v. 197, n. January 2011, 1990.

AUDA, S. H. et al. hashe. Polymer Bulletin, v. 74, n. 10, p. 4041-4054, 2017.

AUDA, S. H. et al. Design, characterization and evaluation of oral fast dissolving polymeric films of isradipine inclusion complex. Polymer Bulletin, v. 76, n. 5, p. 24532469, 2019.

AZEVÊDO, J. C. S. DE. Características bioativas, funcionais e efeito protetor do resíduo desidratado de camu-camu (Myrciaria dubia H.B.K. (McVaugh)) sobre doenças degenerativas utilizando modelos in vivo C elegans. [s.l.] Universidade Federal do Rio Grande do Norte, 2015.

AZEVEDO, J. C. S. et al. Neuroprotective effects of dried camu-camu (Myrciaria dubia HBK McVaugh) residue in C. elegans. Food Research International, v. 73, p. 135$141,2014$.

BALA, R. et al. Orally dissolving strips: A new approach to oral drug delivery system. International journal of pharmaceutical investigation, v. 3, n. 2, p. 67-76, 2013.

BALLESTEROS, L. F. et al. Production and physicochemical properties of carboxymethyl cellulose films enriched with spent coffee grounds polysaccharides. International journal of biological macromolecules, v. 106, p. 647-655, jan. 2018.

BELBUCA. Buprenorphine Buccal Film. 2020. Disponível em:<https://www.belbuca.com/> Acesso em: 30 mar 2021.

BENVENUTTI, L. et al. NADES as potential solvents for anthocyanin and pectin extraction from Myrciaria cauliflora fruit by-product: In silico and experimental approaches for solvent selection. Journal of Molecular Liquids, v. 315, p. 113761, 2020.

BERTUZZI, M. A.; ARMADA, M.; GOTTIFREDI, J. C. Physicochemical characterization of starch based films. Journal of Food Engineering, v. 82, p. 17-25, 2007.

BISWAL, D. R.; SINGH, R. P. Characterisation of carboxymethyl cellulose and polyacrylamide graft copolymer. Carbohydrate Polymers, v. 57 , n. 4, p. 379-387, 2004.

BODINI, R. B. et al. Effect of starch and hydroxypropyl methylcellulose polymers on the properties of orally disintegrating films. Journal of Drug Delivery Science and Technology, v. 51, p. 403-410, jun. 2019. 
BODINI, R. B. et al. Antioxidant and anti-inflammatory properties of orally disintegrating films based on starch and hydroxypropyl methylcellulose incorporated with Cordia verbenacea (erva baleeira) extract. International Journal of Biological Macromolecules, v. 159, p. 714-724, 2020.

BORGES, A. F. et al. Oral films: Current status and future perspectives II - Intellectual property, technologies and market needs. Journal of Controlled Release, v. 206, p. 108-121, 2015.

BORGES, J. G. et al. Printing ethanol pomegranate extract in films by inkjet technology. Industrial Crops and Products, v. 140, p. 111643, 2019.

BORGES, J. G.; DE CARVALHO, R. A. Orally Disintegrating Films Containing Propolis: Properties and Release Profile. Journal of Pharmaceutical Sciences, v. 104, n. 4, p. 1431-1439, 2015.

BOURTOOM, T. Edible films and coatings: characteristics and properties. International Food Research Journal, v. 15, n. 3, p. 237-248, 2008.

BRAND-WILLIAMS, W.; CUVELIER, M. E.; BERSET, C. Use of a free radical method to evaluate antioxidant activity. LWT - Food Science and Technology, v. 28, n. 1, p. 25-30, 1995.

BRITO, T. B. et al. Fruit and vegetable residues flours with different granulometry range as raw material for pectin-enriched biodegradable film preparation. Food Research International, v. 121, p. 412-421, 2019.

BRNIAK, W.; MAŚLAK, E.; JACHOWICZ, R. Orodispersible films and tablets with prednisolone microparticles. European Journal of Pharmaceutical Sciences, v. 75, p. 81-90, 2015.

BUANZ, A. B. M. et al. Ink-jet printing versus solvent casting to prepare oral films: Effect on mechanical properties and physical stability. International Journal of Pharmaceutics, v. 494, n. 2, p. 611-618, 2015.

BUENO, J. M. et al. Analysis and Antioxidant Capacity of Anthocyanin Pigments. Part I: General Considerations Concerning Polyphenols and Flavonoids. Critical Reviews in Analytical Chemistry, v. 42, n. 2, p. 102-125, 2012.

BUILDERS, P. F.; ARHEWOH, M. I. Pharmaceutical applications of native starch in conventional drug delivery. Starch - Stärke, v. 68, n. 9-10, p. 864-873, 1 set. 2016.

C. SILVA, A.; JORGE, N. Bioactive compounds of the lipid fractions of agro-industrial waste. FRIN, v. 66, p. 493-500, 2014.

CARMO, M. A. V. DO et al. Hydroalcoholic Myrciaria dubia (camu-camu) seed extracts prevent chromosome damage and act as antioxidant and cytotoxic agents. Food Research International, v. 125, p. 108551, nov. 2019. 
CARVALHO, V.; CONTI-SILVA, A. Storage study of cereal bars formulated with banana peel flour: Bioactive compounds and texture properties. Nutrition \& Food Science, v. 48, 26 abr. 2018.

CASAROTTI, S. N. et al. Guava, orange and passion fruit by-products: Characterization and its impacts on kinetics of acidification and properties of probiotic fermented products. LWT, v. 98, p. 69-76, 2018.

CASTÁN, H. et al. Design, development and characterization of buccal bioadhesive films of Doxepin for treatment of odontalgia. Drug delivery, v. 22, n. 6, p. 869-876, 2015.

CASTRO, J. C.; MADDOX, J. D.; IMÁN, S. A. Camu-camu-Myrciaria dubia (Kunth) McVaugh. In: RODRIGUES, S.; DE OLIVEIRA SILVA, E.; DE BRITO, E. S. B. T.-E. F. (Eds.). . [s.l.] Academic Press, 2018. p. 97-105.

CASTRO, P. M. et al. Optimization of two biopolymer-based oral films for the delivery of bioactive molecules. Materials Science and Engineering C, v. 76, p. 171-180, 2017.

CHAGAS, E. G. L. DAS. Produção, caracterização e aplicação de farinhas obtidas a partir do resíduo agroindustrial do processamento do camu-camu. Pirassununga: Universidade de São Paulo, 14 maio 2019.

CHAGAS, E. A. et al. Caracterização centesimal e compostos bioativos de frutos de camu-. Congresso Brasileiro de Processamento mínimo e Pós-colheita de frutas, flores e hortaliças. Anais...2015

CHINNA REDDY, P.; CHAITANYA, K. S. C.; MADHUSUDAN RAO, Y. A review on bioadhesive buccal drug delivery systems: current status of formulation and evaluation methods. Daru : journal of Faculty of Pharmacy, Tehran University of Medical Sciences, v. 19, n. 6, p. 385-403, 2011.

CHIRINOS, R. et al. Antioxidant compounds and antioxidant capacity of Peruvian camu camu (Myrciaria dubia (H.B.K.) McVaugh) fruit at different maturity stages. Food Chemistry, v. 120, n. 4, p. 1019-1024, 2010.

$\mathrm{CHOI}$, I. et al. Development of biopolymer composite films using a microfluidization technique for carboxymethylcellulose and apple skin particles. International Journal of Molecular Sciences, v. 18, n. 6, 2017.

CORREA, S. I. et al. Contenido de vitamina $C$ en frutos de camu camu Myrciaria dubia ( H . B . K ) Mc Vaugh, en cuatro estados de maduración, procedentes de la Colección de Germoplasma del INIA Loreto, Perú Vitamin C content in fruits of camu camu Myrc. Scientia Agropecuaria, v. 2, p. 123-130, 2011.

CORREIA, R. T., BORGES, K. C., MEDEIROS, M. F., \& GENOVESE, M. I. Bioactive compounds and phenolic-linked functionality of powdered tropical fruit residues. Food science and technology international, 18(6), 539-547, 2012. 
DA SILVA, F. C. et al. Antigenotoxic effect of acute, subacute and chronic treatments with Amazonian camu-camu (Myrciaria dubia) juice on mice blood cells. Food and Chemical Toxicology, v. 50, n. 7, p. 2275-2281, 2012.

DA SILVA, L. M. R. et al. Quantification of bioactive compounds in pulps and byproducts of tropical fruits from Brazil. Food Chemistry, v. 143, p. 398-404, 2014.

DA SILVA, M. A.; ARÉVALO PINEDO, R.; KIECKBUSCH, T. G. Ascorbic Acid Thermal Degradation during Hot Air Drying of Camu-Camu ( Myrciaria dubia [H.B.K.] McVaugh) Slices at Different Air Temperatures. Drying Technology, v. 23, n. 9-11, p. 22772287, 2005.

DAS CHAGAS, E. G. L. et al. Enrichment of antioxidants compounds in cookies produced with camu-camu (Myrciaria dubia) coproducts powders. LWT, v. 137, p. $110472,2021$.

DAUD, A.; SAPKAL, N.; BONDE, M. Development of Zingiber officinale in oral dissolving films: effect of polymers on in vitro, in vivo parameters and clinical efficacy. Asian Journal of Pharmaceutics, v. 5, n. 3, p. 183-189, 2011.

DE AZEVÊDO, J. C. S. et al. Dried camu-camu (Myrciaria dubia H.B.K. McVaugh) industrial residue: A bioactive-rich Amazonian powder with functional attributes. Food Research International, v. 62, p. 934-940, 2014a.

DE AZEVÊDO, J. C. S. et al. Dried camu-camu (Myrciaria dubia H.B.K. McVaugh) industrial residue: A bioactive-rich Amazonian powder with functional attributes. Food Research International, v. 62, p. 934-940, ago. 2014b.

DE MORAES, J. O. et al. Scale-up of the production of cassava starch based films using tape-casting. Journal of Food Engineering, v. 119, n. 4, p. 800-808, 2013.

DIXIT, R. P.; PUTHLI, S. P. Oral strip technology: Overview and future potential. Journal of Controlled Release, v. 139, n. 2, p. 94-107, 2009.

DJILAS, S.; CANADANOVIC-BRUNET, J.; CETKOVIC, G. By-products of fruits processing as a source of phytochemicals. Chemical Industry and Chemical Engineering Quarterly, v. 15, n. 4, p. 191-202, 2009.

DO CARMO, M. A. V. et al. Camu-camu (Myrciaria dubia) seeds as a novel source of bioactive compounds with promising antimalarial and antischistosomicidal properties. Food Research International, v. 136, p. 109334, 2020.

DOS SANTOS GARCIA, V. A. et al. Gelatin and pregelatinized starch orally disintegrating films: Properties and stability of vitamin C. Journal of Applied Polymer Science, v. 134, n. 20, p. 1-9, 2017.

DRAGAN, E. S.; DINU, M. V. Polysaccharides constructed hydrogels as vehicles for proteins and peptides. A review. Carbohydrate Polymers, v. 225, p. 115210, 2019. 
DU, B. et al. Influence of molecular weight and degree of substitution of carboxymethylcellulose on the stability of acidified milk drinks. Food Hydrocolloids, v. 23, p. 1420-1426, 1 jul. 2009.

EGHAREVBA, H. Chemical Properties of Starch and Its Application in the Food Industry. 2019

EMBRAPA. Ciência que transforma. Resultados e impactos positivos da pesquisa agropecuária na economia, no meio ambiente e na mesa do brasileiro. Frutas e Hortaliças. 2019. Disponível em: < https://www.embrapa.br/grandes-contribuicoespara-a-agricultura-brasileira/frutas-e-hortalicas> Acesso em: 20 mar 2021.

ERBIL, H. Y. et al. Transformation of a simple plastic into a superhydrophobic surface. Science (New York, N.Y.), v. 299, n. 5611, p. 1377-1380, fev. 2003.

ESPARZA, I. et al. Fruit and vegetable waste management: Conventional and emerging approaches. Journal of Environmental Management, v. 265, p. 110510, jul. 2020.

ESPINEL VILLACRÉS, R. A.; FLORES, S. K.; GERSCHENSON, L. N. Biopolymeric antimicrobial films: Study of the influence of hydroxypropyl methylcellulose, tapioca starch and glycerol contents on physical properties. Materials Science and Engineering C, v. 36, n. 1, p. 108-117, 2014.

FARRAHI MOGHADDAM, R. et al. A maximal-information color to gray conversion method for document images: Toward an optimal grayscale representation for document image binarization. 25 jun. 2013.

FDA (Food And Drug Administration). Exservan (riluzole) oral film. 2019.

Disponível em:

<https://www.accessdata.fda.gov/drugsatfda_docs/label/2019/212640s000lbl.pdf> Acesso em: 30 mar 2021.

FDA (Food And Drug Administration). Kynmobi ${ }^{\mathrm{TM}}$ (apomorphine hydrochloride) sublingual film. 2020. Disponível em:

$<$ https://www.accessdata.fda.gov/drugsatfda_docs/label/2020/210875lbl.pdf>.

Acesso em: 30 mar 2021.

FDA (Food And Drug Administration). Onsolis (fentanyl buccal soluble film), CII. Highlights of prescribing information. 2012. Disponível em:

<https://www.accessdata.fda.gov/drugsatfda_docs/label/2012/022266s009lbl.pdf> Acesso em: 20 mar 2021.

FDA. Food, Drug and Administration. Guidance for Industry: Orally Disintegrating Tablets, Center for Drug Evaluation and Research (Centre for Drug Evaluation and Research, CDER) US FDA, Dec. 2008. https://www.fda.gov/media/70877/download. Acesso em 26 fev. 2021.

FDA (Food And Drug Administration). Suboxone® (buprenorphine and naloxone) sublingual film CIII. 2014. Disponível em: 
< https://www.fda.gov/media/79068/download> Acesso em: 30 mar 2021.

FDA (Food And Drug Administration). Sympazantm (clobazam) oral film, CIV. 2018.Disponível em:

$<$ https://www.accessdata.fda.gov/drugsatfda_docs/label/2018/210833s000lbl.pdf>. Acesso em: 30 mar 2021.

FERREIRA, A. C. S. et al. Effects of passion fruit seed (Passiflora edulis) on performance, carcass traits, antioxidant activity, and meat quality of growing rabbits. Animal Feed Science and Technology, v. 275, p. 114888, 2021.

FERRENTINO, G. et al. Biorecovery of antioxidants from apple pomace by supercritical fluid extraction. Journal of Cleaner Production, v. 186, p. 253-261, 2018.

FIDELIS, M. et al. From byproduct to a functional ingredient: Camu-camu (Myrciaria dubia) seed extract as an antioxidant agent in a yogurt model. Journal of Dairy Science, v. 103, n. 2, p. 1131-1140, 2020.

FIERASCU, R. C. et al. Fruits By-Products - A Source of Valuable Active Principles. A Short Review. Frontiers in Bioengineering and Biotechnology, v. 8, n. April, p. $1-8,2020$.

FIORI, A. P. S. DE M. et al. Combined effects of clay minerals and polyethylene glycol in the mechanical and water barrier properties of carboxymethylcellulose films. Industrial Crops and Products, v. 140, p. 111644, nov. 2019.

FRACASSETTI, D. et al. Ellagic acid derivatives, ellagitannins, proanthocyanidins and other phenolics, vitamin $\mathrm{C}$ and antioxidant capacity of two powder products from camucamu fruit (Myrciaria dubia). Food Chemistry, v. 139, n. 1-4, p. 578-588, 2013.

FREITAS, C. A. B. et al. Characterization of the Fruit Pulp of Camu-Camu (Myrciaria dubia) of Seven Different Genotypes and Their Rankings Using Statistical Methods PCA and HCA. Journal of the Brazilian Chemical Society, v. 27, p. 1838-1846, 2016.

FUJITA, A. et al. Evaluation of phenolic-linked bioactives of camu-camu (Myrciaria dubia Mc. Vaugh) for antihyperglycemia, antihypertension, antimicrobial properties and cellular rejuvenation. Food Research International, v. 77, p. 194-203, 2015.

GALALI, Y. M.; AZIZ, K. I.; ALI, S. The Antimicrobial Activity of Peel and Seeds Extracts of Red Grapes. Journal Tikrit Univ. For Agri. Sci, v. 17, n. 3, p. 2017, 2017.

GALALI, Y.; OMAR, Z. A.; SAJADI, S. M. Biologically active components in by-products of food processing. Food Science and Nutrition, v. 8, n. 7, p. 3004-3022, 2020.

GALANAKIS, C. M. Recovery of high added-value components from food wastes: Conventional, emerging technologies and commercialized applications. Trends in Food Science \& Technology, v. 26, n. 2, p. 68-87, 2012. 
GARCIA, V. A. DOS S. et al. Gelatin/starch orally disintegrating fi Ims as a promising system for vitamin C delivery. Food hydrocolloids, v. 79, p. 127-135, 2018.

GARCIA, V. A. DOS S. et al. Orally disintegrating films based on gelatin and pregelatinized starch: new carriers of active compounds from acerola. Food Hydrocolloids, v. 101, p. 105518, abr. 2020.

GARCIA-MENDOZA, M. DEL P. et al. Extraction of phenolic compounds and anthocyanins from juçara (Euterpe edulis Mart.) residues using pressurized liquids and supercritical fluids. The Journal of Supercritical Fluids, v. 119, p. 9-16, 2017.

GARCIA-MENDOZA, M. P. et al. Extracts from mango peel by-product obtained by supercritical $\mathrm{CO} 2$ and pressurized solvent processes. LWT - Food Science and Technology, v. 62, n. 1, p. 131-137, 2015.

GARSUCH, V.; BREITKREUTZ, J. Comparative investigations on different polymers for the preparation of fast-dissolving oral films. The Journal of pharmacy and pharmacology, v. 62, n. 4, p. 539-45, 2010.

GENNADIOS, A. et al. Mechanical and Barrier Properties of Egg Albumen Films. Journal of Food Science, v. 61, n. 3, p. 585-589, 1996.

GODOY, M. G. et al. Chapter 12 - Agricultural Residues as Animal Feed: Protein Enrichment and Detoxification Using Solid-State Fermentation. In: PANDEY, A.; LARROCHE, C.; SOCCOL, C. R. B. T.-C. D. IN B. AND B. (Eds.). . [s.I.] Elsevier, 2018. p. 235-256.

GOMES, A. C. A. et al. Coatings with chitosan and phenolic-rich extract from acerola (Malpighia emarginata D.C.) or jabuticaba (Plinia jaboticaba (Vell.) Berg) processing by-product to control rot caused by Lasiodiplodia spp. in papaya (Carica papaya L.) fruit. International Journal of Food Microbiology, v. 331, p. 108694, 2020.

GÓMEZ-GARCÍA, R. et al. A chemical valorisation of melon peels towards functional food ingredients: Bioactives profile and antioxidant properties. Food Chemistry, v. 335, p. $127579,2021$.

GONÇALVES RODRIGUES, L. G. et al. Recovery of bioactive phenolic compounds from papaya seeds agroindustrial residue using subcritical water extraction. Biocatalysis and Agricultural Biotechnology, v. 22, p. 101367, 2019.

GOWE, C. Review on Potential Use of Fruit and Vegetables By-Products as A Valuable Source of Natural Food Additives. v. 45, n. December, p. 47-61, 2015.

GUERRA, A. P. et al. Incorporation of active compounds from mango peel (Mangifera indica L. Cv. "Tommy Atkins") into corn starch-based oral disintegrating films. Latin American Applied Research, v. 49, n. 2, p. 93-97, 2019.

HASHEMI, M. et al. Formulation and Optimization of Oral Mucoadhesive Patches of Myrtus Communis by Box Behnken Design. Advanced pharmaceutical bulletin, v. 7, n. 3, p. 441-450, set. 2017. 
HEINZE, T. Cellulose: Structure and Properties. v. 271, p. 1-52, 10 set. 2015.

HERNÁNDEZ-CARRANZA, P. et al. Optimization of Antioxidant Compounds Extraction from Fruit By-Products: Apple Pomace, Orange and Banana Peel. Journal of Food Processing and Preservation, v. 40, n. 1, p. 103-115, 2016.

HIGDON, J.; FREI, B. Vitamin C: an Introduction. In: PACKER, L. et al. (Eds.). . Antioxidants. Vitamins $\mathbf{C}$ and $\mathbf{E}$ for Health. [s.l.] AOCS Publishing, 2003.

HIMANI, et al. Physical, Mechanical, Functional, and Thermal Characterization of Chitosan: Maltodextrin Blends Edible Oral Film Incorporated with Aqueous Clove Extract. Starch - Stärke, v. 73, n. 1-2, p. 1900220, 1 jan. 2021.

HOLTZAPPLE, M. T. CELLULOSE. In: CABALLERO, B. B. T.-E. OF F. S. AND N. (SECOND E. (Ed.). . Oxford: Academic Press, 2003. p. 998-1007.

HUANG, R. et al. Antioxidant and pancreatic lipase inhibitory effects of flavonoids from different citrus peel extracts: An in vitro study. Food Chemistry, v. 326, p. 126785, 2020.

IBGE - Instituto Brasileiro de Geografia e Estatística. SIDRA - Sistema IBGE de recuperação automática. Disponível em: <https://sidra.ibge.gov.br/tabela/4117\#resultado> Acesso em: 15 fev. 2021 a.

IBGE - Instituto Brasileiro de Geografia e Estatística. SIDRA - Sistema IBGE de recuperação automática.

Disponível em: <https://sidra.ibge.gov.br/tabela/6966\#resultado> Acesso em: 15 fev. $2021 b$.

INOUE, T. et al. Tropical fruit camu-camu (Myrciaria dubia) has anti-oxidative and antiinflammatory properties. Journal of Cardiology, v. 52, n. 2, p. 127-132, 2008.

IRFAN, M. et al. Orally disintegrating films: A modern expansion in drug delivery system. Saudi Pharmaceutical Journal, 2015.

JASVANTH, E. et al. Formulation and evaluation of ramipril mouth dissolving films. International Journal of Applied Pharmaceutics, v. 11, n. 3, p. 124-129, 2019.

JULIANO, C.; PALA, C. L.; COSSU, M. Preparation and characterisation of polymeric films containing propolis. Journal of Drug Delivery Science and Technology, v. 17, n. 3, p. 177-181, 2007.

JUSTI, K. C. et al. Nutritional composition and vitamin C stability in stored camu-camu (Myrciaria dubia) pulp. Archivos Latinoamericanos de NutriciÃ ltextthreesuperiorn, v. 50, p. 405-408, 2000.

JYOTI, A et al. Fast Dissolving Films: A Novel Approach to Oral Drug Delivery. International Research Journal of Pharmacy, v. 2011, 2 (1, n. 12, p. 69-74, 2011. 
KADOKAWA, J. I. Preparation and applications of amylose supramolecules by means of phosphorylase-catalyzed enzymatic polymerization. Polymers, v. 4, n. 1, p. 116133, 2012.

KATHPALIA, H.; GUPTE, A. An introduction to fast dissolving oral thin film drug delivery systems: a review. Current Drug Delivery, v. 10, n. 6, p. 667-684, 2013.

KEITH, R. E. 2 Ascorbic Acid. In: WOLINSKY, I.; DRISKELL, J. A. (Eds.). . Sports Nutrition, Vitamins and Trace Elements. Taylor \& F ed.Boca Raton, FL: CRC Press, 2006. p. 29-46.

KLEMM, D. et al. Cellulose: Fascinating biopolymer and sustainable raw material. Angewandte Chemie - International Edition, v. 44, n. 22, p. 3358-3393, 2005.

$\mathrm{KOCH}, \mathrm{K}$. et al. Mechanical and structural properties of solution-cast high-amylose maize starch films. International Journal of Biological Macromolecules, v. 46, n. 1, p. 13-19, 2010.

LAI, K. L. et al. Orally-dissolving film for sublingual and buccal delivery of ropinirole. Colloids and surfaces. B, Biointerfaces, v. 163, p. 9-18, mar. 2018.

LAU, E. T. L. et al. Dosage form modification and oral drug delivery in older people. Advanced Drug Delivery Reviews, v. 135, p. 75-84, 2018.

$\mathrm{LI}, \mathrm{X}$. et al. Characterization and antibacterial activity of edible films based on carboxymethyl cellulose, Dioscorea opposita mucilage, glycerol and ZnO nanoparticles. Food Chemistry, v. 349, p. 129208, 2021.

LIU, R. H. Health benefits of fruit and vegetables are from additive and synergistic combinations of phytochemicals. The American Journal of Clinical Nutrition, v. 78, n. 3, p. 517S-520S, 1 set. 2003.

LOURDIN, D.; VALLE, G. DELLA; COLONNA, P. Influence of amylose content on starch films and foams. Carbohydrate Polymers, v. 27, n. 4, p. 261-270, 1995.

LOW, A. Q. J. et al. Effect of type and ratio of solubilising polymer on characteristics of hot-melt extruded orodispersible films. International Journal of Pharmaceutics, v. 455, n. 1, p. 138-147, 2013.

MAEDA, R. N. et al. DETERMINAÇÃO DA FORMULAÇÃO E CARACTERIZAÇÃO DO NÉCTAR DE CAMU-CAMU ( Myrciaria dubia McVaugh ) 1. v. 26, n. 1, p. 70-74, 2006.

MAEDA, R. N.; ANDRADE, J. S. Aproveitamento do camu-camu (Myrciaria dubia) para produção de bebida alcoólica fermentada. Acta Amazonica, v. 33, n. 3, p. 489498, 2003.

MAHMOOD, K. et al. A review: Interaction of starch/non-starch hydrocolloid blending and the recent food applications. Food Bioscience, v. 19, p. 110-120, 2017. 
MAHMOUD, A.-G. et al. Dietary Fibers Effect from Mango Peels and Date Seeds on Rheological properties of Arabic Bread Quality: A Novel approach on applying Fuzzy Modeling in Studying Rolling/Folding and Tearing values. European Academic Research, v. IV, p. 9947-9969, 1 fev. 2017.

MAJERSKA, J.; MICHALSKA, A.; FIGIEL, A. A review of new directions in managing fruit and vegetable processing by-products. Trends in Food Science \& Technology, v. 88, p. 207-219, 2019.

MARANI, P. L. Estudo da influência das características estruturais da HidroxipropilMetil-Celulose (HPMC) nas propriedades de superfície de filmes poliméricos, na incorporação e liberação de nicotina. p. 101, 2015.

MATEOS-APARICIO, I.; MATIAS, A. Food industry processing by-products in foods. In: The Role of Alternative and Innovative Food Ingredients and Products in Consumer Wellness. [s.I.] Elsevier, 2019. p. 239-281.

MATRA, M.; TOTAKUL, P.; WANAPAT, M. Utilization of dragon fruit waste by-products and non-protein nitrogen source: Effects on in vitro rumen fermentation, nutrients degradability and methane production. Livestock Science, v. 243, p. 104386, 2021.

MAUÉS, M. M.; COUTURIER, G. Biologia floral e fenologia reprodutiva do camu-camu (Myrciaria dubia (H.B.K.) McVaugh, Myrtaceae) no Estado Pará, Brasil. Revista Brasileira de Botânica, v. 25, n. 4, p. 441-448, 2002.

MEINI, M.-R. et al. Recovery of phenolic antioxidants from Syrah grape pomace through the optimization of an enzymatic extraction process. Food Chemistry, v. 283, p. 257-264, 2019.

MELO, P. S. et al. Composição fenólica e atividade antioxidante de resíduos agroindustriais. p. 1088-1093, 2011.

MIKSUSANTI et al. Optimization of chitosan-tapioca starch composite as polymer in the formulation of gingival mucoadhesive patch film for delivery of gambier (Uncaria gambir Roxb) leaf extract. International Journal of Biological Macromolecules, $v$. 144, p. 289-295, 2020.

MIRABELLA, N.; CASTELLANI, V.; SALA, S. Current options for the valorization of food manufacturing waste: a review. v. 65, p. 28-41, 2014.

MÜLLER, C. M. O.; LAURINDO, J. B.; YAMASHITA, F. Effect of cellulose fibers addition on the mechanical properties and water vapor barrier of starch-based films. Food Hydrocolloids, v. 23, n. 5, p. 1328-1333, 2009.

MUSAZZI, U. M. et al. A new melatonin oral delivery platform based on orodispersible films containing solid lipid microparticles. International Journal of Pharmaceutics, v. 559, p. 280-288, 2019.

MYODA, T. et al. Antioxidative and antimicrobial potential of residues of camu-camu juice production. v. 8, n. April, p. 3-6, 2010. 
NAS. Selenium. Dietary Reference Intakes for Vitamin C, Vitamin E, Selenium, and CarotenoidsWashington, DC: National Academy of Sciences, National Academy Press, 2000.

NASCIMENTO, O. V. et al. Effects of diet supplementation with Camu-camu (Myrciaria dubia HBK McVaugh) fruit in a rat model of diet-induced obesity. Anais da Academia Brasileira de Ciencias, v. 85, n. 1, p. 355-363, 2013.

NEERAJA, P. et al. Preparation and evaluation of paracetomol mucoadhesive buccal patches using tamarind seed polysaccharide as a natural binder. International Journal of Pharmaceutical Sciences and Research, v. 8, n. 5, p. 2282-2286, 2017.

NEVES, L. C. et al. Bioactive compounds and antioxidant activity in pre-harvest camucamu [Myrciaria dubia (H.B.K.) Mc Vaugh] fruits. Scientia Horticulturae, v. 186, p. 223-229, 2015.

NIESE, S.; QUODBACH, J. Formulation development of a continuously manufactured orodispersible film containing warfarin sodium for individualized dosing. European Journal of Pharmaceutics and Biopharmaceutics, v. 136, p. 93-101, 2019.

NISHIKIMI, M. et al. Cloning and chromosomal mapping of the human nonfunctional gene for L-gulono-gamma-lactone oxidase, the enzyme for L-ascorbic acid biosynthesis missing in man. The Journal of biological chemistry, v. 269, n. 18, p. 13685-13688, 1994.

NOVÁKOVÁ, L.; SOLICH, P.; SOLICHOVÁ, D. HPLC methods for simultaneous determination of ascorbic and dehydroascorbic acids. TrAC - Trends in Analytical Chemistry, v. 27, n. 10, p. 942-958, 2008.

OU, B.; HAMPSCH-WOODILL, M.; PRIOR, R. L. Development and Validation of an Improved Oxygen Radical Absorbance Capacity Assay Using Fluorescein as the Fluorescent Probe Development and Validation of an Improved Oxygen Radical Absorbance Capacity Assay Using Fluorescein as the Fluorescent. v. 49, p. 46194626, 2001.

PALLA-PAPAVLU, A. et al. Characterization of ethylcellulose and hydroxypropyl methylcellulose thin films deposited by matrix-assisted pulsed laser evaporation. Applied Surface Science, v. 302, p. 87-91, 2014.

PATEL, D. A. et al. Buccal mucosa as a route for systemic drug delivery: A review. International Journal of Drug Development and Research, v. 4, n. 2, p. 99-116, 2012.

PATEL, V. F.; LIU, F.; BROWN, M. B. Advances in oral transmucosal drug delivery. Journal of Controlled Release, v. 153, n. 2, p. 106-116, 2011.

PEZIK, E. et al. Development and characterization of pullulan-based orally disintegrating films containing amlodipine besylate. European Journal of Pharmaceutical Sciences, v. 156, p. 105597, 2021. 
Ph.Eur., 2017. European Pharmacopoeia Comission, Orodispersible Tablets, European Pharmacopoeia. European Directorate for the Quality of Medicines \& Healthcare (EDQM), Strasbourg, France (2017).

PORNPITCHANARONG, C. et al. Clotrimazole nanosuspensions-loaded hyaluronic acid-catechol/polyvinyl alcohol mucoadhesive films for oral candidiasis treatment. Journal of Drug Delivery Science and Technology, v. 60, p. 101927, 2020.

PRAJAPATI, V. D. et al. Pullulan based oral thin film formulation of zolmitriptan: Development and optimization using factorial design. International Journal of Biological Macromolecules, v. 107, p. 2075-2085, 2018.

PRASANTHI, N. L. et al. Design and development of sublingual fast dissolving films for an antiasthmatic drug. Der Pharmacia Lettre, v. 3, n. 1, p. 382-395, 2011.

RAMLI, A. N. M. et al. Passion fruit (Passiflora edulis) peel powder extract and its application towards antibacterial and antioxidant activity on the preserved meat products. SN Applied Sciences, v. 2, n. 10, p. 1748, 2020.

RIMKIENE, L. et al. Development and Evaluation of Ginkgo biloba L. Extract Loaded into Carboxymethyl Cellulose Sublingual Films. Applied Sciences, v. 11, n. 1, 2021.

RODRIGUES, R. B. et al. Review article An Amazonian fruit with a high potential as a natural source of vitamin C : the camu-camu (Myrciaria dubia ). v. 56, n. April, p. 345354, 2001.

ROJAS-BRAVO, M. et al. A Potential Application of Mango (Mangifera indica L. cv Manila) Peel Powder to Increase the Total Phenolic Compounds and Antioxidant Capacity of Edible Films and Coatings. Food and Bioprocess Technology, v. 12, n. 9, p. 1584-1592, 2019.

RUFINO, M. D. S. M. et al. Bioactive compounds and antioxidant capacities of 18 nontraditional tropical fruits from Brazil. Food Chemistry, v. 121, n. 4, p. 996-1002, 2010.

SAH, B. N. P. et al. Physicochemical, textural and rheological properties of probiotic yogurt fortified with fibre-rich pineapple peel powder during refrigerated storage. LWT - Food Science and Technology, v. 65, p. 978-986, 2016.

SALMAN, Z. et al. In Vitro/In Vivo Evaluation and Bioavailability Study of Amitriptyline Hydrochloride from the Optimized Oral Fast Dissolving Films. 2014

SÁNCHEZ-MATA, M. C. et al. Comparison of high-performance liquid chromatography and spectrofluorimetry for vitamin $\mathrm{C}$ analysis of green beans (Phaseolus vulgaris $\mathrm{L}$.). European Food Research and Technology, v. 210, n. 3, p. 220-225, 2000.

SCHIEBER, A. Side Streams of Plant Food Processing As a Source of Valuable Compounds: Selected Examples. Annual review of food science and technology, v. 8, p. 97-112, fev. 2017. 
SCHIEBER, A. By-Products of Plant Food Processing as a Source of Valuable Compounds. [s.l.] Elsevier, 2019.

SCHIELE, J. T. et al. Difficulties swallowing solid oral dosage forms in a general practice population: prevalence, causes, and relationship to dosage forms. European journal of clinical pharmacology, v. 69, n. 4, p. 937-948, abr. 2013.

SEBRAE. Mercado de Fruticultura - Panorama do Setor no Brasil. Boletim de Inteligência. Outubro 2015. Disponível em:

<http://www.bibliotecas.sebrae.com.br/chronus/ARQUIVOS_CHRONUS/bds/bds.nsf/ 64ab878c176e5103877bfd3f92a2a68f/\$File/5791.pdf>. Acesso em: 30 mar 2021.

SHIMODA, $\mathrm{H}$. et al. Preparation of a fast dissolving oral thin film containing dexamethasone: A possible application to antiemesis during cancer chemotherapy. European Journal of Pharmaceutics and Biopharmaceutics, v. 73, n. 3, p. 361365, 2009.

SIEPMANN, J.; PEPPAS, N. A. Modeling of drug release from delivery systems based on hydroxypropyl methylcellulose (HPMC). Advanced Drug Delivery Reviews, v. 64, p. 163-174, 1 dez. 2012.

SINGLETON, V. L.; ORTHOFER, R.; LAMUELA-RAVENTÓS, R. M. Analysis of total phenols and other oxidation substrates and antioxidants by means of folin-ciocalteu reagent. Methods in Enzymology, v. 299, p. 152-178, 1998.

SOBRAL, P. J. D. A. Inflûencia da espessura de biofilmes feitos à base de proteínas miofibrilares sobre suas propriedades funcionais. Pesquisa Agropecuaria Brasileira, v. 35, n. 6, p. 1251-1259, 2000.

SOUSA, B. A.; CORREIA, R. T. P. Phenolic content, antioxidant activity and antiamylolytic activity of extracts obtained from bioprocessed pineapple and guava wastes. Brazilian Journal of Chemical Engineering, v. 29, n. 1, p. 25-30, 2012.

SOUSA, M. S. B. et al. Caracterização nutricional e compostos antioxidantes em resíduos de polpas de frutas tropicais. Ciencia e Agrotecnologia, v. 35, n. 3, p. 554559, 2011.

SOUZA, F. DAS C. DO A. et al. Thermosonication applied on camu-camu nectars processing: Effect on bioactive compounds and quality parameters. Food and Bioproducts Processing, v. 116, p. 212-218, jul. 2019.

SPEER, I. et al. Prolonged release from orodispersible films by incorporation of diclofenac-loaded micropellets. International Journal of Pharmaceutics, v. 554, p. 149-160, 2019.

SPINOLA, V.; LLORENT-MARTÍNEZ, E. J.; CASTILHO, P. C. Determination of vitamin $C$ in foods: Current state of method validation. Journal of Chromatography A, v. 1369, p. 2-17, 2014. 
STADING, M.; RINDLAV-WESTLING, A.; GATENHOLM, P. Humidity-induced structural transitions in amylose and amylopectin films. Carbohydrate Polymers, v. 45, n. 3, p. 209-217, 2001.

STAFUSSA, A. P. et al. Biosorption of anthocyanins from grape pomace extracts by waste yeast: kinetic and isotherm studies. Journal of Food Engineering, v. 169, p. 53-60, 2016.

STEPHEN, A. M.; PHILLIPS, G.; WILLIAMS, P. Food Polysaccharides and Their Applications. 2006

SU, J. F. et al. Structure and properties of carboxymethyl cellulose/soy protein isolate blend edible films crosslinked by Maillard reactions. Carbohydrate Polymers, v. 79, n. 1, p. 145-153, 2010.

TAKEUCHI, Y. et al. Mechanical characteristics of orally disintegrating films: Comparison of folding endurance and tensile properties. International Journal of Pharmaceutics, v. 589, p. 119876, 2020.

TANIMOTO, Y.; HAYAKAWA, T.; NEMOTO, K. Tape-Casting Technique Can Prepare $\square$-TCP Sheets with Uniform Thickness and Flexibility. p. 157-163, 2004.

TEDESCO, M. P. Filmes de desintegração oral produzidos por tape casting perspectiva para veiculação de compostos ativos extraídos do resíduo industrial de acerola. Universidade De São Paulo, p. 108, 2018.

TEDESCO, M. P.; GARCIA, V. A. DOS S.; BORGES, J. G.; OSIRO, D.; VANIN, F. M.; PEDROSO YOSHIDA, C. M.; DE CARVALHO, R. A. Production of oral films based on pre-gelatinized starch, CMC and HPMC for delivery of bioactive compounds extract from acerola industrial waste, Industrial Crops and Products, Volume 170, 2021.

TEDESCO, M. P.; MONACO-LOURENCO, C. A.; CARVALHO, R. A. Characterization of oral disintegrating film of peanut skin extract - Potential route for buccal delivery of phenolic compounds. v. 97, p. 418-425, 2017.

TEDESCO, M. P.; MONACO-LOURENÇO, C. A.; CARVALHO, R. A. Gelatin / hydroxypropyl methylcellulose matrices - Polymer interactions approach for oral disintegrating films. Materials Science \& Engineering C, v. 69, p. 668-674, 2016.

TEJADA, G. et al. Development and Evaluation of Buccal Films Based on Chitosan for the Potential Treatment of Oral Candidiasis. AAPS PharmSciTech, v. 18, n. 4, p. 936946, 2017.

TEUBL, B. J. et al. The oral cavity as a biological barrier system: Design of an advanced buccal in vitro permeability model. European Journal of Pharmaceutics and Biopharmaceutics, v. 84, n. 2, p. 386-393, 2013.

TIMUR, S. S. et al. Localized drug delivery with mono and bilayered mucoadhesive films and wafers for oral mucosal infections. International Journal of Pharmaceutics, v. 559, p. 102-112, 2019. 
TOĞRUL, H.; ARSLAN, N. Extending shelf-life of peach and pear by using CMC from sugar beet pulp cellulose as a hydrophilic polymer in emulsions. Food Hydrocolloids, v. 18, n. 2, p. 215-226, 2004.

TREMOCOLDI, M. A. et al. Exploration of avocado by-products as natural sources of bioactive compounds. PloS one, v. 13, n. 2, p. e0192577, 2018.

VALENCIA, G. A. et al. Morphological and physical properties of nano-biocomposite films based on collagen loaded with laponite ${ }^{\circledR}$. Food Packaging and Shelf Life, $v$. 19, p. 24-30, 2019.

VARUN, R. et al. Available online through. v. 2, n. 4, p. 1138-1147, 2011.

VILLANUEVA-TIBURCIO, J. E.; CONDEZO-HOYOS, L. A.; ASQUIERI, E. R. en la cáscara de camu-camu (Myrciaria dubia McVaugh). Ciência e Tecnologia de Alimentos, v. 30, n. 1, p. 151-160, 2010.

VIRIDÉN, A.; WITTGREN, B.; LARSSON, A. Investigation of critical polymer properties for polymer release and swelling of HPMC matrix tablets. European Journal of Pharmaceutical Sciences, v. 36, p. 297-309, 2009.

VISSER, J. C. et al. Quality by design approach for optimizing the formulation and physical properties of extemporaneously prepared orodispersible films. International Journal of Pharmaceutics, v. 485, n. 1, p. 70-76, 2015a.

VISSER, J. C. et al. Orodispersible films in individualized pharmacotherapy: The development of a formulation for pharmacy preparations. International Journal of Pharmaceutics, v. 478, n. 1, p. 155-163, 2015b.

VITAFOL . Vitafol@ Strips Prenatal Supplement. 2019. Disponível em : $<$ https://dailymed.nlm.nih.gov/dailymed/fda/fdaDrugXsl.cfm?setid=83f55f74-16414a6a-bbc0-002f1ade879b\&type=display > Acesso em: 30 mar 2021.

VUDDANDA, P. R. et al. Effect of plasticizers on the physico-mechanical properties of pullulan based pharmaceutical oral films. European Journal of Pharmaceutical Sciences, v. 96, p. 290-298, 2017a.

VUDDANDA, P. R. et al. Effect of surfactants and drug load on physico-mechanical and dissolution properties of nanocrystalline tadalafil-loaded oral films. European journal of pharmaceutical sciences : official journal of the European Federation for Pharmaceutical Sciences, v. 109, p. 372-380, nov. 2017b.

WANG, Y. BIN et al. Bioadhesive drug delivery system of diltiazem hydrochloride for improved bioavailability in cardiac therapy. Tropical Journal of Pharmaceutical Research, v. 15, n. 7, p. 1375-1380, 2016.

WOERTZ, C.; KLEINEBUDDE, P. Development of orodispersible polymer films with focus on the solid state characterization of crystalline loperamide. European Journal of Pharmaceutics and Biopharmaceutics, v. 94, p. 52-63, 2015. 
YADAV, S. et al. Development of dietary fibre enriched chicken sausages by incorporating corn bran, dried apple pomace and dried tomato pomace. Nutrition and Food Science, v. 46, n. 1, p. 16-29, 2016.

YAPU, D. G. et al. Evaluación de la actividad antiplasmódica in vitro de extractos de Euterpe oleracea, Myrciaria dubia y Croton lechleri. ÓRGANO OFICIAL DEL COLEGIO DE BIOQUÍMICA Y FARMACIA DE BOLIVIA, v. 16, p. 16-20, 2008.

YUYAMA, K. A CULTURA DE CAMU-CAMU NO BRASIL. Revista Brasileira de Fruticultura, v. 33, p. 335-690, 2009.

YUYAMA, K. A cultura de camu-camu no Brasil. Revista Brasileira de Fruticultura, v. 33, n. 2, 2011.

ZANATTA, C. F. et al. Determination of anthocyanins from camu-camu (Myrciaria dubia) by HPLC-PDA, HPLC-MS, and NMR. Journal of agricultural and food chemistry, v. 53, n. 24, p. 9531-9535, nov. 2005.

ZHANG, L. et al. Synthesis and characterization of antibacterial polylactic acid film incorporated with cinnamaldehyde inclusions for fruit packaging. International Journal of Biological Macromolecules, v. 164, p. 4547-4555, 2020.

ZHANG, Y.; HAN, J. H. Plasticization of pea starch films with monosaccharides and polyols. Journal of Food Science, v. 71, n. 6, p. 253-261, 2006.

ZIMMER, T. B. R. et al. Biological potential of hydroalcoholic extracts of Physalis pubescens L. Biocatalysis and Agricultural Biotechnology, v. 31, p. 101895, 2021. 